\author{
UNIVERSIDADE DE SÃO PAULO \\ FACULDADE DE SAÚDE PÚBLICA \\ DEPARTAMENTO DE EPIDEMIOLOGIA
}

\title{
ÓBITOS DE MULHERES EM IDADE FÉRTIL EM ARACAJU (SE): estratégias para melhorar a qualidade da informação
}




\section{ÓBITOS DE MULHERES EM IDADE FÉRTIL EM ARACAJU (SE): estratégias para melhorar a qualidade da informação}

ANNA KLARA BOHLAND

Tese apresentada ao Departamento de Epidemiologia da Faculdade de Saúde Pública da Universidade de São Paulo para a obtenção do Grau de Doutor. Área de concentração: Epidemiologia.

ORIENTADOR: $\quad$ PROF $^{\mathrm{a}} . \quad \mathrm{DR}^{\mathrm{a}}$. MARIA HELENA PRADO DE MELLO JORGE.

São Paulo

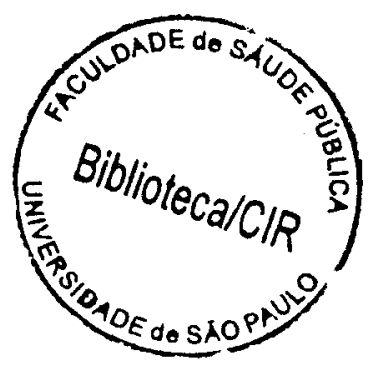


Autorizo, exclusivamente para fins acadêmicos e científicos, a reprodução total e parcial desta tese, por processos fotocopiadores.

Assinatura:

Data: São Paulo, 2003.

4449112004 doc 
À minha filha LUÍZA, minha fonte de alegria, dedico este trabalho 


\section{AGRADECIMENTOS}

À Professora Maria Helena Prado de Mello Jorge pelas lições de epidemiologia, mas, principalmente pelas imprescindiveis lições de vida.

Ao Professor Ruy Laurenti e à Professora Selma Maffei de Andrade pelas valiosas contribuições em todas as fases deste trabalho.

À Professora Ana Cristina D'Andreta Tanaka e ao Professor João Henrique Gunthler Scatena pelas criteriosas observações na fase final deste estudo.

Aos Professores do Departamento de Epidemiologia da Faculdade de Saúde Pública, em especial à professora Sabina Léa Davidson Gotlieb, pelo incentivo.

A Rogério Carvalho dos Santos, Secretário Municipal de Saúde de Aracaju, pela colaboração.

Á Maria Lúcia Ferraz, da Biblioteca da Faculdade de Saúde Pública, pela atenção.

À Anne Regina Pereira Corado, Maria Bergivânia de Jesus e Vânia Regina Moura Farias pela execução da pesquisa de campo.

À Elizabeth Burgath Bohland pela meticulosa correção gramatical.

A todos que direta ou indiretamente contribuíram para a consecução deste trabalho, em especial aos meus pais, José Bohland e Elizabeth Burgath Bohland e ao meu companheiro Arisvaldo Vieira Méllo Júnior. 


\section{RESUMO}

Bohland, AK. Título. Óbitos de mulheres em idade fértil em Aracaju (SE): estratégias para melhorar a qualidade da informação. São Paulo: 2003 [Tese de Doutorado - Faculdade de Saúde Pública da USP].

Objetivo. Descrever óbitos de mulheres de 10 a 49 anos (MIF), residentes em Aracaju (SE), entre 1979 e 2001, enfatizando a melhora da informação sobre mortes maternas. Métodos. Desenvolvido em 3 fases: a primeira descritiva (1979-2001) e aplicando 2 fatores de correção para a Razão de Mortalidade Materna - RMM. Na segunda (2001) realizou-se inquérito simplificado (hospitais, instituto médico legal, unidade de saúde e domicilios). A terceira (2001) utilizando Sistemas de Informação em Saúde (Sistema de Informação de Mortalidade-SIM, Sistema de Informação sobre Nascidos Vivos- SINASC, Sistema de Informação da Atenção Básica- SIAB e Sistema de Informações Hospitalares- SIH) para melhorar a informação. Resultados. Os óbitos (4299 de 1979-2001) apresentaram tendência de queda. Principais causas: circulatórias (23,3\%), neoplasias (19,8\%) e causas externas (19,1\%). A tendência da RMM é de queda, verificando-se ampla variabilidade entre a curva observada e a estimada pelo maior dos fatores de correção aplicados. Nas fases subseqüentes, os óbitos de MIF foram provenientes de casos do SIM (196 casos, sendo $7 \mathrm{com}$ presença de gravidez até um ano antes do óbito), SIAB e SIH totalizando 216 casos. Na segunda foi elaborado o PADRÃO-OURO (177 entrevistas, 13 exclusões/ 26 perdas). Houve mudança no perfil de mortalidade das MIF. Na terceira fase (204 casos, 12 exclusões) as DOs foram complementadas (SIAB, SIH, SINASC e SIM). Quanto à causa básica as alterações não se mostraram satisfatórias. Quanto à presença de gravidez até um ano antes do óbito, a soma das fases 2 e 3 resultou em 13 casos, 7 maternos (RMM: 70,8/100.000 NVs). Conclusões: os SIS melhoraram a quantidade das informações de óbitos MIF e os relativos à gravidez. O inquérito complementou a fase 3 e melhorou a qualidade das informações. A metodologia é factível, tornando as informações mais fidedignas.

Descritores: Sistemas de informação, mortes maternas, mortalidade em mulheres. 


\section{SUMMARY}

Bohland, AK Óbitos de mulheres em idade fértil em Aracaju (SE): estratégias para melhorar a qualidade da informação [Death of women $10-49$ years of age in Aracaju (SE): strategies to improve information quality]. São Paulo (BR); 2003. [Tese de Doutorado - Faculdade de Saúde Pública da Universidade de São Paulo].

Objective. To describe deaths of women from 10 to 49 years of age living in Aracaju (Sergipe), between 1979 and 2001, emphasizing information improvement about maternal deaths. Methods. Developed in 3 phases: the first one (1979 - 2001) was descriptive applying 3 correction factors for Maternal Mortality Rate (MMR). In the second (2001) a simplified inquiry was performed (hospitals, morgue, health units and residences). The third (2001): using Health Information System (HIS) to improve information (SIM, SINASC, SIAB and SIH). Results. The deaths (4299 Between 1979-2001 had shown descent trend. Main causes: circulatory (23.3\%), cancer (19.8\%) and injuries (19.1\%). The trend of MMR was downward, a large variability between the observed and the evaluated by the biggest applied correction factor curves was verified. In following phases, deaths of women from 10 to 49 years of age came from SIM cases (196 cases, 7 with pregnancy presence until a year before death), SIAB and SIH, amounting to 216 cases. In the second phase, gold standard was elaborated: (177 interviews, 13 exclusions / 26 losses). There was a change in the women from 10 to 49 years of age mortality outline.In the third phase (204 cases, 12 exclusions) death declarations were completed as regarding the basic cause, and a few changes in the information of causes were observed. The information related to pregnancy presence until a year before death, sum of phases 2 and 3 were recovered 13 cases, 7 maternal ones (MMR 70.8/100,000). Conclusions. The HIS improved the amount of information about women from 10 to 49 years of age deaths and the one related to pregnancy. The inquiry complemented phase 3 and improved information quality. The methodology is feasible; turning data more reliable.

Descriptors: Information system, maternal mortality, women mortality 


\section{RELAÇÃO DE ABREVIATURAS UTILIZADAS}

AIH Autorização de Internação Hospitalar

CEP Comitê de Ética em Pesquisa

CID 10 Classificação Internacional das Doenças $-10^{\mathrm{a}}$ revisão

CID 9 Classificação Internacional das Doenças $-9^{a}$ revisão

CM Coeficiente de Mortalidade

DAC Doenças do Aparelho Circulatório

DIC Doença Isquêmica do Coração

DN Declaração de Nascido Vivo

DO Declaração de Óbito

DP Delegacias de Polícia

DCV Doenças Cérebro-vasculares

HA Hipertensão Arterial

IBGE Fundação do Instituto Brasileiro de Geografia e Estatística

IML Instituto Médico Legal

MIF Mulheres em Idade Fértil

MS Ministério da Saúde

NVs Nascidos Vivos

OMS Organização Mundial de Saúde

PSF Programa de Saúde da Familia

RIPSA Rede Intergerencial de Informações para a Saúde

RMM Razão de Mortalidade Materna

SAM Sem Assistência Médica

SAMHPS Sistema de Atenção Médico Hospitalar da Previdência Social

SES Secretaria Estadual de Saúde

SIAB Sistema de Informação da Atenção Básica

SIH Sistema de Informações Hospitalares

SIM Sistema de Informação sobre de Mortalidade

SINAN Sistema de Informação de Agravos de Notificação

SINASC Sistema de Informação sobre Nascidos Vivos 
SIPACS Sistema de Informação do Programa de Agentes Comunitários de Saúde SIS Sistemas de Informação em Saúde

SUS Sistema Único de Saúde

SVO Serviço de Verificação de Óbito

UBS Unidade Básica de Saúde

UF Unidade da Federação 


\section{LISTA DE FIGURAS}

Figura 1. Síntese da busca para a elaboração do PADRÃO OURO.

Figura 2. Distribuição dos casos de óbitos de mulheres em todas as idades e de mulheres em idade fértil segundo ano. Aracaju (SE), 1979-2001.

Figura 3. Coeficiente de mortalidade de mulheres de 10 a 49 anos (por cem mil mulheres). Aracaju (SE), 1979-2001.

Figura 4. Distribuição dos casos de óbitos de mulheres em idade fértil e de óbitos maternos segundo ano. Aracaju (SE), 1979-2001.

Figura 5. Razão de mortalidade materna (fonte oficial) por cem mil nascidos vivos. Aracaju (SE), 1979-2001.

Figura 6. Razão de mortalidade materna (por cem mil nascidos vivos), segundo fontes oficiais e razão de mortalidade materna corrigidas. Aracaju (SE), 1979-2001.

Figura 7. Casos da lista única de óbitos de mulheres em idade fértil segundo fonte de informação selecionados na Fase 2 (PADRÃO OURO). Aracaju (SE), 2001.

Figura 8. Casos de óbitos de mulheres em idade fértil segundo fonte de informação selecionados na Fase 3 (NOVA-DO). Aracaju (SE), 2001.

Figura 9. Coeficiente de mortalidade por cem mil mulheres em idade fértil segundo idade. Aracaju (SE), 2001.

Figura 10. Casos de mulheres em idade fértil com resgate informação de gravidez, parto ou puerpério até um ano antes do óbito, segundo fonte da informação. Aracaju (SE), 2001.

Figura 11. Casos de óbitos de mulheres de 10 a 49 anos até um ano após o término da gravidez, segundo fonte e momento do óbito. Aracaju (SE), 2001.

Figura 12. Distribuição dos óbitos maternos segundo bairro de 
residência. Aracaju (SE), 2001. 


\section{LISTA DE QUADROS E TABELAS}

Quadro 1. Grupos de causas básicas de óbito de mulheres de 10 a 49 anos.

Tabela 1. Distribuição dos óbitos de mulheres de 10 a 49 anos segundo causas (capítulos da CID 10), Brasil, 2000.

Tabela 2. Óbitos de mulheres de 10 a 49 anos captados pela IBGE e pelo SIM, em Sergipe e relação SIM/IBGE, de 1979 a 2001.

Tabela 3. Distribuição do $\mathrm{n}^{\circ}$ e $\%$ de óbitos sem assistência médica (SAM) entre mulheres de 10 a 49 anos. Brasil e regiões, 2000.

Tabela 4. Percentual de óbitos captados pelo SIM em relação ao número de óbitos estimados, segundo grandes regiões do Brasil, 1999.

Tabela 5. Cobertura populacional no Programa de Saúde da Família (PSF) e do Programa de Agentes Comunitários de Saúde (PACS) segundo regiões. Brasil, 2000.

Tabela 6. Razão entre nascidos vivos informados pelo SINASC estimados pelo IBGE, segundo grandes regiões do Brasil, 1999.

Tabela $7 \quad \mathrm{~N}^{\circ}$ de óbitos de mulheres e população feminina de 10 a 49 anos e nascidos vivos de mães de residentes em Aracaju (SE), 1979- 2001.

Tabela 8. Número de casos presentes nos SIS consultados em Aracaju e no Estado de Sergipe, 2000-2001.

Tabela 9. Total de óbitos femininos e de mulheres em idade fértil em $\mathrm{n}^{\circ}$ e \%, Aracaju (SE), 1979-2001.

Tabela 10 Óbitos de mulheres em idade fértil segundo idade $\left(\mathrm{n}^{\circ}, \%\right.$ e $\%$ acumulado). Aracaju (SE), 1979 a 2001.

Tabela 11. Distribuição percentual de óbitos de mulheres em idade fértil segundo idade e ano do óbito. Aracaju (SE), 1979-2001.

Tabela 12. Óbitos de mulheres em idade fértil segundo causas (CID 10). Aracaju (SE), 1979-2001. 
Tabela 13. Número de óbitos de mulheres em idade fértil segundo doença cérebro-vascular (DCV) e doença isquêmica do coração (DIC), e respectivos coeficientes de mortalidade - CM (por cem mil mulheres de 10 a 49 anos) e razão entre eles. Aracaju (SE), 1979-2001.

Tabela 14. Número de óbitos de mulheres em idade fértil por neoplasia de colo de útero e de mama, e respectivos coeficientes de mortalidade - CM - (por cem mil mulheres de 10 a 49 anos) e razão entre eles. Aracaju (SE), 1979-2001.

Tabela 15. Óbitos $\left(\mathrm{n}^{\circ} \mathrm{e} \%\right)$ de mulheres em idade fértil por causa externa, segundo tipo e idade. Aracaju (SE), 1979-2001.

Tabela 16. Coeficiente de mortalidade por causa externa em mulheres em idade fértil (por cem mil mulheres), segundo tipo de causa e ano. Aracaju (SE), 1979-2001.

Tabela 17. Mortalidade proporcional de mulheres na idade de 10 a 49 anos e de óbitos por causas maternas entre o total dos óbitos femininos segundo o ano do óbito. Aracaju (SE),1979-2001.

Tabela 18. Óbitos de mulheres por causas maternas segundo idade $\left(\mathrm{n}^{\circ}, \%\right.$ e \% acumulado). Aracaju (SE), 1979-2001.

Tabela 19. Óbitos de mulheres em idade fértil segundo causas maternas e passiveis de serem maternas. Aracaju (SE), 1979-2001.

Tabela 20. $\quad \mathrm{N}^{\circ}, \%$ e \% acumulado dos óbitos por causas maternas segundo grupo. Aracaju (SE), 1979-2001.

Tabela 21. Óbitos por causas maternas segundo as principais categorias (capítulo XV CID 10). Aracaju (SE), 1979-2001.

Tabela 22. Momento do óbito de mulheres em idade fértil com informação na DO sobre a presença de gravidez, puerpério ou puerpério tardio e causa básica. Aracaju (SE), 1995-2001.

Tabela 23. Procedência dos casos do PADRÃO-OURO segundo fonte quantitativa e resultado da segunda fase (inquérito). Aracaju (SE), 2001.

Tabela 24. Procedência dos casos da NOVA-DO segundo fonte 
quantitativa e resultado da terceira fase (SIS). Aracaju (SE), 2001.

Tabela 25. Distribuição dos casos de óbito de mulheres em idade fértil $\left(\mathrm{n}^{\circ}\right.$ e \%) segundo causa básica e a captação de informação adicional (NOVA-DO) sobre causa de óbito nos SIS ${ }^{\text {a }}$. Aracaju (SE), 2001.

Tabela 26. Distribuição dos casos de óbitos de mulheres em idade fértil ( $\mathrm{n}^{\circ}$ e \%) segundo local de ocorrência do óbito e a captação de informação adicional sobre causa de óbito nos SIS. Aracaju (SE), 2001.

Tabela 27. Distribuição dos casos de óbitos de mulheres em idade fértil $\left(n^{\circ}\right.$ e \%) segundo causa básica na DO-ORIGINAL e na NOVA-DO (SIS) e ganho de informações (relação A/B). Aracaju (SE), 2001.

Tabela 28. Distribuição ( $\mathrm{n}^{\circ} \mathrm{e} \%$ ) segundo causa básica na DO-ORIGINAL e causa básica observada no PADRÃO-OURO e relação entre os capítulos. Aracaju (SE), 2001.

Tabela 29. Distribuição ( $\mathrm{n}^{\circ}$ e \%) segundo capitulos da DO-ORIGINAL e do PADRÃO-OURO. Aracaju (SE), 2001.

Tabela 30. Teste de Sensibilidade e estatística Kappa segundo capítulos na DO-ORIGINAL e no PADRÃO-OURO. Aracaju (SE), 2001.

Tabela 31. Posição do capitulo na DO-ORIGINAL e no PADRÃOOURO. Aracaju (SE), 2001.

Tabela 32. Concordância da causa básica na DO-ORIGINAL, na NOVADO com o PADRÃO-OURO. Aracaju (SE), 2001.

Tabela 33. Distribuição $\left(n^{\circ}\right.$ e \%) dos óbitos em mulheres em idade fértil segundo causa básica na DO-ORIGINAL, na NOVA-DO e no PADRÃO-OURO. Aracaju (SE), 2001.

Tabela 34. Distribuição dos óbitos de mulheres em idade fértil segundo local de ocorrência (n ${ }^{\circ}$ e \%). Aracaju (SE), 2001.

Tabela 35. Número, \% e \% acumulado dos óbitos de mulheres em idade 
fértil segundo faixa etária. Aracaju (SE), 2001.

Tabela 36. Distribuição do número de óbitos de mulheres em idade fértil segundo causa e idade. Aracaju (SE), 2001.

Tabela 37. Distribuição acumulada dos óbitos de mulheres em idade fértil segundo causa e idade. Aracaju (SE), 2001.

Tabela 38. Momento do óbito em mulheres no ciclo gravídico-puerperal segundo causa de morte no PADRÃO-OURO. Aracaju (SE), 2001.

Tabela 39. Informação sobre a presença de gravidez, parto ou puerpério na DO-ORIGINAL segundo causa da morte no PADRÃOOURO. Aracaju (SE), 2001.

Tabela 40. Informação sobre a presença de gravidez, parto ou puerpério na DO-ORIGINAL segundo causa da morte no PADRÃOOURO dos casos resgatados pelos SIS. Aracaju (SE), 2001.

Tabela 41. Concordância da informação presença de gravidez, parto ou puerpério na DO-ORIGINAL, na NOVA-DO com 0 PADRÃO-OURO. Aracaju (SE), 2001.

Tabela 42. $\mathrm{N}^{\circ}$ de óbitos segundo causa básica na DO-ORIGINAL, na NOVA-DO e no PADRÃO-OURO, entre mulheres que estiveram grávidas até um ano antes do óbito e razão entre eles. Aracaju (SE), 2001.

Tabela 43. Distribuição dos óbitos com resgate da informação sobre gravidez, parto ou puerpério (inclusive tardio) segundo causas na DO-ORIGINAL e no PADRÃO-OURO . Aracaju (SE), 2001.

Tabela 44. Distribuição em $\mathrm{n}^{\circ}, \mathrm{e} \%$ dos óbitos em mulheres grávidas até um ano antes do óbito segundo causa e idade. Aracaju(SE), 2001.

Tabela 45. Momento do óbito e causa básica no PADRÃO-OURO. Aracaju (SE), 2001. 


\section{ÍNDICE}

1. INTRODUÇÃO 1

1.1 Óbitos de mulheres em idade fértil 2

1.1.1 Óbitos maternos: conceitos necessários 3

1.1.2 A situação das mortes maternas no Brasil 7

1.2 Fontes alternativas para a melhora da informação 10

1.3 Sistemas de informação 11

1.3.1 Sistema de Informação do IBGE 12

1.3.2 Sistema de Informações sobre Mortalidade - SIM 14

1.3.3 Sistemas de Informação em Saúde de apoio à melhora da informação sobre os óbitos $\quad 15$

1.4 Algumas características do Municipio de Aracaju 23

2. OBJETIVOS 24

2.1 Objetivo geral 25

2.2 Objetivos especificos 25

3. METODOLOGIA 26

3.1 Levantamento das informações produzidas pelo SIM no período de 1979 a 2001

3.1.1 População de estudo $\quad 27$

3.1.2 Método de análise da série histórica 29

3.2 Levantamento em outras fontes de informação dos casos de 2001

3.2.1 Levantamento em Sistemas de Informação com dados de óbito: a construção da lista única dos casos $\quad 31$

3.2.2 Inquérito em fontes alternativas 33

3.2.3 Levantamento em Sistemas de Informação em Saúde de apoio ao esclarecimento das causas de óbito $\quad 37$

3.2.4 Método de análise dos casos de $2001 \quad 40$

3.3 Variáveis de estudo $\quad 42$

3.4. Considerações éticas 44

4. RESULTADOS E DISCUSSÃO 45

4.1 Análise da informação dos óbitos no período de 1979 a 2001 
4.1.1 Os óbitos das mulheres em idade fértil

4.1.2 Os óbitos maternos $\quad 56$

4.2 Análise dos óbitos de mulheres em idade fértil em 2001

4.2.1 Ganho quantitativo da informação 65

$\begin{array}{ll}\text { 4.2.2 Ganho qualitativo da informação } & 72\end{array}$

4.2.3 Análise da concordância da causa básica de óbito 75

4.2.4 Perfil epidemiológico dos óbitos das mulheres em idade fértil 81

4.3 Análise dos óbitos ocorridos durante o ciclo gravídico-puerperal em $\quad \mathbf{8 6}$ 2001

4.3.1 Ganho quantitativo da informação 86

4.3.2 Ganho qualitativo da informação $\quad 89$

4.3.3 Análise da concordância dos óbitos relacionados à gravidez, ao parto e ao puerpério $\quad 93$

4.3.4 Perfil epidemiológico das mortes durante o ciclo gravídicopuerperal

5. CONSIDERAÇÕES FINAIS E CONCLUSÕES

REFERÊNCIAS

108

ANEXOS

Anexo 1. Razões

Anexo 2. Causas presumiveis de morte materna

Anexo 3. Instrumentos de coleta de dados utilizados no inquérito

Anexo 4. Instrumento de coleta de dados junto ao SIAB

Anexo 5. Formulário D1: informações para casos não conhecidos pelo SIM

Anexo 6. Parecer do CEP-FSP-USP

Anexo 7. Rapport

A-18

Anexo 8. Consentimento esclarecido 
1. INTRODUÇÃO 


\section{1 Óbitos de mulheres em idade fértil}

A saúde da mulher, especialmente no seu período reprodutivo, depende de medidas simples e de baixo custo, uma vez que a maior parte dos agravos que acomete este grupo é passível de intervenção, desde que implementadas medidas educativas, de diagnóstico e tratamento precoces. Portanto, é fundamental que seja garantido o acesso a ações e serviços de saúde, que permitam aumentar a qualidade de vida do grupo.

Embora o conceito de mulher em idade fértil corresponda à mulher na idade entre 15 e 49 anos, muitos autores vêm trabalhando com os limites 10 e 49 anos (LAURENTI et. al 1990a; ALBUQUERQUE et. al 1997; SIQUEIRA et. al 1999; TANAKA e MITSUIKI 1999; THEME-FILHA et. al 1999), o que se deve ao fato do início precoce da vida reprodutiva. No Brasil, os dados relativos aos nascidos vivos, segundo idade da mãe, deixam clara essa situação, visto que, em número não pequeno desses nascimentos (representaram 28958 em 2000), as mães eram menores de quinze anos (MINISTÉRIO DA SAÚDE 2003a).

Do ponto de vista do perfil de morbidade, entre as principais causas de internações hospitalares no Brasil considerando apenas as pacientes de 10 a 49 anos internadas nos hospitais da rede do Sistema Único de Saúde (SUS), em 2001, as principais causas pertenciam ao capítulo da gravidez, parto e puerpério $(62,0 \%)$, das doenças do aparelho geniturinário $(8,6 \%)$ e das doenças do aparelho respiratório $(5,4 \%)$. Quanto á mortalidade hospitalar neste grupo destacaram as doenças do aparelho circulatório $(18,1 \%)$, as doenças infecciosas e parasitárias $(15,0 \%)$ e as doenças do aparelho respiratório (13,9\%) (MINISTÉRIO DA SAÚDE 2003a).

Quando considerados todos os óbitos de mulheres entre 10 a 49 anos, independentemente do fato de serem hospitalares ou não, a mortalidade proporcional foi em torno de 7\% no Brasil, no período de 1979 a 2000 (MINISTÉRIO DA SAÚDE 2003a). As principais causas de morte, em 2000, foram as doenças do aparelho circulatório, neoplasias e causas externas (Tabela 1). 
Tabela 1. Distribuição dos óbitos de mulheres de 10 a 49 anos segundo causas (capítulos da CID 10), Brasil, 2000.

\begin{tabular}{lrr}
\hline Causas & $\mathrm{N}^{\circ}$ & $\%$ \\
\hline D. Ap. Circulatório & 13077 & 20,4 \\
Neoplasias & 11609 & 18,2 \\
Causas Externas & 10541 & 16,5 \\
Mal Definidas & 7637 & 12,0 \\
Doenças Infecciosas e Parasitárias & 5432 & 8,5 \\
D. Ap. Respiratório & 3987 & 6,2 \\
D. Ap. Digestivo & 2850 & 4,5 \\
D Endócrinas & 2339 & 3,7 \\
Gravidez,'Parto e Puerpério & 1642 & 2,6 \\
Demais & 4707 & 7,4 \\
\hline TOTAL & 63821 & 100,0 \\
\hline
\end{tabular}

Fonte: MINISTÉRIO DA SAÚDE 2003a.

Dos estudos sobre óbitos de mulheres em idade fértil os que utilizam metodologia para melhorar a qualidade da informação da causa de óbito apontaram que, dentre os óbitos de mulheres em idade fértil, as mortes maternas estão entre as mais mal informadas (PUFFER e GRIFFTH 1968; LAURENTI et. al 1990a; BOUVIER-COLLE et. al 1991; ALBUQUERQUE et. al 1997; SIQUEIRA et. al 1999; TANAKA e MITSUIKI 1999; LAURENTI et. al 2003). Por esta razão, as mesmas serão consideradas separadamente.

\subsection{1 Óbitos maternos: conceitos necessários}

Estima-se que anualmente 500.000 mulheres, em todo o mundo, morram de causas relacionadas com a gravidez, o parto ou o puerpério. Se fossem aplicadas medidas de baixo custo, como cuidados primários (pré-natal, planejamento familiar e controle de doenças sexualmente transmissíveis) e adequada atenção às complicações da gravidez e ao parto, grande parte destes óbitos não ocorreria (WHO 2001a).

A razão de mortalidade materna (RMM) mundial foi estimada (WHO 2001b) em 400/100.000 nascidos vivos (NVs), e a maior parte dos óbitos ocorreu nos países 
pobres, sendo que a RMM do bloco de paises considerados desenvolvidos foi de 21/100.000 NVs e a do outro bloco foi de 440/100.000 NVs. A Áustria, o Canadá e a Finlândia apresentaram RMM de 6/100.000 NVs, enquanto diversos países do Continente Africano tiveram taxas superiores a 1000/100.000 NVs. A maior RMM estimada para 1995 foi de 2300/100.000 NVs (em Ruanda), valor similar a taxa de mortalidade materna hospitalar inglesa, por volta de 1750 (ROSEN 1995).

Em março de 1994, diante da magnitude do problema no Brasil, foi instituído o dia 28 de maio como o Dia Nacional de Redução da Mortalidade Materna (MINISTÉRIO DA SAÚDE 1994a). A morte materna é considerada uma tragédia evitável (devido à sua transcendência social e familiar), diante da vulnerabilidade do problema (devido à tecnologia disponível no país), desde que sejam garantidos os princípios do SUS (BRASIL 1988).

Morte Materna é conceituada como:

"a morte de uma mulher durante a gestação ou dentro de um período de 42 dias após o término da gestação, independentemente de duração ou da localização da gravidez, devida a qualquer causa relacionada ou agravada pela gravidez ou por medidas em relação a ela, porém não devida a causas acidentais ou incidentais" (OMS, 1995, v2 p.143).

A $10^{\mathrm{a}}$ Classificação Internacional das Doenças (CID 10) incorporou ainda o conceito de Morte Materna Tardia, que é

"a morte de uma mulher por causas obstétricas diretas ou indiretas mais de 42 dias mas menos de um ano após o término da gravidez" (OMS, 1995, v2 p.143),

baseado no fato de que os recursos terapêuticos podem prolongar a vida dos pacientes além do período de 42 dias (OMS 1995). Estudos que consideram o periodo puerperal estendido já foram realizados há mais de uma década (LAURENTI et. al 1990b; SALANAVE et. al 1999; BERG et. al 2003).

Contudo, para comparações internacionais, são consideradas apenas as mortes maternas que ocorram até 42 dias após o término da gravidez, todavia, a própria Organização Mundial da Saúde (OMS) sugeriu aos países que incluíssem, em seus formulários relativos à declaração do óbito, questões sobre a presença de gravidez até 
um ano antes do óbito. No Brasil, em 1995, foram incluídas na Declaração de Óbito (DO), duas questões referentes às mortes durante a gravidez e puerpério, entretanto, a variável ainda é muito mal preenchida (LAURENTI et. al 2000b). Tal fato poderá levar a distorções nas comparações internacionais, uma vez que o mau preenchimento da variável não permitirá a exclusão dos óbitos maternos tardios.

As mortes maternas ainda são subdivididas em dois grupos: as mortes obstétricas diretas e indiretas. As primeiras são aquelas resultantes de complicações relacionadas à gravidez, ao parto e puerpério, e as segundas devidas a doenças préexistentes, que se agravaram com a gravidez (OMS 1995).

Com o propósito de incluir todos os casos de mulheres grávidas, ou no período puerperal, que forem a óbito, a Organização Mundial da Saúde (OMS 1995) também define a morte relacionada com a gravidez, que consiste na

"morte de uma mulher enquanto grávida ou até 42 dias após o término da gravidez (o destaque é nosso), qualquer que tenha sido a causa da morte" (OMS, 1995, v2 p.143).

Cabe ressaltar que alguns autores verificaram que, em certas condições, há relação entre algumas causas acidentais ou incidentais ou certos agravos e a condição de gestante e, portanto, os óbitos, também deveriam ser considerados como casos de morte materna (LAURENTI et. al 1990b; TANAKA 1995). A despeito desta discussão, para a operacionalização deste conceito, também é necessário um bom preenchimento da DO.

Para fins de comparações, a OMS definiu razões (ou taxas) a serem utilizadas para a análise da mortalidade materna (Anexo 1). Estes consideram no numerador os óbitos maternos (diretos e/ou indiretos) ou os óbitos relacionados com a gravidez. No denominador, recomenda que sejam feitos os cálculos separadamente, isto é, considerando apenas os nascidos vivos ou considerando todos os nascimentos (vivos somados aos óbitos fetais), e que seja sempre indicado o denominador utilizado (OMS 1995). No nosso meio, tradicionalmente, é utilizado apenas o número de nascidos vivos.

Ainda que os estudos acerca das mortes maternas sejam de fundamental importância, sabe-se que a RMM é um indicador bastante frágil e sujeito à correção em, praticamente, todos os países. De fato, recentes estimativas da RMM publicadas 
pela OMS (WHO 2001b) corrigem as taxas inclusive dos países com boa qualidade de registro. SALANAVE et. al (1999) verificaram em estudo envolvendo 13 países europeus que a RMM deveria ser corrigida, sendo o fator de correção médio igual a 1,14 .

No Brasil, diversos fatores contribuem para esta situação: um deles é o alto percentual de óbitos cuja causa é desconhecida, e embora esse valor venha declinando, representando, no ano 2000 , cerca de $8,3 \%$ do total de óbitos, quando se analisa a mortalidade segundo regiões, algumas assumem percentuais bem mais elevados, como na Região Nordeste, em que este valor é 22,2\% (MINISTÉRIO DA SAÚDE 2003a).

No caso dos óbitos em que as DOs são preenchidas por médicos, as mortes por causas maternas são mal informadas.. Somado a este fato a sub-enumeração de nascidos vivos e de óbitos, que, quando elevadas, também podem gerar distorções no cálculo da RMM.

Diversas são as abordagens metodológicas na tentativa de corrigir a RMM, destacando-se métodos indiretos e diretos descritos em diversas publicações (LAURENTI et. al 2000a; WHO 2001b). O principal método indireto é o Método das Irmãs (GRAHAM et. al 1989). Este método apresenta como principal vantagem prescindir dos dados de registro civil, porém têm a desvantagem de estimar a taxa para períodos passados muito anteriores ao levantamento dos dados. Em Sergipe, o método foi aplicado em 1994 e estimou a RMM para 1986 (SES 1994).

Dos métodos diretos, destaca-se o denominado RAMOS (Reproductive Age Mortality Survey). Este método consiste na coleta de informações adicionais de todos os casos de óbitos de mulheres em idade fértil, a partir de diversas fontes (sistema de informação sobre mortalidade, prontuários hospitalares, líderes da comunidade, autoridades religiosas, cemitérios e escolas na fase de busca quantitativa, seguida de entrevistas domiciliares e com médicos ou outros profissionais que cuidaram do caso na fase qualitativa). Seus resultados são considerados como PADRÃO-OURO (WALKER et. al 1986; STANTON et. al 1995). O método apresenta como desvantagem sua complexidade e por despender muito tempo, especialmente nos estudos de larga escala (WHO 2001b). A metodologia de busca de casos foi proposta 
há cerca de quarenta anos por PUFFER e GRIFFTH (1968) e, posteriormente, adaptada para estudos de morte materna.

\subsubsection{A situação das mortes maternas no Brasil}

No Brasil, a situação das mortes maternas pode ser considerada um grave problema de saúde pública. Estudo desenvolvido no Estado do Paraná, em 1991, em que os autores utilizaram critérios de evitabilidade dos óbitos, apontou que $86,8 \%$ dos casos poderiam ter sido evitados: $55,0 \%$ com medidas de caráter assistencial e os restantes, se houvesse garantia de acesso aos serviços de saúde às pacientes (BRAGA et. al 1992).

Aliado a este fato, há a sub-enumeração, de forma que o Ministério da Saúde (MS) adota para as diferentes regiões do pais fatores de correção para a RMM, sendo que para a Região Nordeste este fator é igual a três (MINISTÉRIO DA SAÚDE 1994c). Entretanto, ALBUQUERQUE et. al (1997), estudando as mortes maternas em Recife, verificaram que este fator não se manteve constante, variando entre dois e três no período do estudo. Outro estudo, realizado em 15 municípios brasileiros localizados nas Regiões Nordeste, Centro-Oeste e Sudeste, apontou que este fator foi 2,75, independente da Região do país (MELLO JORGE et. al 2002a). Em recente estudo nas capitais brasileiras, estimou-se o fator de correção de 1,67, sendo que para a região Nordeste o mesmo seria 2,05 (LAURENTI el al. 2003).

Em 1994, diante das altas taxas de mortalidade materna no Brasil, o MS (1994b) criou a Comissão Nacional de Mortalidade Materna, com os seguintes objetivos: diagnóstico da situação, proposição de normas, instrumentos legais e princípios éticos que concretizassem as diretrizes básicas estabelecidas a partir dos levantamentos das necessidades detectadas; acompanhamento das ações do MS no processo de articulação e integração das diferentes instituições e instâncias envolvidas na questão e, por fim, oferecer subsídios para aperfeiçoamento da política do setor saúde na área. 
Em 1997, o Conselho Nacional de Saúde (1997) definiu o óbito materno, nos Estados e Municípios, como evento de Notificação Compulsória para a Vigilância Epidemiológica, dada a dimensão do problema e em face da necessidade de cumprir o compromisso de redução de mortalidade materna em 50,0\%, assumido durante a $23^{a}$ Conferência Pan-americana de Saúde em 1990'. Entretanto, o evento não fazia parte do elenco dos agravos de notificação compulsória até em maio de 2003 (MINISTÉRIO DA SAÚDE 2001e, 2003b), ficando, portanto, a cargo dos Estados e Municípios, a decisão de incluí-lo no rol de agravos notificáveis. Por outro lado, cabe aos municipios realizar a vigilância das mortes materno-infantis, devendo, portanto organizar comitês de investigação destes óbitos (MINISTÉRIO DA SAÚDE $1999 \mathrm{~d})^{2}$.

A metodologia de trabalho, indicada pelo MS, a ser adotada pelos Comitês de Morte Materna (MINISTÉRIO DA SAÚDE 1994c, 2001b), consiste na busca ativa de casos. Do ponto de vista quantitativo, a busca deve integrar dados provenientes de várias fontes de informação, como os cartórios, as secretarias de saúde, os líderes comunitários (igrejas, associações de moradores, curandeiros, parteiras) e outros Sistemas de Informação em Saúde (SIS) além do Sistema de Informação sobre Mortalidade (SIM).

Do ponto de vista qualitativo, são recomendadas buscas em prontuários, em serviços de autópsia, e, onde houver possibilidade, realizar entrevista domiciliar. A vantagem da aplicação deste método para diferentes localidades é que o mesmo permite, em primeiro lugar, conhecer a magnitude da mortalidade materna e, nas localidades onde todos os óbitos de mulheres em idade fértil são investigados tornase possível conhecer as causas presumíveis de morte materna, que diversos autores denominam de máscaras, informadas no nível local.

Entretanto, dados do MS mostraram que estão implantados oficialmente 24 comitês estaduais de morte materna, dos quais apenas 14 estão atuantes. Ainda que o

\footnotetext{
' A avaliação dos resultados das metas da $23^{\mathrm{a}}$ conferência da OPS apontou que as melhoras foram insignificantes, sendo que apenas alguns paises conseguiram alcançar a redução de $15 \%$ prevista para 1995. Em 2000 é definida uma nova agenda para as ações de maternidade sem risco, e a meta passou a ser a reduzir em $75 \%$ os óbitos maternos observados em 1990, até 2015 (OPAS 2002).

${ }^{2}$ Em 28 maio de 2003 a Portaria 653 define como compulsória a notificação de mortes maternas e torna-se obrigatória a investigação dos óbitos de mulheres em idade fértil cujas causas possam ocultar um óbito materno (MS 2003b).
} 
evento seja definido como de notificação compulsória, este procedimento não vem sendo adotado como rotina, haja vista que no Brasil 6,5\% dos óbitos de mulheres em idade fértil, em 2000, se referiam a óbitos sem assistência médica e, destes $49,5 \%$ eram casos da Região Nordeste (MINISTÉRIO DA SAÚDE 2003a).

Por outro lado, se o procedimento estiver sendo adotado, não está havendo a devida correção estatística das DOs nas Unidades da Federação (UFs). Neste sentido, TANAKA e MITSUIKI (1999) recomendam que, para aquelas localidades onde o procedimento esteja ocorrendo, não deveria ser aplicado o fator de correção recomendado pelo MS. Cabe ressaltar que até 2001 não havia nenhum mecanismo definido para que o mesmo tenha o conhecimento ou o controle sobre quais Municípios ou Estados realizam a correção estatística das DOs, nem sobre quais os critérios adotados para a correção estatística do documento em cada uma das localidades.

Nos anos mais recentes, o MS, utilizando informações da Rede Intergerencial de Informações para a Saúde (RIPSA), responsável pela elaboração dos indicadores e dados básicos para a saúde, passou a publicar a RMM apenas das UFs que têm cobertura dos óbitos de mulheres em idade fértil no Sistema de Informação de Mortalidade (SIM) maior ou igual a 90\% (MINISTÉRIO DA SAÚDE 2002c).

Em Sergipe e em Aracaju existem comitês estadual e municipal atuantes desde 1996 e $1999^{3}$, respectivamente, que realizam busca ativa e investigação dos óbitos maternos entre todos os casos de óbitos de mulheres na idade fértil, especialmente os de ocorrência na capital. Cabe ressaltar que os resultados da investigação do Comitê Municipal são incorporados ao SIM, porém com cerca de um ano de defasagem.

\footnotetext{
${ }^{3}$ Comunicação pessoal.
} 


\subsection{Fontes alternativas para a melhora da informação}

Uma das estratégias para melhorar quantitativa e qualitativamente a informação dos óbitos de mulheres em idade fértil pode se dar por meio da aplicação do método RAMOS (OMS 1995; STATON et. al 1995; LAURENTI et. al 2000a; WHO 2001b), que consiste em entrevistas com médicos que preencheram as DOs, levantamentos em prontuários dos serviços de saúde, visitas domiciliares, ao Instituto Médico Legal (IML), às delegacias de polícia (DP), na imprensa, nos cartórios, cemitérios ou entrevistas com líderes comunitários, conforme referido.

Apesar de estudos deste tipo produzirem excelentes resultados demandam tempo, alto custo e carecem de recursos humanos treinados e destinados para tal finalidade. Embora fundamentais, trabalhos, deste tipo são mais comuns no âmbito das universidades, não fazendo parte da rotina de grande parte dos serviços de saúde. Neste sentido, diversos projetos deste tipo foram desenvolvidos (LAURENTI et. al 1990a; SIQUEIRA et. al 1999; TANAKA e MITSUIKI 2000, LAURENTI et. al 2003).

Alguns municípios brasileiros têm organizado serviços de aperfeiçoamento das informações de mortalidade, como é o caso de São Paulo (ESCRIVÃo e LIRA 1990), Londrina (SILVA et. al 1996), entre outros. São Paulo conta com o Programa de Aprimoramento de Informações de Mortalidade - PRO-AIM- , desde 1992, que utiliza diversas estratégias para melhorar a qualidade da declaração de óbito.

Recentemente foi desenvolvido o projeto intitulado "O Sistema de Informação de Mortalidade: problemas e propostas para seu enfrentamento - Projeto SIM (MELLO JORGE e GOTLIEB 1998; MELLO JORGE et. al 2002a)". O objetivo deste projeto foi avaliar para algumas áreas o SIM, do ponto de vista quantitativo e qualitativo, e propor medidas simples e factiveis pelos serviços de saúde no sentido de melhorar a informação. O mesmo desenvolveu-se em fases, sendo que em uma delas foi realizada a vigilância dos óbitos em 16 municípios brasileiros.

O Município de Aracaju foi uma das áreas selecionadas. Entre outros casos, foram investigados os óbitos de mulheres com idade entre 10 e 49 anos, ocorridos em 
Aracaju (período dezembro de 1999 a fevereiro de 2000). Os resultados do Projeto SIM mostram que a metodologia utilizada é uma excelente ferramenta para melhorar a qualidade da informação de mortalidade e sua aplicação vem sendo considerada simples e factível (BAGGIO 2002; OLIVEIRA 2002; MELLO JORGE et. al 2002a e b).

\subsection{Sistemas de informação}

Dentre os Sistemas de Informação do MS, além do sistema oficial de dados de mortalidade (Sistema de Informação sobre Mortalidade -SIM), existem outros que podem ser utilizados como fontes para estudos de óbitos, como o Sistema de Informações Hospitalares (SIH) do SUS e o Sistema de Informação da Atenção Básica (SIAB) e o Sistema de Informação de Agravos de Notificação (SINAN). Além destes sistemas, cabe ressaltar que as informações de mortalidade são também constantes do Instituto Brasileiro de Geografia e Estatística (IBGE), tratando-se dos casos de óbitos registrados.

Embora tenham sido concebidos com diferentes objetivos, podem ser considerados como sistemas de informação com dados de óbitos, ou seja, podem ser utilizados para melhorar a informação no presente estudo do ponto de vista quantitativo.

O SIH também pode ser utilizado para melhorar a qualidade das informações sobre os óbitos, pois permite conhecer o motivo de internações em um período imediatamente anterior àquele que antecedeu o óbito. Diversos autores verificaram que é possivel melhorar a qualidade da informação da DO utilizando a técnica de ligação (linkage) dos bancos de dados de óbitos e de internações hospitalares (GOLDACRE 1993; BRAMELD et. al 1998).

Especificamente, no caso dos óbitos relacionados com o ciclo gravídicopuerperal, além do SIH, o Sistema de Informação sobre Nascidos Vivos (SINASC), o SIAB e o próprio SIM podem contribuir para melhorar a informação, por conterem 
variáveis que indicam direta ou indiretamente ${ }^{4}$ a presença de gravidez ou parto no momento da morte, ou em um espaço de tempo entre este evento e o fatal.

Estes quatro sistemas podem ser considerados como sistemas de apoio ao esclarecimento das causas de óbito, ou seja, podem ser utilizados para melhorar a informação do ponto de vista qualitativo, no que se refere às mortes maternas ou aquelas ocorridas durante o ciclo gravídico-puerperal.

Diversos estudos internacionais foram conduzidos, no sentido de aprimorar a informação sobre as mortes maternas utilizando técnicas de linkage, confrontando os casos de mortes de mulheres em idade fértil (MIF) e os dados de óbitos fetais e de nascidos vivos, com objetivo de verificar a presença de gravidez num determinado período antes do óbito (BENEDETTI et. al 1986; ALLEN et. al 1991; DYE et. al 1992; JOCUMS et. al 1995; BERG et. al 2003).

No Brasil alguns estudos foram realizados no sentido de verificar a subenumeração das mortes maternas a partir de dois sistemas de informação (SILVA e RUSSOMANO 1996), sendo que os autores utilizaram o SIM e os resumos de alta hospitalar de um sistema especial de informação no Rio de Janeiro. GOMES (2002) verificou a potencialidade do uso do banco de dados do SIH para a detecção e complementação dos casos de mortes maternas.

\subsubsection{Sistema de Informação do IBGE}

É o mais antigo sistema de coleta de óbitos existente no país (1938). Não é ligado ao Ministério da Saúde (VASCONCELOS 1998) e o instrumento de coleta é a DO. Entretanto o mesmo não trabalha informações de interesse epidemiológico, apenas as demográficas. O sistema é alimentado pelos casos de óbitos que têm o respectivo registro em cartório.

Embora seja um sistema que tenha, teoricamente, cobertura populacional de $100 \%$, uma vez que a legislação prevê que nenhum sepultamento deve ser realizado antes do devido registro do evento, é sabido que no Brasil, principalmente nas

\footnotetext{
${ }^{4}$ Por conter casos de óbitos fetais e infantis.
} 
Regiões Norte e Nordeste, ainda persiste o sub-registro, apesar de legislação datada de 1997 garantir a gratuidade do mesmo (BRASIL 1997). TANAKA e MITSUIKI (2000) no Rio Grande do Norte, em 1997, verificaram que não havia sido emitida a DO para $20 \%$ dos óbitos de mulheres em idade fértil.

Apesar disto, VASCONCELOS (1998) aponta que o IBGE captou cerca de $4,0 \%$ mais casos que o SIM, em 1995, porém com diferenças regionais. A Tabela 2 mostra a relação dos óbitos de mulheres de 10 a 49 anos registrados e captados pelo SIM em Sergipe. Observa-se que a partir de 1991 a captação do SIM superou a captação de casos do IBGE em praticamente todo o periodo.

Tabela 2. Óbitos de mulheres de 10 a 49 anos captados pelo IBGE e pelo SIM, em Sergipe e relação SIM/IBGE, de 1979 a 2001.

\begin{tabular}{|c|c|c|c|}
\hline \multirow[t]{2}{*}{ Ano } & \multicolumn{2}{|c|}{ Fonte } & \multirow[t]{2}{*}{ SIM/IBGE } \\
\hline & IBGE & SIM & \\
\hline 1979 & 567 & 535 & 94,4 \\
\hline 1980 & 541 & 508 & 93,9 \\
\hline 1981 & 490 & 528 & 107,8 \\
\hline 1982 & 481 & 470 & 97,7 \\
\hline 1983 & 477 & 446 & 93,5 \\
\hline 1984 & 433 & 403 & 93,1 \\
\hline 1985 & 457 & 449 & 98,2 \\
\hline 1986 & 487 & 480 & 98,6 \\
\hline 1987 & 483 & 410 & 84,9 \\
\hline 1988 & 497 & 446 & 89,7 \\
\hline 1989 & 487 & 462 & 94,9 \\
\hline 1990 & 456 & 427 & 93,6 \\
\hline 1991 & 485 & 529 & 109,1 \\
\hline 1992 & 505 & 622 & 123,2 \\
\hline 1993 & 548 & 590 & 107,7 \\
\hline 1994 & 499 & 552 & 110,6 \\
\hline 1995 & 551 & 661 & 120,0 \\
\hline 1996 & 516 & 531 & 102,9 \\
\hline 1997 & 579 & 584 & 100,9 \\
\hline 1998 & 608 & 598 & 98,4 \\
\hline 1999 & 624 & 713 & 114,3 \\
\hline 2000 & 528 & 699 & 132,4 \\
\hline
\end{tabular}

Fonte: MINISTÉRIO DA SAÚDE 2003a, IBGE 1981-2003. 


\subsubsection{Sistema de Informações sobre Mortalidade - SIM}

O SIM foi implantado em 1975 (MINISTÉRIO DA SAÚDE 1999b), captando informaç̃es sobre os óbitos do país. As informações correspondentes ao período de 1979 a 2000 estão disponibilizadas em meio eletrônico (MINISTÉRIO DA SAÚDE 2000, 2002a, 2003a).

O instrumento de coleta das informações é a DO e muitos autores apontam falhas no seu preenchimento, especialmente quanto à causa básica de óbito. Nos estudos de avaliação da qualidade das informações segundo causas de óbito, foram verificadas incorreções, com baixo grau de concordância entre a opinião do investigador $\mathrm{e}$ o documento original, principalmente no tocante às categorias $\mathrm{e}$ subcategorias, embora as alterações nos capítulos não tivessem sido muito expressivas. Entretanto, diversos autores chamaram a atenção para o fato de que as mortes maternas são as mais mal informadas nas DOs (LAURENTI et. al 1990b; ALBUQUERQUE et. al 1997; SIQUEIRA et. al 1999; TANAKA e MITSUIKI 1999; THEME-FILHA et. al 1999).

Outra questão importante é que existe um elevado percentual de óbitos por causas mal definidas, sendo que grande parte destes, ocorreu sem assistência médica, principalmente nas regiões Norte e Nordeste (Tabela 3). No Estado de Sergipe estes corresponderam a $18,5 \%$ dos óbitos em 2000 , considerados apenas os óbitos de mulheres em idade fértil (MINISTÉRIO DA SAÚDE 2003a). SIQUEIRA et. al (1999) mostraram que é possivel tornar bem definidas as causas mal-definidas, e que destas apenas $13,6 \%$ tratava-se de causas maternas. 
Tabela 3. Distribuição do $\mathrm{n}^{\circ}$ e \% de óbitos sem assistência médica (SAM) entre mulheres de 10 a 49 anos. Brasil e regiões, 2000.

\begin{tabular}{lrrr}
\hline Região & \multicolumn{2}{c}{ Óbitos SAM } & Total \\
\cline { 2 - 3 } & $\mathrm{N}^{\mathrm{o}}$ & $\%$ & \\
\hline Norte & 444 & 11,1 & 3992 \\
Nordeste & 2045 & 13,2 & 15502 \\
Sudeste & 709 & 2,3 & 30599 \\
Sul & 219 & 2,4 & 9291 \\
Centro-Oeste & 85 & 1,9 & 4437 \\
\hline Total & 3502 & 5,5 & 63821 \\
\hline
\end{tabular}

Fonte: MINISTÉRIO DA SAÚDE 2003a.

Além das questões apontadas acima, o MS admite que o SIM tenha captado $81,8 \%$ dos casos ocorridos no país em 1999, sendo novamente as regiões Norte e Nordeste as maiores responsáveis pela subenumeração (Tabela 4). Para o Estado de Sergipe esta é da ordem de 20,5\% (MINISTÉRIO DA SAÚDE 2003a).

Tabela 4. Percentual de óbitos captados pelo SIM em relação ao número de óbitos estimados, segundo grandes regiões do Brasil, 1999.

\begin{tabular}{lc}
\hline Região & $\%$ \\
\hline Norte & 67,7 \\
Nordeste & 60,9 \\
Sudeste & 94,3 \\
Sul & 95,3 \\
Centro-Oeste & 86,7 \\
\hline Total & 81,8 \\
\hline
\end{tabular}

Fonte: MINISTÉRIO DA SAÚDE 2003a.

\subsubsection{Sistemas de Informação em Saúde de apoio à melhora da informação sobre os óbitos}

Conforme referido anteriormente, considera-se que, além do SIM, outras bases de dados podem contribuir para melhorar a informação quantitativa e 
qualitativa dos óbitos, por se tratarem de sistemas de informação que contêm dados de óbitos (SIH, SIAB e o SINAN), ou por conterem informações que potencialmente melhoram sua qualidade (SIH, SINAN, SINASC e o próprio SIM), o que será detalhado a seguir.

\section{- $\mathrm{SIH}$}

O SIH reúne informações sobre as internações hospitalares ocorridas no país e permite o conhecimento de casos de óbitos de pacientes internados na rede de serviços do SUS (hospitais federais, estaduais, municipais, e privados filantrópicos ou lucrativos) (CARVALHO 1997). As informações desde 1992 estão disponibilizadas e atualizadas segundo o mês, em meio eletrônico, de forma ágil (é possivel coletar o dado após três meses da ocorrência). $O$ instrumento de coleta das informações geradas é a Autorização de Internação Hospitalar (AIH).

Antes de 1986, a AIH era documento restrito dos hospitais privados conveniados com o Sistema de Atenção Médico Hospitalar da Previdência Social (SAMHPS). Porém, a partir desta data, o SAMHPS/AIH foi estendido aos hospitais filantrópicos e aos universitários de ensino e, recentemente (1991), aos hospitais públicos de todas as esferas de governo. Neste mesmo momento, passou a ser denominado SIH (CARVALHO 1997).

São feitas algumas críticas ao uso das informações do SIH para análises epidemiológicas, uma vez que este foi concebido como um sistema de pagamento de serviços prestados. Apesar destas críticas, entretanto, têm sido apontadas as possibilidades do uso dos dados, desde a vigilância, o planejamento, a avaliação e controle em saúde e para as auditorias hospitalares.

Do ponto de vista quantitativo, admite-se que os dados do $\mathrm{SIH}$ representem um valor aproximado das internações, uma vez que as transferências e reinternações são computadas com duplicidade (CARVALHO 1997; MINISTÉRIO DA SAÚDE 1998), fato este que dificulta as análises.

Estudos internacionais contornaram os problemas gerados pela duplicidade do paciente (casos de reinternações ou transferências) utilizando técnica de linkage dentro do banco de dados de internações hospitalares. A metodologia permite, inclusive, estabelecer o número de internações por paciente. No caso do SIH, 
também é possível a aplicação de tal técnica desde que se utilize o banco de dados identificado (BRAMELD et. al 1998).

Quanto à qualidade da informação do SIH, deve-se considerar que a causa de internação (definida como sendo aquela que motivou a internação), no decorrer da mesma, pode mudar, o que nem sempre é registrado no documento, o que também pode levar a distorções. Em 1992, MATHIAS e SOBOLL (1998) avaliaram a qualidade do preenchimento das AIHs e verificaram um bom grau de adequação entre o documento e as anotações de prontuário, recomendando seu uso em estudos epidemiológicos.

Embora as informações geradas pelo SIH sejam parciais, do ponto de vista da cobertura populacional, estima-se que o mesmo seja responsável por cobertura aproximada de $77,5 \%$ das internações hospitalares do pais (IBGE 2000).

O SIH, por conter dados de internações hospitalares, portanto permite o conhecimento de casos cujo motivo da internação foi obstétrico. GOLDACRE (1993) utilizando a técnica de linkage dos dados de internação hospitalar e da declaração de óbito, durante o ano que precedeu a morte, verificou que houve melhora na qualidade da informação da DO. GOMES (2002) analisando os dados de óbitos de mulheres em idade fértil do SIH para 5 estados brasileiros verificou casos de mortes maternas mascaradas, recomendando que o sistema seja incluso como fonte de informação na busca de óbitos maternos e de outros agravos.

- SIAB

O SIAB foi concebido em 1994, quando da implantação do Programa de Saúde da Família (PSF) e consistiu num aprimoramento do Sistema de Informação de Programa de Agentes Comunitários de Saúde (SIPACS), criado em 1991, tendo como referencia uma base populacional (SAS, 1998).

O SIAB ampliou o número de informações em relação ao SIPACS e também pode ser aplicado para o acompanhamento de outros modelos de atenção básica (demanda espontânea, oferta programática, entre outros). As informações correspondentes ao periodo de 1998 a 2000 estão disponibilizadas em meio eletrônico. 
O SIAB é um instrumento de gestão da atenção básica e produz informações sócio-sanitárias e de acompanhamento da população. Possibilita a avaliação dos serviços de saúde oferecidos por meio de indicadores e marcadores de saúde. Existem dezesseis instrumentos (sendo oito de coletas de dados e os demais para a consolidação dos mesmos), sendo que todos eles podem ser utilizados em áreas onde o modelo de atenção é o PSF. Quando a modalidade for outra, apenas parte destes instrumentos é utilizada.

Para atender o modelo de atenção existente em cada município, o sistema apresenta diferentes níveis de desagregação de informações: no caso de modelos como o PACS/PSF o menor nível é a micro-área. Para os outros modelos de atenção, este nivel é a área de abrangência da Unidade Básica de Saúde. Portanto, ainda que as informações produzidas pelo sistema não sejam individualizadas, é possivel localizar as micro-áreas em que ocorreram determinados eventos, entre eles, os casos de óbitos.

Um estudo recente, que objetivava avaliar a implantação e o funcionamento do PSF, apontou que o SIAB estava implantado em 100\% dos locais onde há o PSF, e que $87,6 \%$ das equipes têm pelo menos um membro treinado para o preenchimento das fichas do sistema (MINISTÉRIO DA SAÚDE 1999c).

Em algumas localidades da Região Nordeste (Maranhão, Paraíba e Alagoas), do ponto de vista quantitativo foi verificado, entre os óbitos de menores de um ano, que o número de casos informados pelo SIAB foi maior que o informado pelo SIM (MINISTÉRIO DA SAÚDE 2001a). Neste sentido, o próprio MS recomenda que para contornar subenumeração, os municipios podem realizar busca ativa de casos, utilizando para a coleta de informações os Agentes Comunitários de Saúde (BRASIL 2000a, 2000b).

MELLO JORGE e GOTLIEB (2001) recomendam que sejam incluídas entre as atividades dos agentes de saúde do PACS/PSF a notificação das informações de óbitos e de nascidos vivos e que sejam remetidas aos responsáveis pelo SIM e SINASC, a partir do preenchimento de formulários específicos. Se verificado nas secretarias municipais e estaduais que o caso não está incluso no SIM e SINASC, o mesmo poderia ser resgatado ou se emitiria a DO ou a Declaração de Nascido Vivo (DN) e as mesmas seriam incluídas no sistema correspondente, isto é, SIM ou 
SINASC, respectivamente. Quanto à avaliação da qualidade das informações produzidas pelo SIAB, até o presente momento, não foram encontrados estudos abordando este problema.

A cobertura populacional do PACS/PSF é baixa $(21,6 \%)$, mas, sabe-se que entre os critérios de eleição de áreas para a implantação destes programas são as que a população apresenta maior risco de morte ou doença. No país, as maiores coberturas são nas Regiões Norte $(31,9 \%)$ e Nordeste (40,3\%) (Tabela 5). Em Sergipe, a população cadastrada nestes programas era de 54,7\% em 2000 (MINISTÉRIO DA SAÚDE 2003a).

Tabela 5. Cobertura populacional no Programa de Saúde da Família (PSF) e do Programa de Agentes Comunitários de Saúde (PACS) segundo regiões. Brasil, 2000.

\begin{tabular}{lrrr}
\hline \multirow{2}{*}{ Região } & \multicolumn{3}{c}{ População Cadastrada } \\
\cline { 2 - 4 } & PACS & PSF & Total \\
\cline { 2 - 4 } & 25,7 & 6,2 & 31,9 \\
Norte & 31,7 & 8,6 & 40,3 \\
Nordeste & 3,5 & 4,7 & 8,2 \\
Sudeste & 16,0 & 4,4 & 20,4 \\
Sul & 16,9 & 2,6 & 19,5 \\
Centro-Oeste & 15,6 & 5,7 & 21,3 \\
\hline Total & & &
\end{tabular}

Fonte: MINISTÉRIO DA SAÚDE 2003a.

No sentido de melhorar a qualidade das informações, o SIAB contém informações das gestantes cadastradas e acompanhadas segundo micro-área, sendo possível localizar seus domicílios junto às equipes do PACS/PSF, de forma a proceder à busca da condição de gestante entre os casos de óbitos de mulheres em idade fértil.

- SINAN

O SINAN também é um recurso informatizado para coletar e disseminar dados gerados rotineiramente pelo Sistema de Vigilância Epidemiológica das Secretarias Municipais e Estaduais de Saúde (MINISTÉRIO DA SAÚDE 2002b). 
Possibilita uma análise global integrada de todas as doenças e agravos que constituem objeto de notificação compulsória, de interesse nacional, estadual ou municipal, sendo os instrumentos de coleta as fichas de notificação e investigação e fornece informações para o acompanhamento de doenças como a Hanseníase e Tuberculose. Todos os agravos têm campos para classificação final e evolução, portanto a partir do sistema é possivel coletar casos cuja evolução foi o óbito.

As informações contidas no SINAN podem melhorar quantitativamente a informação de mortalidade, fato é que o próprio MS inclui o uso deste sistema como fonte complementar de óbitos, sugerindo que sejam verificadas no SIM os óbitos informados pelo SINAN (MINISTÉRIO DA SAÚDE 2002b). Por outro lado, somente nos casos de AIDS o SINAN inclui entre as variáveis informações mais completas sobre o óbito, como o número da DO e as causas de óbito.

O SINAN por conter em sua base de dados a investigação dos casos de óbitos do rol de agravos de notificação, pode contribuir para melhorar qualitativamente a informação de mortalidade, entre eles, os casos de óbitos de mulheres em idade fértil por agravos notificáveis.

\section{- SINASC}

O SINASC, implantado em 1990, capta informações sobre as mães, os nascidos vivos e o parto (MINISTÉRIO DA SAÚDE 1999a). Dados correspondentes ao periodo de 1994 a 2000 estão disponibilizados em meio eletrônico (MINISTÉRIO DA SAÚDE 2002a, 2003a).

O instrumento de coleta das informações é a DN, cujo preenchimento se mostrou adequado: na Região Sudeste foi realizado inquérito em hospitais, que apontaram uma fidedignidade da DN (MELLO JORGE et. al 1993). Outro estudo em nivel nacional, que avaliou o percentual de preenchimento das DNs e a taxa de captação do documento, apontou que para o Estado de Sergipe estas proporções foram bastante satisfatórias (MELLO JORGE et. al 1996). A DN é preenchida na unidade de saúde onde ocorreu o parto (independente do registro do evento em cartório) ou nos cartórios de registro civil, apenas no caso de partos domiciliares sem assistência médica, evidentemente, quando houver registro dos mesmos (MINISTÉRIO DA SAÚDE 1999a). Cabe ressaltar que até a data da implantação do 
SINASC, os dados s4obre nascidos vivos eram provenientes do Registro Civil (IBGE, 1981-2003).

Entretanto, estima-se que o sub-registro de nascimento seja da ordem de 32,0\% no Brasil e 44,5\% em Sergipe em 1999 (MINISTÉRIO DA SAÚDE 2003a). O SINASC possibilitou contornar grande parte dos problemas gerados pelo subregistro de nascimento, uma vez que há estimativas que apontam que 90,0\% dos partos, no Brasil, são hospitalares. No país a cobertura do SINASC foi de $92,8 \%$, em 1999 (Tabela 6). No Estado de Sergipe o SINASC captou neste ano 92,5\% dos nascidos vivos estimados pelo IBGE em 1999.

Tabela 6. Razão entre nascidos vivos informados pelo SINASC estimados pelo IBGE, segundo grandes regiões do Brasil, 1999.

\begin{tabular}{lc}
\hline Região & Razão \\
\hline Norte & 79,6 \\
Nordeste & 80,2 \\
Sudeste & 102,8 \\
Sul & 102,5 \\
Centro-Oeste & 99,0 \\
\hline Total & 92,8 \\
\hline
\end{tabular}

Fonte: MINISTÉRIO DA SAÚDE 2003a.

O banco de dados do SINASC pode ser uma ferramenta de apoio à detecção dos casos de óbitos de MIF relacionados com o ciclo gravídico-puerperal, uma vez que todos os casos referem-se a gestantes e seu(s) respectivo(s) nascido(s) vivo(s). Para tanto é necessário utilizar técnica de ligação de bancos de dados do SIM e do SINASC (linkage). Esta técnica vem usualmente sendo utilizada no nosso meio para estudos de mortalidade infantil (ALMEIDA e MELLO JORGE 1996; OKABE 2000).

De modo análogo, é possível utilizá-la para estudos de mortalidade materna, conforme estudos conduzidos em outras localidades (BENEDETTI et. al 1986; ALLEN et. al 1991; DYE et. al 1992; JOCUMS et. al 1995; BERG et. al 2003). Ou seja, é possivel realizar a busca entre as DNs dos casos de óbitos de mulheres em idade fértil objetivando verificar se a mãe trata-se de caso foi óbito relacionado com 
o ciclo gravídico-puerperal, em todos as localidades do pais que seguem as portarias 474 e 475 do Ministério da Saúde.

- SIM

O SIM, por sua vez, também pode ser uma fonte de apoio a buscas de casos de óbitos de MIF relacionados com o ciclo gravídico-puerperal, uma vez que é possível captar, de forma indireta, os casos de gestantes, a partir dos casos de óbitos fetais e infantis em um periodo de tempo pré-determinado (isto é, até no período menor ou igual a um ano antes do óbito da MIF).

Conforme referido anteriormente, foram conduzidos estudos utilizando declarações de óbitos fetais e que somadas as de nascidos vivos produziram informação sobre casos de óbitos em um determinado periodo anterior a morte das MIF (BENEDETTI et. al 1986; ALLEN et. al 1991; DYE et. al 1992; JOCUMS et. al 1995; BERG et. al 2003). Tais estudos foram conduzidos em países com boa qualidade das estatísticas vitais, e imagina-se que não houve preocupação da inclusão dos óbitos de menores de um ano, uma vez que todos os casos possuíam a declaração de nascido vivo. Entretanto, no nosso meio, como é sabido, ainda existem falhas de captação tanto do SIM quanto do SINASC (MINISTÉRIO DA SAÚDE 2002c), motivo pelo qual também devem ser considerados os casos de óbitos infantis como potencial fonte de informação.

As técnicas que utilizam comunicação de bancos de dados são de aplicação relativamente recente em nosso meio (ALMEIDA e MELLO JORGE 1996), porém em diversos países, estudos deste tipo são bastante comuns, e ocorrem há cerca de duas décadas (BENEDETTI et. al 1986; ALLEN et. al 1991; DYE et. al 1992; GOLDACRE 1993; KENDRICK e CLARKE 1993; JOCUMS et. al 1995; BRAMELD et. al 1998; BERG et. al 2003).

$\mathrm{O}$ desenvolvimento de metodologia visando a melhora quantitativa $\mathrm{e}$ qualitativa da informação, neste caso abordando o tema mulheres em idade fértil, e mais especificamente as mortes maternas, utilizando técnicas de baixo custo com possibilidade de ser padronizada, poderia contribuir para a otimização dos resultados do SIM, com menor dispêndio de recursos (humanos e materiais), como é o caso do 
uso de técnicas de comunicação entre os sistemas e bases de dados disponíveis, visando à correção estatística das DOs.

\subsection{Algumas características do Município de Aracaju}

Com 146 anos de existência o Municipio de Aracaju é a capital do Estado de Sergipe e localiza-se na região Nordeste do Brasil. Em 2001, apresentou população de 468297 habitantes. Segundo dados censitários, a maioria é composta por mulheres $(53,2 \%)$ e trata-se de população estacionária (27,7\% menores de 15 anos e 13,8\% com 50 anos e mais). No tocante à saúde, Aracaju é município pólo, e passou a ter gestão plena do sistema em julho de 2002. Em 2001 apresentou cobertura de 53,0\% da população nos programas PACS e PSF, e vêm expandindo a cobertura populacional na atenção básica.

O município é dividido em 4 distritos sanitários. Em 2001, o coeficiente de mortalidade geral foi 5,8 por mil habitantes sendo a principal causa de mortalidade as doenças do aparelho circulatório $(24,8 \%)$, seguidas das causas externas $(14,1 \%)$ e das neoplasias (13,9\%). O município é responsável pela alimentação dos bancos de dados que foram objeto deste estudo como o SIM, SINASC, SINAN (todos desde 1999), SIAB (desde 1998) e pelo SIH somente a partir de 2002. No tocante à saúde materno-infantil, o município além da rede básica, conta com serviço de referência para pré-natal de alto risco e com cinco maternidades, tendo sido realizados 19197 partos em 2001, com taxa de baixo peso de 8,6\%. O coeficiente de mortalidade infantil foi de 29,9 óbitos/1000 NVs (2001), sendo os casos concentrados no período neonatal (78,0\%), principalmente o precoce $(68,6 \%)$. Em 1999 foi criado o comitê de prevenção das mortes maternas e de menores de cinco anos.

Diante do exposto, o Município de Aracaju foi escolhido pelo fato de carecer de estudos sobre a mortalidade de mulheres em idade fértil, por tratar-se de município pólo de atenção à saúde, e dispor dos bancos de dados referentes aos Sistemas de Informação em Saúde previamente descritos. 
2. OBJETIVOS 


\subsection{Objetivo geral}

Descrever do ponto de vista epidemiológico os óbitos de mulheres em idade fértil, no período de 1979 a 2001, com ênfase na melhoria das informações sobre as mortes maternas, de residentes em Aracaju (SE).

\subsection{Objetivos específicos}

- Descrever a informação produzida pelo SIM no período de 1979 a 2001.

- Descrever a melhora quantitativa, a partir da busca de casos em bases de dados de apoio à informação, para os casos de 2001 .

- Avaliar a possibilidade de uso dos sistemas de informação em saúde disponiveis para melhorar qualitativamente, a informação da DO, especialmente no tocante às mortes maternas.

- Descrever o perfil epidemiológico utilizando inquérito em fontes alternativas (entrevistas em hospitais e outros serviços de saúde, nos domicilios e nos serviços de autópsia). 
3. METODOLOGIA 
O presente estudo foi desenvolvido em três etapas ou fases:

- $1^{\mathrm{a}}$ : Análise das informações sobre óbitos de mulheres em idade fértil produzidas pelo SIM - periodo de referência: 1979 a 2001.

- $2^{\mathrm{a}}$ : Inquérito em fontes alternativas - período de referência: 2001

- $3^{\text {a }}$ : Levantamento qualitativo em outros Sistemas de Informação - período de referência: 2001

A metodologia será descrita para cada uma das etapas do desenvolvimento da pesquisa. Cabe ressaltar que as etapas foram tratadas de forma independente; portanto, houve necessidade, em cada uma delas, de definir-se uma hierarquia para a análise dos dados, o que será visto em momento oportuno.

\subsection{Levantamento das informações produzidas pelo SIM no período de 1979 a 2001}

\subsubsection{População de estudo}

No periodo ocorreram 4299 óbitos casos de óbitos de mulheres de 10 a 49 anos, residentes em Aracaju, Sergipe, ocorridos no periodo compreendido entre $1^{\circ}$ janeiro de 1979 e 31 de dezembro de 2001 (Tabela 7).

As estimativas populacionais foram obtidas junto ao Departamento de Informática do SUS -DATASUS- (MINISTÉRIO DA SAÚDE 2003a), exceto as referentes ao ano de 1979, não disponíveis. Neste caso, foi realizada a estimativa populacional utilizando o Método de Lagrange (SANTOS 1992).

O número de nascidos vivos de mães residentes em Aracaju foi proveniente do IBGE para o periodo de 1979 a 1996. Cabe lembrar que, neste caso, são captados apenas os nascidos vivos ocorridos e registrados no mesmo ano e para tentar a correção deste valor utilizou-se os nascidos vivos registrados até cinco anos após o nascimento (IBGE 1981-2003). Para o restante da série foram utilizados os dados do 
SINASC (MS 2002a) provenientes do MS (1995-1999) e da Secretaria Estadual de Saúde (SES 2000) de Sergipe (2000-2001).

Tabela 7. $\quad N^{\circ}$ de óbitos de mulheres e população feminina de 10 a 49 anos e nascidos vivos de mães de residentes em Aracaju (SE), 1979- 2001.

\begin{tabular}{cccc}
\hline Ano & $\begin{array}{c}\text { Óbitos de Mulheres } \\
\text { de 10 a 49 Anos }\end{array}$ & $\begin{array}{c}\text { População Feminina de 10 a } \\
\text { 49 Anos }\end{array}$ & Nascidos Vivos $^{b}$ \\
\hline 1979 & 176 & 93777 & 10213 \\
1980 & 197 & 97150 & 11800 \\
1981 & 163 & 100906 & 12815 \\
1982 & 199 & 105234 & 13040 \\
1983 & 171 & 109574 & 12704 \\
1984 & 130 & 113904 & 12599 \\
1985 & 158 & 118216 & 13167 \\
1986 & 178 & 122497 & 13834 \\
1987 & 149 & 126708 & 13956 \\
1988 & 204 & 130834 & 14545 \\
1989 & 181 & 134856 & 13701 \\
1990 & 194 & 138781 & 12635 \\
1991 & 140 & 143295 & 11536 \\
1992 & 259 & 145932 & 13071 \\
1993 & 213 & 149904 & 13161 \\
1994 & 240 & 152528 & 12605 \\
1995 & 231 & 155086 & 12286 \\
1996 & 136 & 157228 & 11406 \\
1997 & 160 & 159593 & 10417 \\
1998 & 186 & 161589 & 10222 \\
1999 & 243 & 163602 & 11050 \\
2000 & 195 & 168099 & 10654 \\
$2001^{\mathrm{a}}$ & 196 & 170562 & 9889 \\
\hline
\end{tabular}

a: os dados de 2001 são referentes apenas à primeira fase do estudo.

b: nascidos vivos no periodo de 1979-1996: registrados até cinco anos após o nascimento.

c: população de 1979 (SANTOS 1992).

Fonte: dados de nascidos vivos até 1996 provenientes do IBGE (IBGE 1980-2001), a partir de 1997 SINASC (MS 2002a, SES 2002).

dados de população: DATASUS (MS 2003a).

dados de óbitos: SIM (MS 2000, MS, 2002a, SES, 2002). 


\subsubsection{Método de análise da série histórica}

Conforme referido, o material foi constituído pelo banco de dados de óbitos disponibilizado pelo Ministério da Saúde (1979-1999) e pela Secretaria Estadual de Saúde de Sergipe (2000-2001 ${ }^{1}$ ).

Quanto às mortes relacionadas à gravidez, parto ou puerpério, foram selecionadas as DOs de mulheres com idade entre 10 e 49 anos, cuja causa básica fosse pertencente ao capítulo das mortes XI da CID 9 e XV da CID 10: houve 186 casos no período.

Foram verificados mais oito casos que a causa básica pertencia ao capítulo das mortes maternas: XI da CID 9 e XV da CID 10 (OMS 1978; OMS 1995). Destes oito casos em um não houve compatibilidade entre a causa básica e a idade (optou-se por priorizar a causa básica, e considerar a idade ignorada) e em cinco, a idade foi ignorada. Houve um caso que se tratava de óbito fetal, cuja causa básica era pertencente ao capitulo XV da CID 10, o que possivelmente referiu-se a erro de codificação, motivo pelo qual foi excluído. Portanto, estes sete casos foram acrescidos aos 186 , totalizando 192 casos.

Conforme recomendação internacional, também foram selecionados para inclusão os casos de tétano obstétrico, necrose pós-parto da hipófise, osteomalácia puerperal e os transtornos mentais e comportamentais associados ao puerpério (OMS 1995), não havendo, entretanto, nenhum caso por estas causas. Cabe lembrar que, na CID 9, o tétano obstétrico fazia parte do capitulo das mortes maternas e os demais agravos não tinham rubrica específica (assim como a osteomalácia puerperal na CID 10). Também não houve nenhum caso na série codificada pela CID 9.

As demais causas definidas pela CID 10, que deveriam ser objeto de investigação, por não pertencerem ao capítulo XV, (AIDS e lesões traumáticas), não foram incluidas, por impossibilidade de investigação. Entretanto, no caso do preenchimento dos campos 43 e 44, se indicassem óbito durante a gravidez, parto e puerpério, foram considerados, resultando em mais 28 inclusões. Cabe lembrar que estes campos estão presentes na DO apenas a partir de 1995.

\footnotetext{
'Dados ainda preliminares.
} 
Utilizando os dados disponiveis em CD-ROM (MS 2000, 2002a) e da Secretaria de Estado da Saúde de SE (período de 2000-2001), após a homogeneização das variáveis, bem como de algumas das categorias, criou-se um banco de dados único para todo o periodo. No total, observaram-se 4299 casos. Destes, 192 pertencentes ao capitulo das mortes maternas no periodo de 1979 a 2001. Houve 220 casos com informações sobre gravidez, parto e puerpério, ou seja, em 192 como causa básica e nos 28 restantes haviam sido preenchidos os campos 43 ou 44, a partir de 1995, de forma que esta análise será feita separadamente.

$\mathrm{Na}$ primeira fase, os casos foram descritos segundo freqüência relativa e absoluta e coeficientes, de acordo com as variáveis do estudo. Quanto às causas de óbito, estas foram descritas segundo capítulos da CID 10 e segundo os seis grupos de causas referidas no Quadro 1 . Os casos de óbitos maternos também foram descritos segundo categorias da CID 10.

Foram estimados os coeficientes de mortalidade das mulheres em idade fértil e a razão de mortalidade materna (RMM). No tocante aos óbitos maternos, por recomendação da OMS (1995), foram excluídos do cálculo da RMM aqueles ocorridos no puerpério tardio bem como, aqueles que foram codificados como tardios (O96) ou seqüelas de causas maternas (O97). Cabe lembrar que o conceito de óbito materno tardio foi incluído apenas na CID em vigor.

Para avaliar a informação quantitativa das mortes maternas, a RMM anual foi comparada à obtida segundo duas técnicas:

- Pelo coeficiente estimado a partir dos casos de mortes maternas somados aos casos cuja causa é presumível de morte materna (Grupos 1 e 2, do Quadro 1) (MS 2001b).

- Pelo fator de correção obtido por LAURENTI et. al (2003) para a Região Nordeste 


\subsection{Levantamento em outras fontes de informação dos casos de}

2001

Para a análise de 2001, conforme citado anteriormente, em cada uma das fases, houve necessidade de definir-se uma hierarquia para definir uma referência para a análise dos dados. Na primeira fase, que envolveu apenas o SIM, não houve necessidade de tal hierarquização, trabalhando-se com os dados oficiais.

Na segunda fase, a partir da lista única, procedeu-se à busca de informações adicionais utilizando a metodologia proposta por MELLO JORGE e GOTLIEB (1998), detalhada em publicação recente (MELLO JORGE et. al 2002a). Definiu-se que as informações, nesta fase, seriam as de referência. Na terceira fase, utilizando novamente a lista única, nos casos em que houve discrepância das informações, definiu-se que o SIM seria a referência. Em síntese, em razão dessas disposições metodológicas, em cada uma das fases, obteve-se um número de casos diferentes. A metodologia para a obtenção dos mesmos será descrita a seguir.

\subsubsection{Levantamento em Sistemas de Informação com dados de óbito: a construção da lista única dos casos}

Nesta etapa, a metodologia proposta visou melhorar a informação quantitativa a partir do levantamento nos sistemas de informação em saúde com dados de óbito. A partir deste levantamento, foi elaborada uma lista única que se constituiu de base para a definição do número de casos de cada uma das etapas subseqüentes deste estudo.

A partir de quatro sistemas - SIM, SIH, SINAN e SIAB - foi obtida a quantidade de casos de óbitos. Do banco de dados do SIM foram identificados 196 casos, junto ao SIH, 81 casos e junto ao SIAB, 44 casos. Quanto ao SIM e SINAN, a partir de janeiro de 2001, em Aracaju, já eram confrontados os bancos de dados e feitas as devidas correções, tanto quantitativas como qualitativas, portanto, não foram 
incluídos os casos para a construção da lista única, pois todos seriam casos de duplicidade.

Após a exclusão das duplicidades de casos, a lista única foi composta por 216 casos. As variáveis que nortearam sua elaboração foram àquelas comuns aos três sistemas: nome, idade, data do nascimento, data do óbito (no caso do SIH a data de saída hospitalar em óbito) e endereço. A metodologia de busca de casos será detalhada a seguir:

Banco de dados do SIM: foram selecionados 196 DOs de mulheres de 10 a 49 anos, cujo município de residência informado na DO era Aracaju (periodo de referência: $1^{\circ}$ de janeiro a 31 de dezembro de 2001).

Banco de dados do SIH: foram selecionadas as AIHs referentes a mulheres com idade entre 10 e 49 anos, cujo município de residência fosse Aracaju, internadas na rede SUS em Sergipe, cujo desfecho da internação foi o óbito (período de referência: $1^{\circ}$ de janeiro a 31 de dezembro de 2001). Inicialmente, foram selecionados 91 casos de óbitos de mulheres em idade fértil, sendo excluídas dez duplicidades (por transferências ou duplicação da $\mathrm{AIH}$ ), portanto 81 casos. Após a linkage com o banco de dados do SIM (referente aos óbitos de mulheres em idade fértil residentes em Aracaju), havia 70 casos comuns.

Nos 11 casos restantes foi realizada a busca no banco de dados estadual do SIM, sem considerar o município de residência, tendo sido localizadas $10 \mathrm{DOs}$ e, em um caso, a mesma não foi localizada.

Banco de dados do SIAB: a principio seriam selecionados os casos de óbitos de mulheres de 10 a 49 anos residentes em Aracaju, em áreas cobertas pelo PACS/PSF, por meio de consulta aos relatórios SSA2 (80 casos). Porém, durante o desenvolvimento deste projeto, o Ministério da Saúde, com o objetivo de aprimorar a informação do SIM (MINISTÉRIO DA SAÚDE 2001a e 2001c), implementou como rotina, junto aos municípios cobertos pelo PACS/PSF a remessa de listas contendo os casos de óbitos de menores de um ano e de nascidos vivos.

Em Aracaju, estendeu-se a lista de óbito para todas as faixas etárias, tendo sido coletadas retrospectivamente, em janeiro de 2002, as informações referentes aos anos 2000 e 2001. De forma que este estudo utilizou estas listagens como fonte de informação (Anexo 4). Embora o número de casos captados (44) tenha sido menor 
que o informado pelo SIAB (80 casos), o fato das informações terem sido individualizadas aponta que as mesmas sejam uma razoável aproximação da realidade.

A metodologia proposta inicialmente consistia na busca junto as Unidades Básicas de Saúde (UBS) destas informações de forma que as perdas ou discrepâncias entre os dados informados no sistema e aqueles obtidos podem ser devidas a dois fatores: ao intervalo de tempo entre a coleta das informações sobre óbitos e ocorrência do evento, ou à baixa qualidade das informações do banco de dados do SIAB. Após a linkage com o banco de dados do SIM, dos 44 casos, houve 35 casos comuns aos dois sistemas e em nove casos não havia DO. Para estes nove casos procedeu-se à busca no banco de dados estadual do SIM, sem considerar o município de residência, tendo sido localizadas duas DOs e, em sete casos, a mesma não foi localizada.

Portanto, de posse das informações levantadas nos distintos sistemas, foi possivel elaborar a lista única de mulheres de 10 a 49 anos, residentes em Aracaju, que foram a óbito em 2001. Esta lista foi composta por 216 casos.

$\mathrm{Na}$ lista única existem, portanto, dois tipos de casos: aqueles que possuem DO (208 casos) e aqueles cuja DO não foi localizada, ou seja, caso não conhecido pelo SIM (oito casos). Neste último caso, foi preenchido um formulário especifico (Formulário D1-Anexo 5), com os dados provenientes do(s) sistema(s) em que o caso foi localizado.

\subsubsection{Inquérito em fontes alternativas}

Nesta etapa, a coleta foi realizada utilizando-se a metodologia de busca de informações em fontes alternativas como: Serviços de Saúde, Serviço de Verificação de Óbitos (SVO), Instituto Médico Legal (IML) e domicílio. O número de óbitos de mulheres em idade fértil foi proveniente da lista única (216 casos), bem como os dados de população, de nascidos vivos e as variáveis do estudo foram as descritas 
anteriormente. Após a aplicação da metodologia detalhada a seguir, trabalhou-se com 177 casos de óbitos de mulheres em idade fértil.

A partir da lista única, a coleta de dados em fontes alternativas foi similar à do Projeto SIM (MELLO JORGE e GOTLIEB 1998). Foram aplicados os instrumentos de coleta F1 a F5 (Figura 1, Anexo 3). Cabe ressaltar que a metodologia original proposta pelos autores do projeto SIM previa visitas domiciliares para todos os casos de óbitos em MIF (MELLO JORGE et. al 2001a). No presente estudo, optou-se por utilizar a metodologia definida para os outros casos de óbitos analisados que não os MIF: ou seja, para os casos de óbitos por causas mal definidas, pelas residuais de capítulos e pelas causas externas, portanto trata-se de uma simplificação da metodologia proposta pelo Projeto SIM, uma vez que só foram realizadas visitas domiciliares entre os casos de óbitos que foram classificados como desconhecidos pelo SIM e dos óbitos constantes no SIM apenas se fossem óbitos domiciliares. Segue a descrição dos formulários utilizados:

F1: Investigação no domicílio dos óbitos não conhecidos pelo SIM (critério: todos os casos captados por outros sistemas de informação, que não o SIM, isto é, pelo SIH ou pelo SIAB). O instrumento $F 1$ foi aplicado para oito casos não conhecidos pelo SIM. Após a aplicação, dois foram excluídos e houve quatro perdas. Nos dois casos restantes foi aplicado o formulário F1. A partir de F1 definiu-se que outros instrumentos seriam utilizados: um dos casos tratava-se de óbito domiciliar com assistência médica prestada à paciente no decorrer da doença que causou a morte (Formulários F2 e F4) e o outro de óbito em estabelecimento de saúde (Formulário F3).

Para a definição dos demais instrumentos que foram aplicados (F2 a F5), foi considerada, para cada caso, a causa básica e o local de ocorrência do evento. Segue a descrição da aplicação dos instrumentos F2 a F5, bem como os critérios utilizados, de acordo com o caso. Para os casos em que havia DO (208), os critérios estão descritos a seguir:

F2: Investigação no domicilio dos óbitos conhecidos pelo SIM (critério: casos de óbitos domiciliares ou cuja causa é ignorada ou indeterminada, tendo sido realizadas 17 visitas). 
F3: Investigação nos hospitais (critério: todos os casos ocorridos em hospitais, exceto aqueles por causas externas, 139 casos).

F4: Investigação em outros serviços de saúde (critério: casos com causa básica ignorada ou indeterminada, mas que tiveram alguma assistência médica anterior ao evento, 9 casos).

F5: Investigação no IML/DP (critério: óbitos por causas externas, 32 casos).

Nesta etapa, de posse dos instrumentos referentes aos casos, uma Ficha Resumo foi preenchida (Anexo 3), e uma nova DO elaborada e codificada de acordo com as normas da CID 10 (OMS 1995), o que se definiu como PADRÃO OURO. Destes 210 casos em que foram aplicados os instrumentos F2 a F5, mais 11 foram excluidos e houve 22 perdas. Portanto, na construção do PADRÃO-OURO, houve 177 casos válidos, 13 exclusões e 26 perdas. 


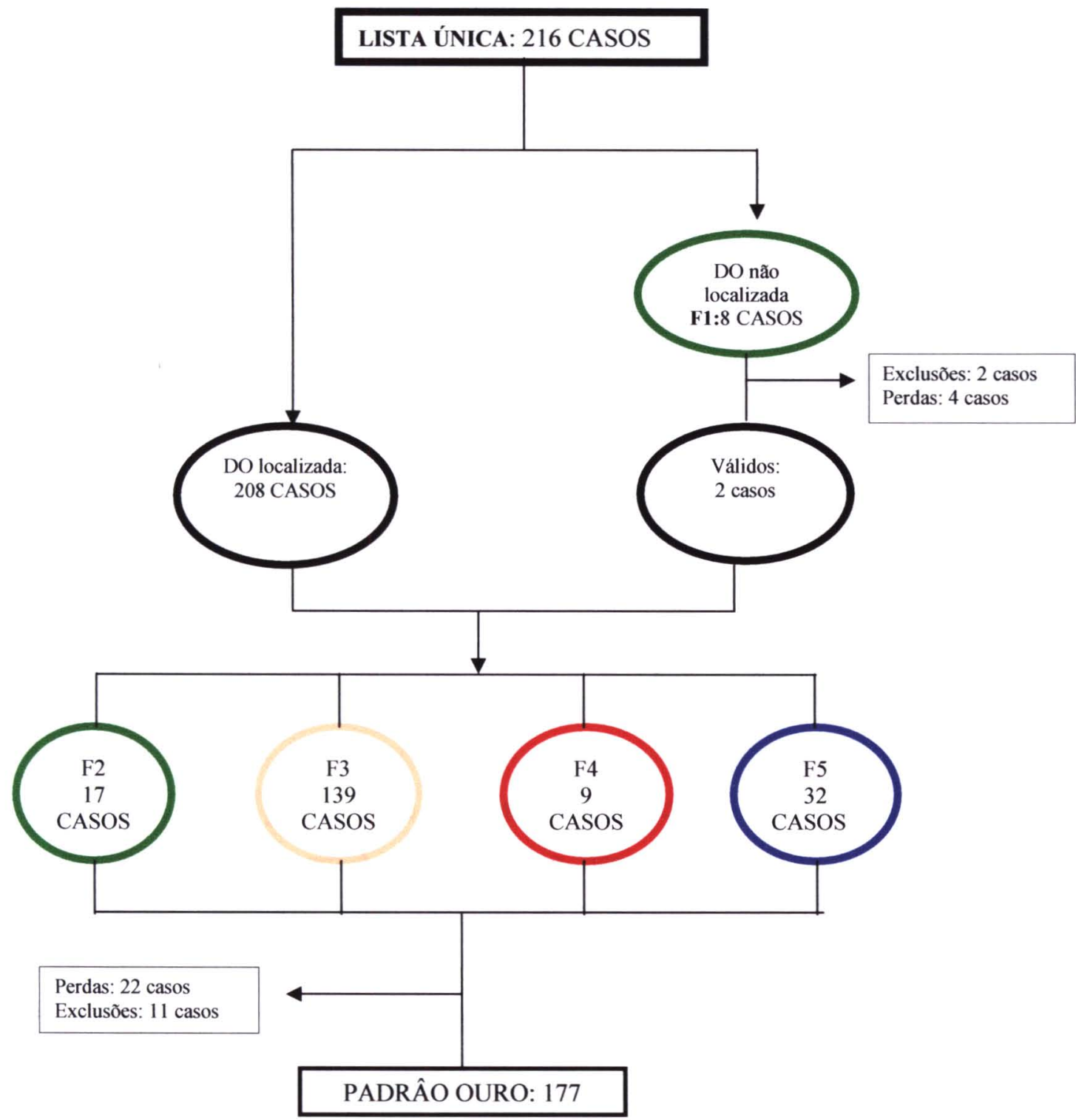

Figura 1. Síntese da busca para a elaboração do PADRÃO OURO ${ }^{\mathrm{a}}$.

a: a soma dos valores de F1 a F5 é maior que o total de casos em decorrência de que para alguns casos mais de uma fonte foi consultada. 


\subsubsection{Levantamento em Sistemas de Informação em Saúde de apoio ao esclarecimento das causas de óbito}

Nesta etapa, de posse da lista única (216 casos) foi realizada a busca qualitativa, a partir do levantamento nos sistemas que possibilitem o esclarecimento das causas de óbito, especialmente os maternos. Cabe ressaltar que foram levantadas informações nos bancos de dados identificados do SIM, SINASC e SIH. Os procedimentos serão descritos a seguir.

Foram mantidos nesta fase todos os casos de óbitos de mulheres de 10 a 49 anos cujo município de residência informado na DO era Aracaju (196 casos) somados àqueles em que não se obteve a DO (oito casos). Dos casos restantes após confrontar a informação com a DO ORIGINAL, 12 foram excluidos, uma vez que conforme referido anteriormente, quando as variáveis idade no óbito, data do nascimento, sexo, ou município de residência apresentassem conflito de informações, nos diferentes sistemas, definiu-se, que o SIM nesta etapa, seria o sistema de referência.

O material, portanto, se constitui em 204 casos de óbitos de mulheres em idade fértil, residentes em Aracaju, Sergipe, ocorridos no período de $1^{\circ}$ janeiro a 31 de dezembro de 2001. Este conjunto de casos foi o documento-chave para o levantamento nos sistemas de apoio para o esclarecimento das causas de morte.

Visando melhorar qualitativamente a informação, para cada caso pertencente a esta etapa, foi realizada busca em três sistemas - SIH, SINASC e SIM visando o esclarecimento das causas de óbito de cada um deles (Tabela 8). As variáveis comuns aos sistemas possibilitaram a aplicação da técnica de relacionamento dos bancos de dados, permitindo a coleta de informações adicionais e a complementação da DO ORIGINAL e a construção de um documento denominado NOVA-DO (Anexo 3). 
Tabela 8. Número de casos presentes nos SIS consultados em Aracaju e no Estado de Sergipe, 2000-2001.

\begin{tabular}{lrr}
\hline Sistema de informação & Aracaju & Sergipe \\
\hline SIM $\quad$ Óbitos fetais - 2000 & 214 & 710 \\
$\quad$ Óbitos fetais - 2001 & 186 & 436 \\
$\quad$ Óbitos de menores de um ano-2000 & 310 & 1072 \\
$\quad$ Óbitos de menores de um ano-2001 & 296 & 894 \\
SINASC & & \\
$\quad$ Nascidos vivos - 2000 & 10654 & 41561 \\
$\quad$ Nascidos vivos - 2001 & 9889 & 40156 \\
SIH $\quad$ Internações hospitalares MIF - 2000 a & 627 & 2951 \\
$\quad$ Internaçôes hospitalares MIF - 2001 & 10979 & 53109 \\
\hline
\end{tabular}

SIH: foram selecionados todos os casos de internação hospitalar de mulheres de 10 a 49 anos. As variáveis que possibilitaram o relacionamento dos bancos de dados foram: nome da paciente, idade e/ou data de nascimento, endereço, município de residência. Tipo de informação obtida: a data(s) de internação, o motivo(s) de internação, e especialmente se havia a presença de gravidez, de parto ou aborto até 42 dias antes da morte (período de referência: 20 de novembro de 2000 a 31 de dezembro de 2001). No periodo ocorreram 11606 internações hospitalares de mulheres na idade de 10 a 49 anos cujo município de residência informado era Aracaju e 56060 cujo Estado de residência era Sergipe. Entre estes casos, verificouse 81 casos de óbitos de MIF durante a internação hospitalar, e, 26 deles haviam tido pelo menos mais de uma internação hospitalar nos 42 dias que antecederam o óbito.

SINASC: as variáveis que possibilitaram o relacionamento dos bancos de dados foram o nome e idade da mãe, endereço, município de residência. Tipo de informação obtida: data do parto para verificar a existência de parto até um ano antes do óbito (período de referência: $1^{\circ}$ de janeiro de 2000 a 31 de dezembro de 2001). Em 2000 ocorreram 10645 NVs de residentes na capital e 41561 NVs de residentes no Estado. Em 2001 ocorreram 9889 NVs de residentes na capital e 40516 NVs de residentes no Estado. 
SIM: selecionados os casos de óbitos fetais e infantis. Variáveis que possibilitaram o relacionamento dos bancos de dados: nome da mãe, idade da mãe, endereço, município de residência. Tipo de informação obtida: data do nascimento, data do óbito da criança, o que permite verificar a existência do parto até um ano antes do óbito (período de referência: $1^{\circ}$ de janeiro de 2000 a 31 de dezembro de 2001). Em 2000 ocorreram 214 e 710 óbitos fetais e 310 e 1072 óbitos de menores de um ano entre os residentes na capital e no Estado, respectivamente. Em 2001 ocorreram 186 e 463 óbitos fetais e 296 e 894 óbitos de menores de um ano entre os residentes na capital e no Estado, respectivamente.

As informações do SIM e SINASC coletadas referem-se a um periodo de doze meses que antecederam a morte, portanto, entre $1^{\circ}$ de janeiro de 2000 a 31 de dezembro de 2001. Quanto às provenientes do SIH, por problemas operacionais, os dados foram analisados apenas no período de 42 dias que antecederam o óbito. Para minimizar possíveis perdas, foram considerados os eventos registrados nos bancos de dados do SINASC, SIH e SIM em todos os municípios do Estado de Sergipe.

Evidentemente, os dados provenientes do SINASC e SIM, visaram melhorar a qualidade da informação acerca da presença de gravidez até um ano antes da morte, enquanto que, aquelas provenientes do SIH contribuíram para melhorar a qualidade tanto da informação dos casos de óbito relacionados com o ciclo gravídico-puerperal (inclusive tardio) quanto nos outros casos.

Quanto ao uso do SIH para melhorar as outras causas de óbito, adaptou-se a recomendação de GOLDACRE (1993): o motivo da internação foi analisado apenas no periodo de até 42 dias antes do óbito, uma vez que foi dada ênfase aos óbitos ligados à gravidez, ao parto ou ao puerpério.

Para contornar os problemas de transferências e reinternações do SIH, foi aplicada a técnica sugerida por BRAMELD et. al (1998): as transferências foram consideradas como uma única internação. Quanto as reinternações, foi aplicada a técnica de linkage no banco de dados do SIH, o que possibilitou verificar o número de internações anteriores ao óbito por paciente. Neste caso, as variáveis analisadas no banco de dados do SIH foram as seguintes: nome da paciente, idade e/ou data de nascimento, endereço, município de residência. Tipo de informação obtida: data(s) e motivo(s) da internação para cada paciente de 10 a 49 anos. 
Finalmente, quanto às causas de óbito, a partir dos três sistemas de informação, a DO ORIGINAL foi complementada. Em 94 casos havia informação adicional proveniente dos sistemas e procedeu-se da seguinte maneira: a causa de óbito foi complementada e foram preenchidos os campos 43 e 44, conforme citado anteriormente. Quando a informação se referisse a uma patologia informada como motivo da internação que levou ao óbito, esta foi inserida na Parte 2 do documento original; entretanto, nos casos em que a informação adicional fosse proveniente apenas do SIAB, atribuiu-se o código R99, por se tratar de informação leiga. Enquanto não houver determinação a esse respeito, optou-se por essa metodologia, visto ser essa a recomendação do Centro Brasileiro de Classificação de Doenças. Nos casos em que a informação fosse procedente do SIH e com código específico de morbidade, este foi convertido para o código de mortalidade correspondente.

Dos casos em foi possivel acrescentar informações adicionais para a construção da NOVA-DO esta foi comparada às provenientes da $2^{a}$ etapa do estudo, consideradas o PADRÃO-OURO.

\subsubsection{Método de análise dos casos de 2001}

A partir do levantamento quantitativo (lista única) foi estimado o número e o percentual de melhora da captação de casos, utilizando os bancos de dados dos sistemas de informação com dados de óbitos. Também foi avaliada a contribuição para a melhoria da informação de cada uma das fontes de apoio, bem como a contribuição de todas estas fontes somadas.

Para a avaliação da melhora da informação dos casos de óbitos em MIF, a partir do inquérito, a causa básica informada na DO ORIGINAL foi comparada ao PADRÃO OURO. Dos 177 casos, foi excluído de parte da análise um caso de óbito não conhecido pelo SIM, em que não foi possivel resgatar a DO. Para verificar a melhora da informação da causa básica foram utilizadas as análises de sensibilidade e o Teste de Kappa (GORDIS 1996; JEKEL et. al 1999). 
Por grau de sensibilidade foi considerado o percentual de óbitos por um determinado grupo de causas, classificados como concordantes entre a DOORIGINAL e o PADRÃO-OURO. Para a interpretação da estatística Kappa os critérios utilizados foram os de LANDIS e $\mathrm{KOCH}$, conforme recomenda GORDIS (1996), a saber: concordância fraca (entre zero e 39,9\%), intermediária (de 40,0 a $74,9 \%$ ) e excelente (maior que $75,0 \%$ ).

Para avaliar a melhora da qualidade da informação dos casos de óbitos de MIF a partir do uso dos SIS, as causas de morte foram comparadas entre a DO ORIGINAL e a NOVA-DO e o PADRÃO-OURO. Cabe lembrar que houve 204 casos, sendo 196 comuns a DO-ORIGINAL e a NOVA-DO.

Finalmente, os 83 casos comuns às duas fases (inquérito e uso de SIS) foram comparados, ou seja: a DO-ORIGINAL, os casos em que se obteve informações adicionais nos SIS (NOVA-DO) e PADRÃO-OURO.

$\mathrm{Na}$ análise descritiva dos óbitos de MIF foram utilizados a freqüência absoluta e relativa e os coeficientes de mortalidade, de acordo com as variáveis do estudo, a partir dos resultados obtidos com a construção do PADRÃO-OURO.

Para as mortes ocorridas durante a gravidez, puerpério e puerpério tardio, a análise foi feita a partir da soma das informações provenientes de ambas as fases. Somadas as fontes, verificou-se a existência de 15 casos onde em pelo menos uma delas havia presença de gravidez, parto, ou puerpério (inclusive tardio). Dois casos foram descartados: portanto trabalhou-se com 13 casos.

Foi analisada a contribuição do PADRÃO-OURO para a melhora da informação da presença de gravidez até um ano antes do óbito. Também foi analisada a contribuição dos SIS. O procedimento adotado para avaliação da causa básica e do preenchimento dos campos 43 e 44 também consistiu em análise de concordância, onde se comparou a DO ORIGINAL, a NOVA-DO e o PADRÃO OURO.

Foi realizada a análise descritiva dos óbitos ocorridos durante o ciclo gravidico-puerperal, o que permitiu classificar os casos de acordo com os critérios de morte materna, morte materna tardia e morte materna relacionada à gravidez. Além disso, os óbitos maternos foram classificados como obstétricos diretos ou indiretos. No caso de óbitos ocorridos no puerpério ou no puerpério tardio, foi possivel 
verificar a causa básica e o tempo decorrido entre o término da gestação e o óbito. Por fim, foram descritos os números absoluto, relativos e os coeficientes, referentes a estes casos, de acordo com as variáveis do estudo.

\subsection{Variáveis de estudo}

Us casos foram descritos segundo três conjuntos de variáveis: o primeiro composto por variáveis comuns a todo o período, o segundo, por variáveis recentemente introduzidas na DO (a partir de 1995), e o terceiro por variáveis especificas para o estudo dos casos de 2001.

- Variáveis comuns à série (1979-2001)

- Idade: Houve distribuição dos casos em classes, sendo a inferior 10 a 14 anos, e a superior 40 a 49 . A partir da idade 20 anos o intervalo de classe foi igual a dez anos. Além destas categorias, foi necessário criar a categoria idade ignorada.

- Local de ocorrência: utilizadas as mesmas categorias da DO (hospital, via pública, domicílio, outro e local ignorado).

- Município de ocorrência: foram criadas quatro categorias, a saber: Aracaju, municípios do Estado de Sergipe, municipios de outras Unidades da Federação que não Sergipe e municípios pertencentes ao Estado de Sergipe, porém ignorados.

- Ano de ocorrência: de 1979 a 2001

- Causa básica: segundo capítulos da CID 10. Cabe ressaltar que para garantir a continuidade da análise da série histórica, uma vez que a partir de 1996 houve a mudança na revisão da CID, foi realizada a compatibilização das mesmas.

Sabe-se que, em decorrência da compatibilização das classificações (CID 9 e 10), podem ocorrer alterações em alguns grupos de causas devido a lógicas distintas adotadas para a seleção de causa básica, ou ainda pelas mudanças de capítulos para algumas causas. Um exemplo é o tétano obstétrico que na revisão atual pertence ao capitulo das doenças infecciosas e parasitárias ou a AIDS que passou do capitulo das 
doenças das glândulas endócrinas, da nutrição e metabolismo e transtornos imunitários para o capítulo das doenças infecciosas e parasitárias.

Também foi descrita a mortalidade das mulheres em idade fértil segundo seis grupos de causas (Quadro 1). O primeiro constituído dos casos de óbitos maternos, o segundo, pelo conjunto de causas consideradas como presumíveis de morte materna (Anexo 2), conforme lista sugerida pelo Ministério da Saúde (2001b), excetuando-se os óbitos sem assistência ou por causa desconhecida, que foram apresentados no terceiro grupo. O quarto grupo é composto pelos óbitos por AIDS, o quinto pelas causas externas e finalmente o sexto grupo por todas as demais causas (Quadro 1).

Quadro 1. Grupos de causas básicas de óbito de mulheres de 10 a 49 anos.

\section{Grupos}

1. Óbitos maternos

2. Óbitos classificados como presumiveis de morte materna ${ }^{a}$

3. Mortes sem assistência ou por causa desconhecida

4. Óbitos por AIDS

5. Óbitos por causas externas

6. Demais causas

a: exceto as mortes sem assistência ou por causa desconhecida.

$\mathrm{Na}$ primeira fase do estudo, os casos cujas causas básicas fossem presumiveis de morte maternas ou se tratassem de óbitos maternos, a equivalência foi realizada segundo as subcategorias da CID 10. Para tal utilizaram-se os quatro dígitos da CID 9 adaptados a CID 10.

- Variáveis recentemente introduzidas (1995-2001)

- Morte durante a gravidez, o parto ou aborto: utilizadas as mesmas categorias da DO (sim, não e ignorado).

- Morte durante o puerpério: neste caso as categorias foram sim, até 42 dias; sim, de 42 dias a um ano; não e ignorado.

- Variáveis utilizadas apenas em 2001

- Nome da paciente: informado na DO. 
- Endereço completo: incluindo rua, número e bairro de residência, informados na DO.

- Data do nascimento

\subsection{Considerações éticas}

Este trabalho norteou-se segundo as referências que regulamentam a pesquisa em saúde pública, não ferindo, portanto, aos princípios da beneficência e da não maleficência e corrobora o princípio da justiça (HOSNE e VIEIRA 1998), uma vez que seus resultados poderão contribuir para um melhor desempenho da gestão e planejamento do Sistema Único de Saúde. O projeto foi apreciado e aprovado pela Comissão de Ética em Pesquisa (CEP) da Faculdade de Saúde Pública da Universidade de São Paulo. Os Anexos 6, 7 e 8 contêm, respectivamente, o Parecer da CEP-FSP, o modelo de rapport e do consentimento esclarecido.

Finalmente, em todas as etapas do estudo, foram salvaguardados a confidencialidade e o sigilo dos dados, bem como será garantida a não identificação das pacientes. 
4. RESULTADOS E DISCUSSÃO 


\subsection{Análise da informação dos óbitos no período de 1979 a 2001}

\subsubsection{Os óbitos das mulheres em idade fértil}

Os 4299 casos de óbitos de mulheres de 10 a 49 anos residentes em Aracaju, Sergipe, ocorridos no período compreendido entre $1^{\circ}$ janeiro de 1979 e 31 de dezembro de 2001 distribuiram-se conforme a Tabela 9 e Figura 2. A mortalidade proporcional esteve em torno de $15,0 \%$ dos óbitos femininos, não havendo flutuações importantes no periodo sendo que estas acompanharam as ocorridas no total de óbitos femininos, podendo ser atribuídas à falta de homogeneidade de captação de casos pelo SIM.

Entretanto, a partir de 1999 observa-se uma discreta diminuição do número total de casos de óbitos de mulheres em idade fértil e uma estabilidade no número de óbitos femininos, o que pode estar apontando uma real queda da mortalidade neste grupo, uma vez que ao longo da série, melhoraram tanto a captação de casos pelo SIM quanto a qualidade das informações do sistema. Cabe ressaltar que a partir deste ano a alimentação do SIM passou para a responsabilidade da esfera municipal. 
Tabela 9. Total de óbitos femininos e de mulheres em idade fértil em $\mathrm{n}^{\circ} \mathrm{e} \%$, Aracaju (SE), 1979-2001.

\begin{tabular}{lcccc}
\hline \multirow{2}{*}{ Ano } & \multicolumn{2}{c}{$\begin{array}{c}\text { Óbitos de mulheres em idade } \\
\text { fértil }\end{array}$} & \multicolumn{2}{c}{ Total de óbitos } \\
femininos \\
\cline { 2 - 5 } & $\mathrm{N}^{\mathrm{o}}$ & $\%$ & $\mathrm{~N}^{\text {o }}$ & $\%$ \\
\hline 1979 & 176 & 14,9 & 1179 & 100,0 \\
1980 & 197 & 15,9 & 1240 & 100,0 \\
1981 & 163 & 13,4 & 1215 & 100,0 \\
1982 & 199 & 16,0 & 1247 & 100,0 \\
1983 & 171 & 15,2 & 1128 & 100,0 \\
1984 & 130 & 10,7 & 1220 & 100,0 \\
1985 & 158 & 12,7 & 1244 & 100,0 \\
1986 & 178 & 15,4 & 1157 & 100,0 \\
1987 & 149 & 13,5 & 1106 & 100,0 \\
1988 & 204 & 17,6 & 1159 & 100,0 \\
1989 & 181 & 13,6 & 1331 & 100,0 \\
1990 & 194 & 16,3 & 1193 & 100,0 \\
1991 & 140 & 15,0 & 936 & 100,0 \\
1992 & 259 & 16,0 & 1614 & 100,0 \\
1993 & 213 & 18,1 & 1179 & 100,0 \\
1994 & 240 & 14,6 & 1648 & 100,0 \\
1995 & 231 & 15,0 & 1540 & 100,0 \\
1996 & 136 & 11,4 & 1193 & 100,0 \\
1997 & 160 & 13,5 & 1188 & 100,0 \\
1998 & 186 & 14,7 & 1266 & 100,0 \\
1999 & 243 & 18,6 & 1303 & 100,0 \\
2000 & 195 & 16,3 & 1199 & 100,0 \\
2001 & 196 & 15,8 & 1239 & 100,0 \\
\hline
\end{tabular}

Fonte: SIM (MS 2000, MS, 2002a, SES, 2002). 


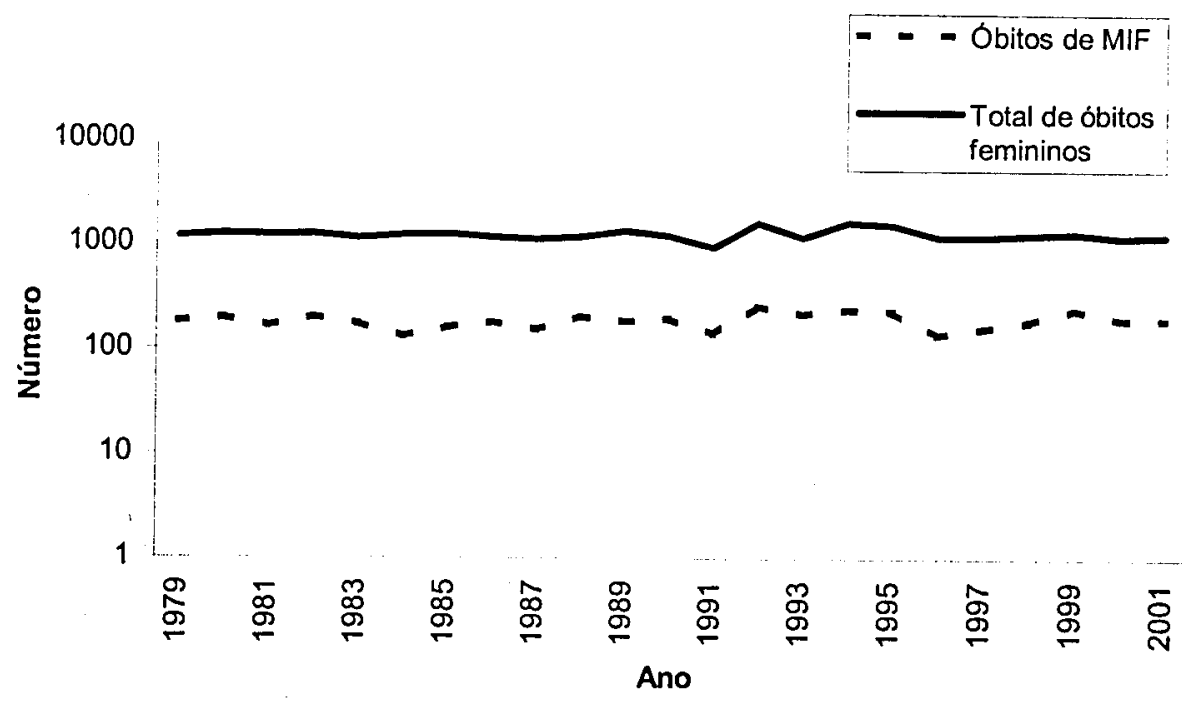

Figura 2. Distribuição dos casos de óbitos de mulheres em todas as idades e de mulheres em idade fértil segundo ano. Aracaju (SE), 1979-2001.

Fonte: SIM (MS 2000, MS, 2002a, SES, 2002).

Entretanto, a evolução do coeficiente de mortalidade de mulheres de 10 a 49 anos (por cem mil mulheres) não apresentou tendência de queda, sendo o valor de $\mathrm{r}=0,9$, o que representa uma queda real da mortalidade das MIF, na série observada (Figura 3).

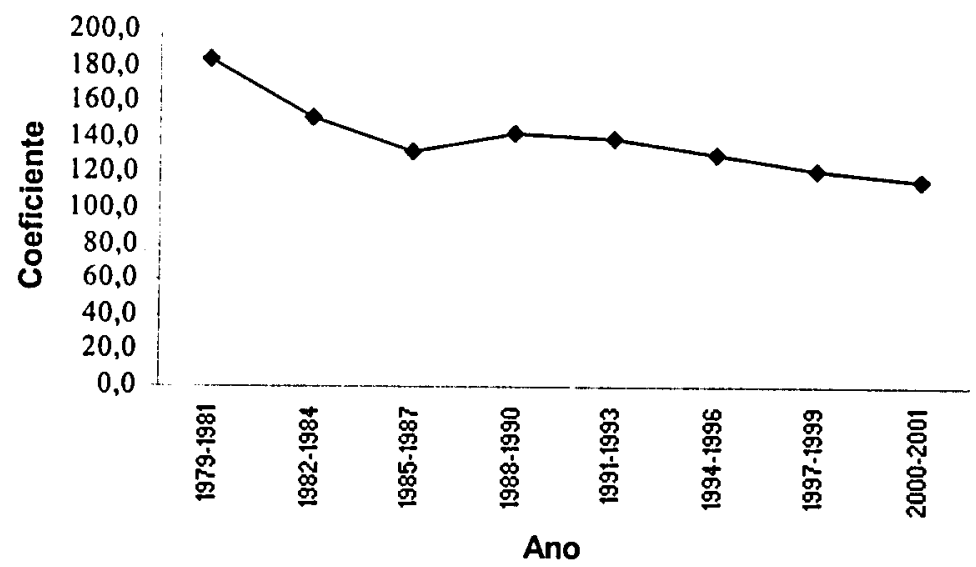

Figura 3. Coeficiente de mortalidade de mulheres de 10 a 49 anos (por cem mil mulheres). Aracaju (SE), 1979-2001.

Fonte: SIM (MS 2000, MS, 2002a, SES, 2002), MS (2003a). 
Quanto ao local de ocorrência do óbito, $73,2 \%$ dos casos de óbitos foram hospitalares e 16,5\% domiciliares. A maioria dos casos ocorreu no municipio de residência $(97,2 \%)$, sendo que aqueles que ocorreram em outros locais decorreram, principalmente, de causas externas (48,7\%).

A idade média ao morrer foi de 33,4 anos, a mediana de 35 anos e a mortalidade proporcional segundo faixas de idade obedeceu ao disposto na Tabela 10. A maior parte dos casos ocorreu em pacientes com idade entre 40 e 49 anos $(38,4 \%)$. ALBUQUERQUE et. al (1997) verificaram que $41,9 \%$ dos casos de óbitos pertenciam a esta faixa etária.

Tabela 10. Óbitos de mulheres em idade fértil segundo idade $\left(\mathrm{n}^{\circ}, \%\right.$ e $\%$ acumulado). Aracaju (SE), 1979 a 2001.

\begin{tabular}{lrrr}
\hline Idade & Número & $\%$ & $\%$ Acumulado \\
\hline 10 a 14 & 268 & 6,2 & 6,2 \\
15 a 19 & 363 & 8,5 & 14,7 \\
20 a 29 & 901 & 21,0 & 35,7 \\
30 a 39 & 1111 & 25,9 & 61,6 \\
40 a 49 & 1650 & 38,4 & 100,0 \\
\hline Total & 4293 & 100 & \\
\hline
\end{tabular}

Excluidos seis casos com idade ignorada.

Fonte: SIM (MS 2000, MS, 2002a, SES, 2002).

Ao longo da série houve deslocamento dos óbitos para a ultima faixa, no triênio 1979-1981. Para cada óbito na idade de 10 a 19 anos ocorriam dois óbitos na idade de 40 a 49 anos; no final da série, esta relação foi próxima de um para quatro (Tabela 11). Provavelmente, porque no periodo de 1979 a 2001 aumentou a oferta de serviços de saúde e foram incorporadas novas tecnologias que evitaram mortes, ou as postergaram. 
Tabela 11. Distribuição percentual de óbitos de mulheres em idade fértil segundo idade e ano do óbito. Aracaju (SE) ${ }^{\mathrm{a}}, 1979-2001$.

\begin{tabular}{|c|c|c|c|c|c|}
\hline \multirow[t]{2}{*}{ Ano } & \multicolumn{4}{|c|}{ Idade } & \multirow[t]{2}{*}{ Total } \\
\hline & 10 a 19 & 20 a 29 & 30 a 39 & 40 a 49 & \\
\hline $1979-1981$ & 16,6 & 21,6 & 28,4 & 33,4 & 100,0 \\
\hline $1982-1984$ & 17,8 & 21,0 & 24,6 & 36,6 & 100,0 \\
\hline $1985-1987$ & 16,9 & 20,9 & 24,2 & 38,0 & 100,0 \\
\hline $1988-1990$ & 10,4 & 23,6 & 28,2 & 37,8 & 100,0 \\
\hline 1991-1993 & 13,7 & 21,1 & 26,6 & 38,6 & 100,0 \\
\hline 1994-1996 & 17,5 & 21,2 & 24,0 & 37,4 & 100,0 \\
\hline 1997-1999 & 12,8 & 20,7 & 22,4 & 44,0 & 100,0 \\
\hline $2000-2001$ & 11,8 & 16,4 & 29,7 & 42,3 & 100,0 \\
\hline
\end{tabular}

a: Excluídos seis casos com idade ignorada.

Fonte: SIM (MS 2000, MS, 2002a, SES, 2002).

Quanto à causa básica de óbito, a distribuição segundo capitulos da CID, evidenciou que se destacaram as doenças do aparelho circulatório $(20,7 \%)$, as neoplasias $(17,6 \%)$ e as causas externas $(17,0 \%)$. As mal definidas representaram $10,9 \%$ dos casos. A distribuição dos grupos de causas na série apontou mudança no perfil de mortalidade, com diminuição dos óbitos por causas mal definidas, aumento das neoplasias e sem grandes flutuações das demais causas (Tabela 12). As principais causas de óbito descritas por FAÚNDES et. al (2000) para mulheres em idade fértil residentes no município de Campinas, no período de 1985 a 1994 foram as doenças do aparelho circulatório $(28,6 \%)$, as causas externas $(22,3 \%)$ seguidas das neoplasias $(22,1 \%)$. Ainda que as principais causas de morte de mulheres de 10 a 49 anos sejam as mesmas, as diferenças observadas são possivelmente devidas às peculiaridades regionais e pelo fato de que o autor obteve um percentual de mal definidas menor que o do presente estudo $(4,0 \%)$. 
Tabela 12. Óbitos de mulheres em idade fértil segundo causas (CID 10). Aracaju (SE), 1979-2001.

\begin{tabular}{|c|c|c|c|c|c|c|c|c|c|c|}
\hline \multirow[t]{2}{*}{ Ano } & \multicolumn{9}{|c|}{ Causa } & \multirow[t]{2}{*}{ Total } \\
\hline & 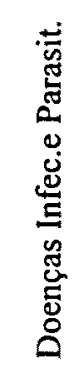 & 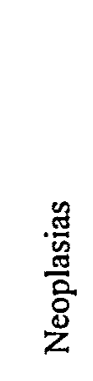 & 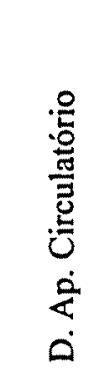 & 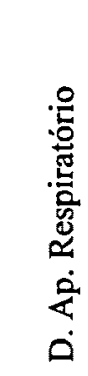 & 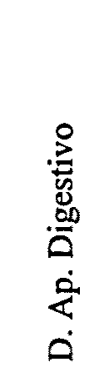 & 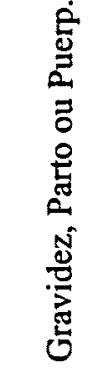 & 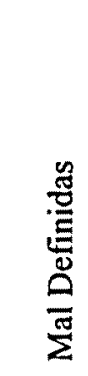 & 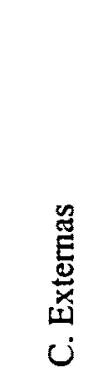 & 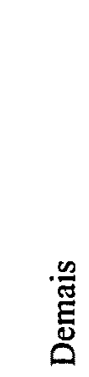 & \\
\hline 1979 & 19 & 18 & 34 & 7 & 12 & 13 & 32 & 23 & 18 & 176 \\
\hline 1980 & 11 & 34 & 43 & 15 & 9 & 17 & 10 & 38 & 20 & 197 \\
\hline 1981 & 12 & 21 & 42 & 9 & 11 & 12 & 14 & 22 & 20 & 163 \\
\hline 1982 & 11 & 31 & 47 & 12 & 16 & 10 & 11 & 38 & 23 & 199 \\
\hline 1983 & 9 & 19 & 41 & 11 & 14 & 11 & 11 & 33 & 22 & 171 \\
\hline 1984 & 7 & 14 & 26 & 9 & 9 & 8 & 22 & 21 & 14 & 130 \\
\hline 1985 & 11 & 36 & 33 & 8 & 10 & 6 & 13 & 25 & 16 & 158 \\
\hline 1986 & 11 & 34 & 37 & 16 & 6 & 11 & 19 & 27 & 17 & 178 \\
\hline 1987 & 9 & 26 & 38 & 8 & 5 & 7 & 20 & 23 & 13 & 149 \\
\hline 1988 & 15 & 25 & 51 & 12 & 9 & 8 & 25 & 32 & 27 & 204 \\
\hline 1989 & 19 & 32 & 38 & 11 & 6 & 4 & 23 & 23 & 25 & 181 \\
\hline 1990 & 16 & 30 & 48 & 12 & 11 & 8 & 22 & 23 & 24 & 194 \\
\hline 1991 & 5 & 18 & 17 & 4 & 6 & 3 & 46 & 24 & 17 & 140 \\
\hline 1992 & 6 & 46 & 48 & 20 & 13 & 15 & 16 & 60 & 35 & 259 \\
\hline 1993 & 4 & 41 & 43 & 16 & 16 & 6 & 21 & 37 & 29 & 213 \\
\hline 1994 & 13 & 43 & 49 & 16 & 11 & 8 & 26 & 38 & 36 & 240 \\
\hline 1995 & 9 & 39 & 46 & 16 & 3 & 8 & 28 & 51 & 31 & 231 \\
\hline 1996 & 11 & 31 & 20 & 5 & 1 & 7 & 22 & 21 & 18 & 136 \\
\hline 1997 & 11 & 25 & 40 & 13 & 5 & 2 & 21 & 30 & 13 & 160 \\
\hline 1998 & 14 & 29 & 29 & 6 & 11 & 6 & 26 & 38 & 27 & 186 \\
\hline 1999 & 18 & 63 & 43 & 8 & 13 & 12 & 16 & 38 & 31 & 243 \\
\hline 2000 & 14 & 49 & 35 & 9 & 10 & 7 & 9 & 38 & 24 & 195 \\
\hline 2001 & 6 & 54 & 44 & 9 & 6 & 3 & 15 & 29 & 30 & 196 \\
\hline Total & 261 & 758 & 892 & 252 & 213 & 192 & 468 & 732 & 530 & 4299 \\
\hline
\end{tabular}

Fonte: SIM (MS 2000, MS, 2002a, SES, 2002).

Excluindo as causas mal definidas, as doenças do aparelho circulatório (DAC) foram as mais freqüentes e representando $23,3 \%$ dos óbitos das mulheres em idade fértil no período de 1979 a 2001, e devidas principalmente às doenças cérebrovasculares (DCV-37,9\%). Quando se verifica a proporção de óbitos por DCV em 
relação aos óbitos por doença isquêmica do coração (DIC), observa-se o predomínio das primeiras ao longo de toda a série, numa relação de 2,9 casos de DCV para um caso de DIC (Tabela 13). É sabido que a relação DCV/DIC tende a ser menor que um nas áreas onde o tratamento da principal patologia de base, isto é, a hipertensão arterial, é realizada de forma mais adequada. Portanto, a relação maior que um, indica falhas na atenção. Cabe ressaltar que no último período da série esta relação foi igual a 1,7 casos de DCV para um caso de DIC. O predomínio da mortalidade das DCV sobre as DIC, na região Nordeste foi descrita anteriormente (LOTUFO 2000; MELLO JORGE et. al 2001), Cabe ressaltar que estas duas doenças representaram $51,1 \%$ dos óbitos por DAC.

Na faixa dos 40 aos 49 anos ocorreu a maior parte dos casos de DCV e DIC, respectivamente $56,5 \%$ e $72,9 \%$. Entre os óbitos de mulheres em idade fértil a proporção das mortes por DCV na idade de 40 a 49 anos, pode ser considerada baixa, o que novamente aponta problemas na atenção à saúde.

Tabela 13. Número de óbitos de mulheres em idade fértil segundo doença cérebrovascular (DCV) e doença isquêmica do coração (DIC), e respectivos coeficientes de mortalidade- CM - (por cem mil mulheres de 10 a 49 anos) e razão entre eles. Aracaju (SE), 1979-2001.

\begin{tabular}{crrrrr}
\hline ANO & $\begin{array}{r}\text { DCV } \\
\text { (A) }\end{array}$ & $\begin{array}{r}\text { DIC } \\
\text { (B) }\end{array}$ & $\begin{array}{r}\text { CM } \\
\text { DCV }\end{array}$ & $\begin{array}{r}\text { CM } \\
\text { DIC }\end{array}$ & $\begin{array}{r}\text { Razão } \\
\text { A/B }\end{array}$ \\
\hline $1979-1981$ & 31 & 15 & 10,6 & 5,1 & 2,1 \\
$1982-1984$ & 43 & 10 & 13,1 & 3,0 & 4,3 \\
$1985-1987$ & 45 & 17 & 12,2 & 4,6 & 2,6 \\
$1988-1990$ & 61 & 12 & 15,1 & 3,0 & 5,1 \\
$1991-1993$ & 40 & 19 & 9,1 & 4,3 & 2,1 \\
$1994-1996$ & 48 & 13 & 10,3 & 2,8 & 3,7 \\
$1997-1999$ & 39 & 14 & 8,0 & 2,9 & 2,8 \\
$2000-2001$ & 31 & 18 & 9,2 & 5,3 & 1,7 \\
\hline Total & 338 & 118 & 10,8 & 3,8 & 2,9 \\
\hline
\end{tabular}

Fonte: SIM (MS 2000, MS, 2002a, SES, 2002).

As neoplasias foram as doenças que tiveram o maior incremento durante 0 período em análise, representando $19,8 \%$ dos casos. Dentre elas destacaram-se as neoplasias de mama $(18,9 \%)$ e colo de útero $(19,5 \%)$. A relação entre o total de 
neoplasias de mama e de colo de útero foi de 1,0. Entretanto, ao longo da série observa-se que o número de casos de câncer de mama superou ou igualou o número de casos de neoplasia de colo a partir do triênio 1994-1996. Até este ano, em vários anos, houve predomínio do câncer de colo de útero, patologia de diagnóstico simples, porém mais uma vez dependente da oferta de serviços de saúde para sua prevenção e diagnóstico precoce (Tabela 14).

Tabela 14. Número de óbitos de mulheres em idade fértil por neoplasia de colo de útero e de mama, e respectivos coeficientes de mortalidade - CM - (por cem mil mulheres de 10 a 49 anos) e razão entre eles. Aracaju (SE), 1979-2001.

\begin{tabular}{lccccc}
\hline Ano & $\begin{array}{c}\text { Neoplasia de } \\
\text { Mama }\end{array}$ & $\begin{array}{c}\text { Neoplasia } \\
\text { de Colo de } \\
\text { Utero }\end{array}$ & $\begin{array}{c}\text { CM por } \\
\text { Neoplasia de } \\
\text { Colo de Útero } \\
\text { (A) }\end{array}$ & $\begin{array}{c}\text { CM por } \\
\text { Neoplasia } \\
\text { Mama } \\
\text { (B) }\end{array}$ & $\begin{array}{c}\text { Razão } \\
\text { A/B }\end{array}$ \\
\hline $1979-1981$ & 17 & 15 & 5,8 & 5,1 & 1,1 \\
$1982-1984$ & 9 & 16 & 2,7 & 4,9 & 0,6 \\
$1985-1987$ & 21 & 28 & 5,7 & 7,6 & 0,8 \\
$1988-1990$ & 18 & 21 & 4,5 & 5,2 & 0,9 \\
$1991-1993$ & 11 & 21 & 2,5 & 4,8 & 0,5 \\
$1994-1996$ & 18 & 12 & 3,9 & 2,6 & 1,5 \\
$1997-1999$ & 23 & 22 & 4,7 & 4,5 & 1,0 \\
$2000-2001$ & 26 & 13 & 7,7 & 3,8 & 2,0 \\
\hline Total & 143 & 148 & 4,6 & 4,7 & 1,0 \\
\hline Fon
\end{tabular}

Fonte: SIM (MS 2000, MS, 2002a, SES, 2002).

Além disto, chama a atenção o fato de que em 30 casos a DO foi preenchida como câncer de útero, em porção não especificada, podendo tratar-se de câncer do corpo ou do colo do útero, o que pode estar mascarando ainda mais esta relação. Quanto à distribuição etária, o câncer de mama acometeu as mulheres mais tardiamente (a partir dos 30 anos), enquanto foram verificados casos de câncer de colo de útero entre as maiores que 20 anos.

NUNES et. al (2001) propõem, entre um conjunto de indicadores de qualidade de atenção à saúde, a razão de mortalidade entre o câncer de mama pelo câncer de colo de útero. E verificaram que para o Brasil esta relação, em 1998, foi de 2,2 , sendo para a região Nordeste de 1,4 e para a Sudeste 3,1. Portanto em Aracaju, a relação obtida indica uma situação de iniqüidade com relação à qualidade de saúde 
da mulher, embora a razão venha apresentando tendência de queda, ainda está aquém da média nacional.

Finalmente, a terceira causa de óbito foi representada pelo conjunto de causas externas (19,1\%). A principal correspondeu aos acidentes de transporte $(32,8 \%)$, seguidos das agressões (15,3\%). Chama a atenção o alto percentual de causas externas mal definidas (26,8\%), o que impõe dificuldades na análise. Excluindo as causas ignoradas, os acidentes de transporte foram a causa mais freqüente em todas as faixas etárias, seguidos das agressões (Tabela 15).

Tabela 15. Óbitos ( $\mathrm{n}^{\circ} \mathrm{e} \%$ ) de mulheres em idade fértil por causa externa, segundo tipo e idade. Aracaju (SE), 1979-2001.

\begin{tabular}{|c|c|c|c|c|c|c|c|c|c|c|c|c|}
\hline \multirow[t]{3}{*}{ Tipo } & \multicolumn{10}{|c|}{ Idade } & \multirow[b]{3}{*}{$N^{0}$} & \multirow{3}{*}{$\begin{array}{r}\text { Total } \\
\quad \% \\
\end{array}$} \\
\hline & \multicolumn{2}{|c|}{10 a 14} & \multicolumn{2}{|c|}{15 a 19} & \multicolumn{2}{|c|}{20 a 29} & \multicolumn{2}{|c|}{30 a 39} & \multicolumn{2}{|c|}{40 a 49} & & \\
\hline & $\mathrm{N}^{\circ}$ & $\%$ & $\mathrm{~N}^{\circ}$ & $\%$ & $\mathrm{~N}^{\circ}$ & $\%$ & $N^{\circ}$ & $\%$ & $N^{\circ}$ & $\%$ & & \\
\hline Ac.Transporte & 37 & 40,7 & 27 & 23,1 & 85 & 35,3 & 50 & 32,1 & 41 & 32,3 & 240 & 32,8 \\
\hline Suicidios & 1 & 1,1 & 8 & 6,8 & 7 & 2,9 & 7 & 4,5 & 9 & 7,1 & 32 & 4,4 \\
\hline Agressões & 7 & 7,7 & 22 & 18,8 & 45 & 18,7 & 18 & 11,5 & 20 & 15,7 & 112 & 15,3 \\
\hline Ignorada & 20 & 22,0 & 41 & 35,0 & 60 & 24,9 & 49 & 31,4 & 26 & 20,5 & 196 & 26,8 \\
\hline Demais & 26 & 28,6 & 19 & 16,2 & 44 & 18,3 & 32 & 20,5 & 31 & 24,4 & 152 & 20,8 \\
\hline Total & 91 & 100,0 & 117 & 100,0 & 241 & 100,0 & 156 & 100,0 & 127 & 100,0 & 732 & 100,0 \\
\hline
\end{tabular}

Fonte: SIM (MS 2000, MS, 2002a, SES, 2002).

Diversos trabalhos apontaram a possibilidade de reduzir o número de causas externas mal-definidas. MELLO JORGE et. al (2002b) verificaram que entre 83 causas externas do tipo ignorado, em $82,3 \%$ existia informação sobre o tipo de violência ou acidente que causou a morte, mostrando que a informação existe e não é transcrita para a DO. Este resultado aponta, por um lado, a necessidade dos serviços responsáveis pelo SIM de incorporarem metodologia de busca de informações adicionais neste tipo de óbito, e ao mesmo tempo, devem ser elaboradas estratégias mais eficazes junto aos médicos de serviços médico-legais, para melhorar a informação no momento do preenchimento da DO. 
Observa-se ao longo da série, períodos em que o coeficiente de mortalidade por CE do tipo ignorada, foi predominante entre 1985 e 1990 e entre 1997 e 1999 (Tabela 16). O coeficiente de mortalidade por CE foi maior que 20,0 por cem mil mulheres em idade fértil em, praticamente, todo o período. HADDAD e SILVA (2000), verificaram coeficientes em torno de 25,0 por cem mil mulheres em idade fértil no Estado de São Paulo, no periodo de 1991 a 1995, destacando os acidentes e as agressões como as principais causas de morte no período.

LIRA e DRUMOND (2000), estudando os Anos Potenciais de Vida Perdidos (APVP) nas capitais brasileiras em 1980 e 1997, verificaram que as causas externas, especialmente os acidentes de trânsito e os homicídios foram os dois principais motivos de APVP no Brasil. Em Aracaju, os autores destacaram as CE ignoradas, seguidas dos acidentes e dos homicídios como os três principais motivos de APVP. Cabe ressaltar que os autores estudaram o APVP para toda a população.

FAÚNDES et. al (2000), estudando o comportamento das CE em residentes em Campinas, em mulheres em idade fértil, verificaram que no período de 1985 a 1994 houve incremento dos acidentes de trânsito e das agressões e concluíram que apesar de elevados, essas duas causas de morte não conseguem gerar politicas públicas adequadas à gravidade do problema.

Tabela 16. Coeficiente de mortalidade por causa externa em mulheres em idade fértil (por cem mil mulheres), segundo tipo de causa e ano. Aracaju (SE), 1979-2001.

\begin{tabular}{lrrrrrrr}
\hline Ano & \multicolumn{4}{c}{ Coeficiente de mortalidade } & \multicolumn{3}{c}{ Total } \\
\cline { 2 - 7 } & Ac. Transporte & Demais Acidentes & Suicídios & Agressões & Ignorado & \\
\hline $1979-1981$ & 8,5 & 14,0 & 1,0 & 4,1 & 0,7 & 28,3 \\
$1982-1984$ & 8,8 & 8,8 & 1,5 & 2,4 & 6,4 & 28,0 \\
$1985-1987$ & 5,4 & 2,2 & 0,0 & 2,7 & 10,1 & 20,4 \\
$1988-1990$ & 4,9 & 1,7 & 0,5 & 2,0 & 10,1 & 19,3 \\
$1991-1993$ & 13,2 & 7,3 & 2,5 & 3,4 & 1,1 & 27,6 \\
$1994-1996$ & 9,7 & 2,6 & 0,2 & 5,8 & 5,4 & 23,7 \\
$1997-1999$ & 5,2 & 2,9 & 0,4 & 2,7 & 10,7 & 21,9 \\
$2000-2001$ & 5,3 & 2,7 & 2,4 & 5,6 & 3,8 & 19,8 \\
\hline Total & 7,7 & 4,9 & 1,0 & 3,6 & 6,3 & 23,5 \\
\hline
\end{tabular}

Fonte: SIM (MS 2000, MS, 2002a, SES, 2002). 


\subsubsection{Os óbitos maternos}

Quanto às mortes maternas, estas representaram 5,0\% dos casos de óbitos de mulheres em idade fértil, excluindo aqueles por causas mal definidas (média anual de 8,3 casos) e $0,7 \%$ da mortalidade feminina (Figura 4 e Tabela 17). Também neste caso as flutuações acompanham as mesmas do total de óbitos de mulheres em idade fértil, o que deve ser reflexo da captação de casos pelo SIM.

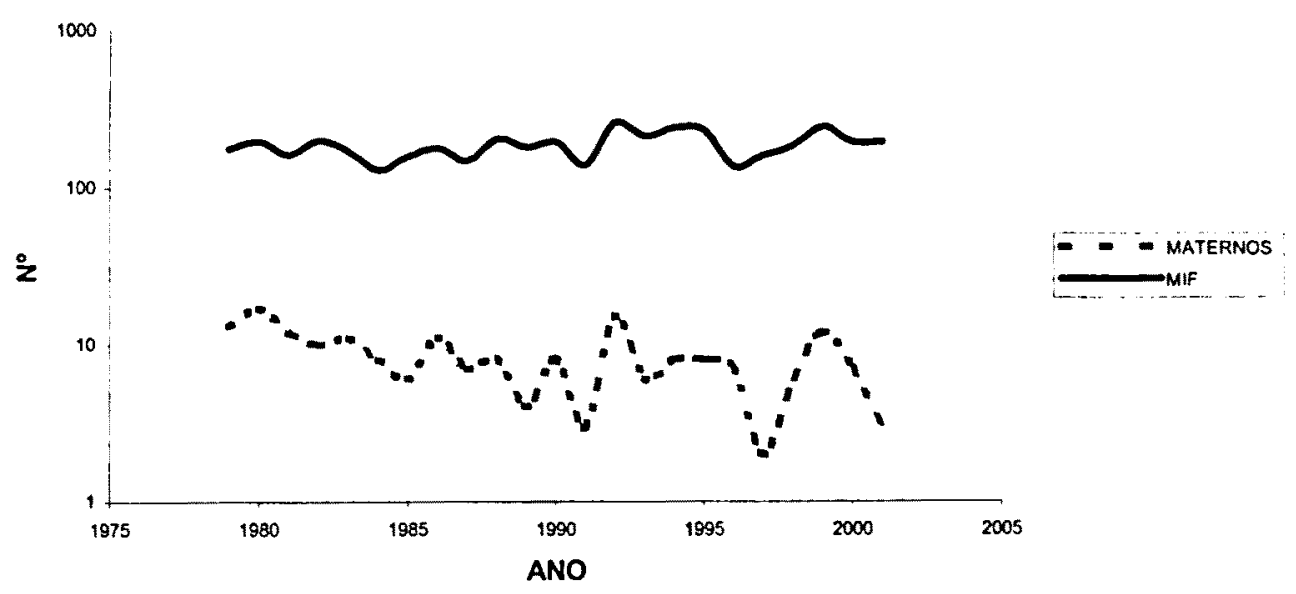

Figura 4 Distribuição dos casos de óbitos de mulheres em idade fértil e de óbitos maternos segundo ano. Aracaju (SE), 1979-2001.

Fonte: SIM (MS 2000, MS, 2002a, SES, 2002).

Observa-se que, em alguns anos da série, os óbitos maternos correspondem a até $1,0 \%$ dos óbitos femininos, e que em outros representa até $0,2 \%$ destes. Como é sabido que os óbitos maternos são os mais mal informados, mesmo em países onde a qualidade das informações de mortalidade é considerada adequada (WHO 2001; MELLO JORGE et. al 2002a), a aplicação de fatores de correção poderia gerar valores mais fidedignos. 
Tabela 17. Mortalidade proporcional de mulheres na idade de 10 a 49 anos e de óbitos por causas maternas entre o total dos óbitos femininos segundo o ano do óbito. Aracaju (SE),1979-2001.

\begin{tabular}{lccc}
\hline Ano & Maternos & Mulheres em idade fértil & Total de óbitos femininos \\
\hline 1979 & 1,1 & 14,9 & 100,0 \\
1980 & 1,4 & 15,9 & 100,0 \\
1981 & 1,0 & 13,4 & 100,0 \\
1982 & 0,8 & 16,0 & 100,0 \\
1983 & 1,0 & 15,2 & 100,0 \\
1984 & 0,7 & 10,7 & 100,0 \\
1985 & 0,5 & 12,7 & 100,0 \\
1986 & 1,0 & 15,4 & 100,0 \\
1987 & 0,6 & 13,5 & 100,0 \\
1988 & 0,7 & 17,6 & 100,0 \\
1989 & 0,3 & 13,6 & 100,0 \\
1990 & 0,7 & 16,3 & 100,0 \\
1991 & 0,3 & 15,0 & 100,0 \\
1992 & 0,9 & 16,0 & 100,0 \\
1993 & 0,5 & 18,1 & 100,0 \\
1994 & 0,5 & 14,6 & 100,0 \\
1995 & 0,5 & 15,0 & 100,0 \\
1996 & 0,6 & 11,4 & 100,0 \\
1997 & 0,2 & 13,5 & 100,0 \\
1998 & 0,5 & 14,7 & 100,0 \\
1999 & 0,9 & 18,6 & 100,0 \\
2000 & 0,6 & 16,3 & 100,0 \\
2001 & 0,2 & 15,8 & 100,0 \\
\hline & 0,6 & & \\
\hline
\end{tabular}

Fonte: SIM (MS 2000, MS, 2002a, SES, 2002).

No tocante aos óbitos maternos, observou-se a ocorrência de 192 casos cuja causa básica pertencia ao capítulo gravidez, parto e puerpério da CID 10. A idade média foi 28,6 anos, a mediana de 29,6 anos, e quanto aos grupos etários, verificouse que o de 20 a 29 anos detém a maior freqüência e em 6 casos a idade foi ignorada.(Tabela 18). Quanto ao local de ocorrência 92,7\% foram em ambiente hospitalar, sendo que, a partir de 1996, houve apenas um caso de óbito extrahospitalar. Quanto ao município de ocorrência 99,0\% dos casos ocorreu no próprio município de residência. 
Tabela 18. Óbitos de mulheres por causas maternas segundo idade $\left(\mathrm{n}^{\circ}, \%\right.$ e $\%$ acumulado). Aracaju (SE), 1979-2001.

\begin{tabular}{crrr}
\hline Idade $^{\text {a }}$ & $\mathrm{N}^{\circ}$ & $\%$ & \% Acumulado \\
\hline 10 a 14 & 2 & 1,1 & 1,1 \\
15 a 19 & 24 & 12,9 & 14,0 \\
20 a 29 & 82 & 44,1 & 58,1 \\
30 a 39 & 63 & 33,9 & 91,9 \\
40 a 49 & 15 & 8,1 & 100,0 \\
\hline Total & 186 & 100,0 & \\
\hline
\end{tabular}

a: excluídos sèis casos com idade ignorada.

Fonte: SIM (MS 2000, MS, 2002a, SES, 2002).

Quanto à RMM, embora seja apontada tendência de queda é necessário ter cautela, uma vez que é sabido que a qualidade da informação não é adequada (Figura 5). Diversos problemas têm sido apontados, mesmo onde há comitê atuante, não se verificando reflexo destas informações resgatadas pelos comitês no banco de dados do SIM. Em 2000, no município de Aracaju, o comitê de mortalidade materna detectou 14 óbitos relacionados à gravidez, ao parto e ao puerpério. Entretanto, no banco de dados consultado (SES 2002), observaram-se sete casos de mortes maternas e mais oito casos em que havia a presença de gravidez, parto ou puerpério (inclusive tardio), o que resultou em 15 casos no SIM. A dificuldade de gerar ações integradas entre os responsáveis pelo SIM e pelos comitês já foi apontada anteriormente. 


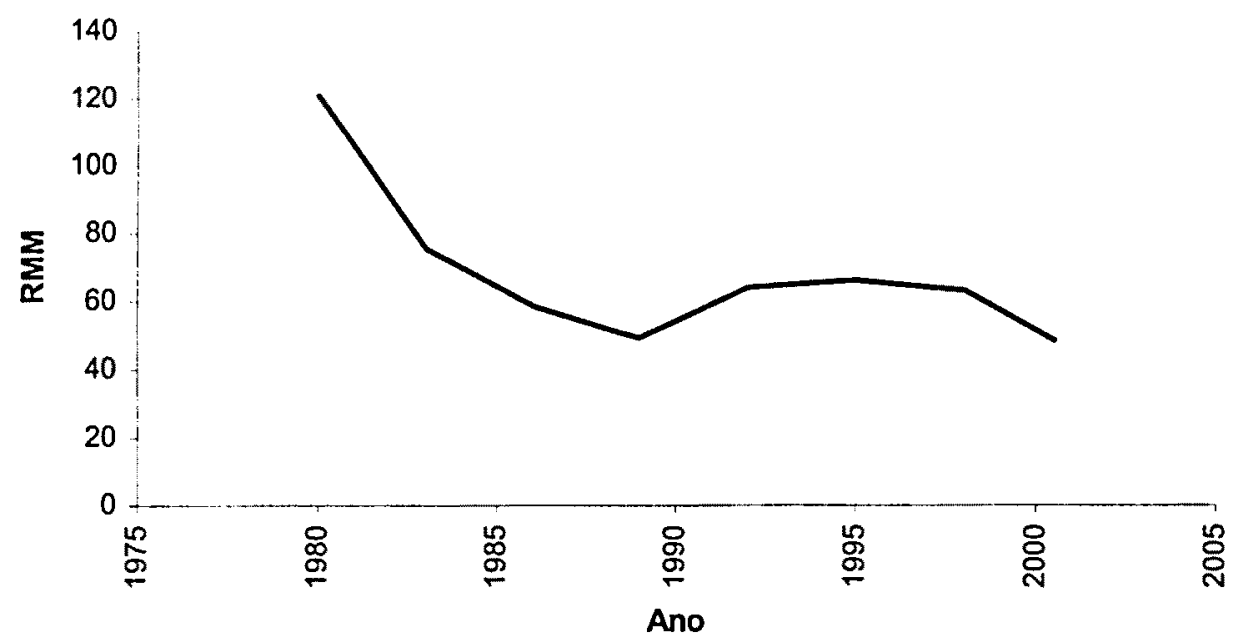

Figura 5. Razão de mortalidade materna (fonte oficial) por cem mil nascidos vivos. Aracaju (SE), 1979-2001.

Fonte: SIM (MS 2000, MS 2002a, SES 2002), IBGE (1981-2003), SINASC (MS 2000, SES 2002).

$\mathrm{Na}$ tentativa de melhorar a informação no tocante aos óbitos por causas maternas, conforme referido anteriormente, foram criadas quatro categorias para a análise dos óbitos de mulheres em idade fértil, objetivando verificar, dentro deste conjunto de óbitos, aqueles que poderiam ser maternos. Observa-se que $21,8 \%$ dos casos de óbitos deveria ser objeto de investigação, segundo as normas da CID 10 (OMS 1995): maternas, causas externas e AIDS. Utilizando os critérios do Comitê Nacional de Morte Materna (MS 1994c; MS 2001b), este percentual seria maior, ou seja, $42,2 \%$ dos casos (as citadas anteriormente somadas aos óbitos por causas desconhecidas e aos presumíveis de morte materna). A Tabela 19 mostra a distribuição dos casos segundo os Grupos. 
Tabela 19. Óbitos de mulheres em idade fértil segundo causas maternas e passiveis de serem maternas. Aracaju (SE), 1979-2001.

\begin{tabular}{|c|c|c|c|c|c|c|c|}
\hline \multirow[t]{2}{*}{ Ano } & \multicolumn{6}{|c|}{ Grupos de causas } & \multirow[t]{2}{*}{ Tota } \\
\hline & Maternos & $\begin{array}{l}\text { Presumiveis } \\
\text { de morte } \\
\text { materna }\end{array}$ & $\begin{array}{c}\text { Mortes sem } \\
\text { assistência ou por } \\
\text { causa } \\
\text { desconhecida } \\
\end{array}$ & AIDS $^{b}$ & $\begin{array}{l}\text { Causa } \\
\text { externa }\end{array}$ & $\begin{array}{l}\text { Demais } \\
\text { causas }\end{array}$ & \\
\hline 1979 & 13 & 15 & 27 & - & 23 & 98 & 176 \\
\hline 1980 & 17 & 21 & 3 & - & 38 & 118 & 197 \\
\hline 1981 & 12 & 25 & 11 & - & 22 & 93 & 163 \\
\hline 1982 & 10 & 21 & 5 & - & 38 & 125 & 199 \\
\hline 1983 & 11 & 26 & 8 & - & 33 & 93 & 171 \\
\hline 1984 & 8 & 13 & 20 & - & 21 & 68 & 130 \\
\hline 1985 & 6 & 20 & 10 & - & 25 & 97 & 158 \\
\hline 1986 & 11 & 17 & 17 & - & 27 & 106 & 178 \\
\hline 1987 & 7 & 13 & 17 & - & 23 & 89 & 149 \\
\hline 1988 & 8 & 24 & 25 & - & 32 & 115 & 204 \\
\hline 1989 & 4 & 21 & 19 & - & 23 & 114 & 181 \\
\hline 1990 & 8 & 23 & 22 & 2 & 23 & 116 & 194 \\
\hline 1991 & 3 & 7 & 45 & 1 & 24 & 60 & 140 \\
\hline 1992 & 15 & 28 & 14 & 2 & 60 & 140 & 259 \\
\hline 1993 & 6 & 26 & 16 & 2 & 37 & 126 & 213 \\
\hline 1994 & 8 & 27 & 18 & 5 & 38 & 144 & 240 \\
\hline 1995 & 8 & 30 & 24 & 2 & 51 & 116 & 231 \\
\hline 1996 & 7 & 13 & 22 & 0 & 21 & 73 & 136 \\
\hline 1997 & 2 & 17 & 21 & 1 & 30 & 89 & 160 \\
\hline 1998 & 6 & 16 & 24 & 3 & 38 & 99 & 186 \\
\hline 1999 & 12 & 27 & 13 & 1 & 38 & 152 & 243 \\
\hline $2000^{c}$ & 7 & 25 & 6 & 5 & 38 & 114 & 195 \\
\hline $2001^{c}$ & 3 & 24 & 13 & 3 & 29 & 124 & 196 \\
\hline Total & 192 & 479 & 400 & 13 & 732 & 2483 & 4299 \\
\hline
\end{tabular}

a: exceto as mortes sem assistência ou por causa desconhecida.

b: no periodo de 1979-1995: casos codificados como 279.1.

c: dados preliminares.

Fonte: SIM (MS 2000, MS, 2002a, SES, 2002). 
$\mathrm{Na}$ tentativa de corrigir a informação quantitativa das mortes maternas, a IMM obtida foi comparada com a estimada segundo duas técnicas:

- pela taxa observada a partir da soma dos casos de mortes maternas somadas los casos cuja causa é presumível de morte materna (Grupos 1 e 2, do Quadro 1) MS 2001b);

- pelo fator de correção proposto pelo Projeto Gravidez, Parto ou Puerpério ara a Região Nordeste, que foi igual a 2,05 (LAURENTI et. al 2003).

Na Figura 6 podem ser observados os resultados. Nota-se que o uso de um ator de correção constante ao longo da série pode estar gerando distorções, uma vez jue o mesmo varia em função do tempo. O comitê nacional de morte materna Itilizava o fator igual a três para a Região Nordeste até 2001, ano da nova publicação MS 2001) em que o mesmo deixa de utilizar tais fatores. LAURENTI et. al (2003) ıpontaram que o fator, nas capitais é de 2,05 , portanto a curva representada pela IMM corrigida é possivelmente subestimada no início do período, podendo atingir alores superiores ao representado pela curva das mortes maternas somadas às resumíveis.

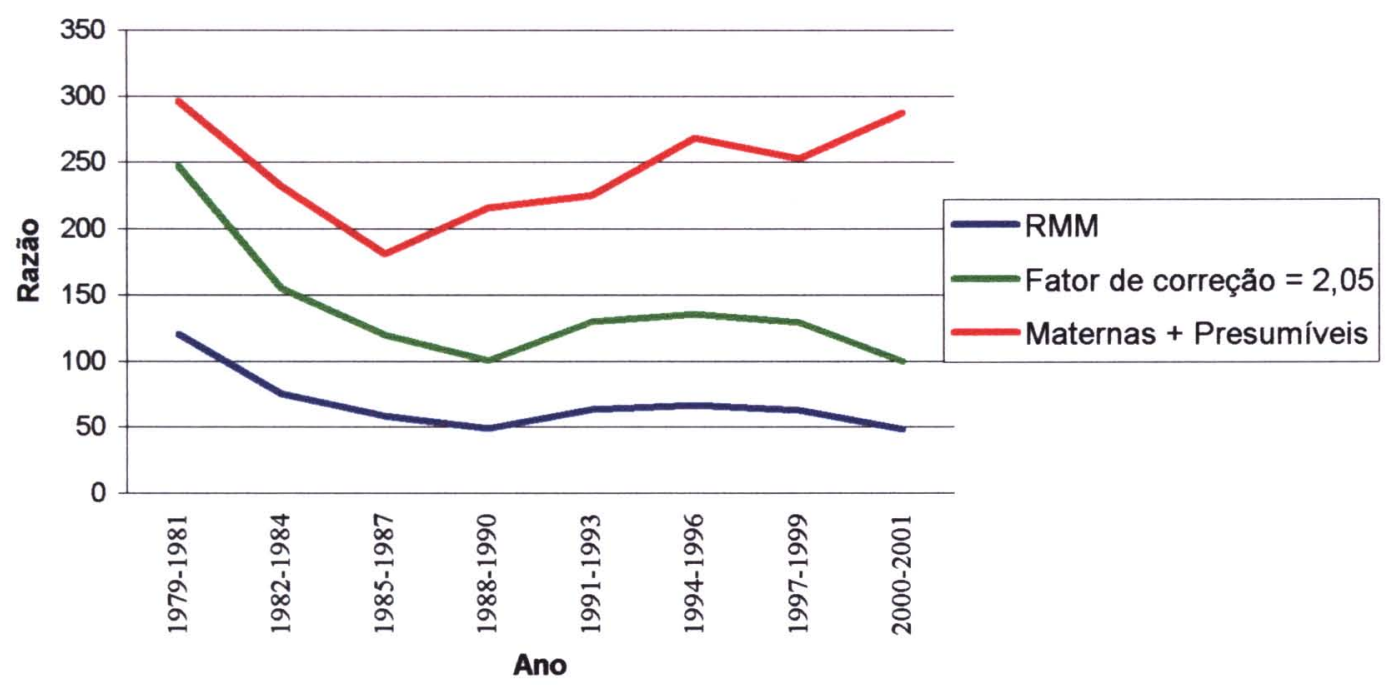

Figura 6. Razão de mortalidade materna (por cem mil nascidos vivos), segundo fontes oficiais e razão de mortalidade materna corrigidas ${ }^{\mathrm{a}}$. Aracaju (SE), 1979-2001.

I para conceito adotado de causas corrigidas: ver Quadro 1.

Fonte: SIM (MS 2000,MS, 2002a, SES, 2002). 
A verdadeira taxa de mortalidade materna está entre os valores representados pela RMM (oficial) e pela curva que representa as mortes maternas somadas às presumíveis. Evidentemente que, ao utilizar todas as presumíveis está se elevando artificialmente o valor da RMM, uma vez que apenas parte delas refere-se realmente de óbitos maternos. Um exemplo: no ano de 2001 supõe-se que a RMM esteja entre 30,3 e 273,0 óbitos maternos por cem mil nascidos vivos, apresentando amplitude de variação igual a 242,7 , ou seja, excessivamente grande, devendo neste ano ser a curva representada pelo fator de correção a mais próxima da realidade neste ano.

Quanto às causas de morte maternas (Tabelas 20 e 21), destacaram-se os transtornos hipertensivos $(25,0 \%)$, os abortos $(22,4 \%)$ e as complicações do parto $(20,8 \%)$. Somados, estes três grupos de causa perfizeram $68,2 \%$ dos óbitos. Observou-se que estas causas permanecem presentes, durante toda a série, mostrando terem sofrido baixo ou nenhum impacto com as mudanças nas politicas públicas voltadas para a saúde nos últimos vinte e três anos.

Tabela 20. $\mathrm{N}^{\circ}, \%$ e \% acumulado dos óbitos por causas maternas segundo grupo. Aracaju (SE), 1979-2001.

\begin{tabular}{lrrr}
\hline Causas & $\mathrm{N}^{\mathrm{o}}$ & $\%$ & $\% \mathrm{Ac}$ \\
\hline Transtornos hipertensivos & 48 & 25,0 & 25,0 \\
Gravidez que termina em aborto & 43 & 22,4 & 47,4 \\
Complicações do trabalho do parto e parto & 40 & 20,8 & 68,2 \\
Complicações relacionadas predominantemente com o puerpério & 31 & 16,1 & 84,4 \\
Assistência prestada à mãe por motivos ligados ao feto & 14 & 7,3 & 91,7 \\
Outras afeç̧ões obstétricas, não classificadas em outra parte & 11 & 5,7 & 97,4 \\
Outros transtornos maternos & 5 & 2,6 & 100,0 \\
\hline Total & 192 & 100,0 & \\
\hline
\end{tabular}

Fonte: SIM (MS 2000, MS, 2002a, SES, 2002).

Quando se observa a distribuição anual dos casos de morte materna segundo grupos de causas, verificou-se que, no início da série, os três mais citados (hipertensão, aborto e atenção ao parto) representam até 100,0\% dos casos de mortes, ou seja, todas elas por causas diretas. $\mathrm{Na}$ análise da série, observa-se uma pequena diminuição das causas do grupo $\mathrm{A}, \mathrm{B}, \mathrm{E}$ e $\mathrm{F}$, estabilidade nos grupos $\mathrm{C}$ e D e 
discreta tendência de aumento do agrupamento G (Outras Afecções Obstétricas), o que pode estar indicando uma mudança no perfil da mortalidade do grupo.

O aumento das causas obstétricas consideradas indiretas vêm sendo observado nacionalmente, a partir de meados da década passada (MS 2001d). Entretanto, conclusões a respeito do padrão de mortalidade devem ser feitas com cautela, uma vez que diversos estudos apontam a subinformação dos óbitos maternos (LAURENTI et. al 1990a; SIQUEIRA et. al 1999; LAURENTI et. al 2003).

Tabela 21. Óbitos por causas maternas segundo as principais categorias (capitulo XV CID 10). Aracaju (SE), 1979-2001.

\begin{tabular}{lrrrrrrrrr}
\hline Ano & \multicolumn{8}{c}{ Categorias $^{\text {a }}$} & Total \\
\cline { 2 - 8 } & A & B & C & D & E & F & G & \\
\hline $1979-1981$ & 10 & 7 & 1 & 2 & 15 & 6 & 1 & 42 \\
$1982-1984$ & 7 & 8 & 1 & 1 & 5 & 7 & - & 29 \\
$1985-1987$ & 8 & 7 & - & 2 & 4 & 3 & - & 24 \\
$1988-1990$ & 2 & 9 & 1 & 1 & 3 & 4 & - & 20 \\
$1991-1993$ & 7 & 5 & 1 & 4 & 4 & 2 & 1 & 24 \\
$1994-1996$ & 6 & 5 & 1 & 3 & 3 & 4 & 1 & 23 \\
$1997-1999$ & - & 5 & - & - & 5 & 4 & 6 & 20 \\
$2000-2001$ & 3 & 2 & - & 1 & 1 & 1 & 2 & 10 \\
\hline Total & 43 & 48 & 5 & 14 & 40 & 31 & 11 & 192 \\
\hline
\end{tabular}

Fonte: SIM (MS 2000, MS, 2002a, SES, 2002).

a: As categorias são:

A: Gravidez que termina em aborto.

B: Edema, proteinúria e transtornos hipertensivos na gravidez, parto e puerpério.

C: Outros transtomos maternos relacionados predominantemente com a gravidez.

D: Assistência prestada à mãe por motivos ligados ao feto e à cavidade amniótica e por possíveis problemas relativos ao parto.

E: Complicações do trabalho de parto e do parto.

F: Complicações relacionadas predominantemente com o puerpério.

G: Outras afecções obstétricas, não classificadas em outra parte 
Quanto às variáveis recentemente introduzidas na DO (1995-2001), isto é, se a morte ocorreu durante a gravidez, parto ou aborto ou no puerpério, em 220 DOs havia informação sobre a presença destes eventos. Deve-se salientar que seu grau de preenchimento ainda é bastante precário (LAURENTI et. al 2000b).

Em Aracaju, dos 1346 casos de óbito de mulheres em idade fértil que ocorreram após a introdução dos campos (43 e 44) no documento, havia preenchimento de $10,7 \%$ do primeiro e de $11,7 \%$ do segundo, incluindo os casos cujo preenchimento foram os campos ignorados. Entretanto, no periodo do estudo, observou-se uma melhora do preenchimento dos mesmos: em 1995 apenas 1,0\% DOs tiveram preenchimento de pelo menos uma das variáveis e, em 2001, este percentual elevou-se para $45,6 \%$. Por outro lado, foram observados problemas no preenchimento destes campos em 10,0\% dos casos.

Do total de casos em que havia preenchimento destes campos, 40 casos referiam-se a óbitos com informação conhecida, a saber: grávidas, 18 casos, no período puerperal oito, no puerpério tardio dez e em quatro casos foram observadas inconsistências no preenchimento dos campos 43 e 44, não sendo possivel precisar se tratavam de mulheres grávidas ou no puerpério ou no puerpério tardio.

Em 12 casos (26,7\%), a causa básica estava alocada no capitulo XV da CID 10. Entretanto, no período de 1995 a 2001, ocorreram 45 mortes maternas, o que mostra que houve omissão do preenchimento destes campos. Quantos às demais causas, destacaram-se as neoplasias (oito), as causas externas (seis) e as infecciosas e parasitárias (cinco). Vale ressaltar que, em apenas dois casos, a causa básica pertencia ao grupo das presumíveis de morte materna.

A Tabela 22 mostra a distribuição destes casos segundo a causa básica. Estes resultados sugerem poder existir problemas de três origens: na codificação da DO (o codificador ignora o preenchimento deste campo), o que fica mais evidente nos casos em que há presença de gravidez no momento da morte com causa básica natural e não pertencente ao capítulo das maternas; outro fator pode ser o preenchimento incorreto pelo médico dos campos 43 e 44 ou ainda, a falhas na digitação do documento. 
Tabela 22. Momento do óbito de mulheres em idade fértil com informação na DO sobre a presença de gravidez, puerpério ou puerpério tardio e causa básica. Aracaju (SE), 1995-2001.

\begin{tabular}{|c|c|c|c|c|c|c|c|c|c|c|}
\hline \multirow{3}{*}{ CAUSA BÁSICA } & \multicolumn{8}{|c|}{ MOMENTO DO ÓBITO } & \multirow{2}{*}{\multicolumn{2}{|c|}{ TOTAL }} \\
\hline & \multicolumn{2}{|c|}{ Grávida } & \multicolumn{2}{|c|}{$\begin{array}{l}\text { Até } 42 \text { dias após } \\
\text { o término da } \\
\text { gravidez }\end{array}$} & \multicolumn{2}{|c|}{$\begin{array}{c}\text { De } 43 \text { a } 364 \text { dias } \\
\text { completos após o } \\
\text { término da gravidez }\end{array}$} & \multicolumn{2}{|c|}{$\begin{array}{l}\text { Gravidez,Parto } \\
\text { ou Puerpério } \\
\text { IGNORADO }^{\text {a }}\end{array}$} & & \\
\hline & $\mathrm{n}^{\circ}$ & $\%$ & $\mathrm{n}^{\circ}$ & $\%$ & $\mathrm{n}^{\circ}$ & $\%$ & $n^{\circ}$ & $\%$ & $\mathrm{n}^{\circ}$ & $\%$ \\
\hline D.Infecciosas e Parasitárias & 3 & 60,0 & 1 & 20,0 & 1 & 20,0 & - & - & 5 & 100,0 \\
\hline Neoplasias & 5 & 62,5 & - & - & 3 & 37,5 & & & 8 & 100,0 \\
\hline D. Endócrinas & - & - & - & - & - & - & 1 & 100,0 & 1 & 100,0 \\
\hline D. Ap. Circulatório & 1 & 25,0 & 2 & 50,0 & 1 & 25,0 & - & - & 4 & 100,0 \\
\hline D. Ap. Respiratório & - & - & - & - & 1 & 100,0 & - & - & 1 & 100,0 \\
\hline D. Ap. Digestivo & - & - & - & - & 1 & 100,0 & - & - & 1 & 100,0 \\
\hline Gravidez,Parto ou Puerpério & 5 & 41,7 & 5 & 41,7 & - & - & 2 & 16,7 & 12 & 100,0 \\
\hline Mal Definidas & - & - & - & - & 3 & 100,0 & - & - & 3 & 100,0 \\
\hline C. Externas & 4 & 80,0 & - & - & - & - & 1 & 20,0 & 5 & 100,0 \\
\hline TOTAL & 18 & 45,0 & 8 & 20,0 & 10 & 25,0 & 4 & 10,0 & 40 & 100,0 \\
\hline
\end{tabular}

Fonte: SIM (MS 2000, MS, 2002a, SES, 2002).

a: casos em que houve inconsistência quanto ao preenchimento dos campos 43 e 44 , que informavam a presença de gravidez e de puerpério.

\subsection{Análise dos óbitos de mulheres em idade fértil em 2001}

A partir da lista única foram desenvolvidas as duas fases subseqüentes do estudo, especificamente para o ano de 2001. Conforme referido, na segunda fase foi construído o PADRÃO-OURO e na terceira a NOVA-DO, derivada da busca dos sistemas de informação em saúde.

\subsubsection{Ganho quantitativo da informação}

Para o levantamento quantitativo de 2001, foi construída a lista única, e a partir dela foram desenvolvidas as demais fases do estudo. Conforme referido, 196 casos foram provenientes do SIM. Do SIAB foram verificados 44 casos, sendo que, inicialmente em 35 a DO foi encontrada na base municipal, duas localizadas na base estadual do SIM e em sete não foi possível resgatar o documento. No SIH foram observados 81 casos, sendo que em apenas um deles não foi possível resgatar a DO, 
dos demais casos, 70 foram localizados na base municipal e dez foram localizadas na base Estadual do SIM.

Após a construção do PADRÃO-OURO os casos foram classificados segundo a permanência nesta fase do estudo: houve 190 casos em que foi possivel resgatar informações adicionais nas fontes consultadas (88,0\%), sendo que 177 tratavam-se de casos válidos $(81,9 \%), 13$ casos foram excluídos $(6,0 \%)$ e em 26 $(12,0 \%)$ houve perda da informação (Tabela 23 ).

Tabela 23. Procedência dos casos do PADRÃO-OURO segundo fonte quantitativa e resultado da segunda fase (inquérito). Aracaju (SE), 2001.

\begin{tabular}{lrrrr}
\hline Fonte & \multicolumn{3}{c}{ Tipo de Caso } & Total \\
\cline { 2 - 5 } & Exclusões & Perdas & Válidos $^{a}$ & \\
\hline SIM & 4 & 16 & 84 & 105 \\
SIAB & 3 & 4 & 2 & 9 \\
SIH & 0 & 1 & 0 & 1 \\
SIM-SIH & 5 & 1 & 60 & 66 \\
SIM-SIAB & 1 & 4 & 17 & 21 \\
SIM-SIH-SIAB $_{\text {Total }^{\text {a }}}$ & 0 & 0 & 14 & 14 \\
\hline
\end{tabular}

a: em um caso não foi resgatada a DO.

Cabe ressaltar que dos casos comuns aos três sistemas (SIM, SIH e SIAB) não houve exclusões. Comuns a dois sistemas, SIM e SIAB ou SIM e SIH-SUS, foram excluídos um e cinco casos respectivamente. Dos presentes apenas no SIM mais quatro casos. E presentes em apenas um sistema que não o SIM, três informados pelo SIAB.

Observa-se que o uso dos SIS aumentou de 196 para 216 o total de casos, o que representa um incremento de 10,2\%. A contribuição do SIH foi de 5,1\% (11 casos) e do SIAB foi igual a 4,2\% (nove casos). Entretanto, após a construção do PADRÃO-OURO, este valores diminuíram em função das exclusões (Figura 7). 


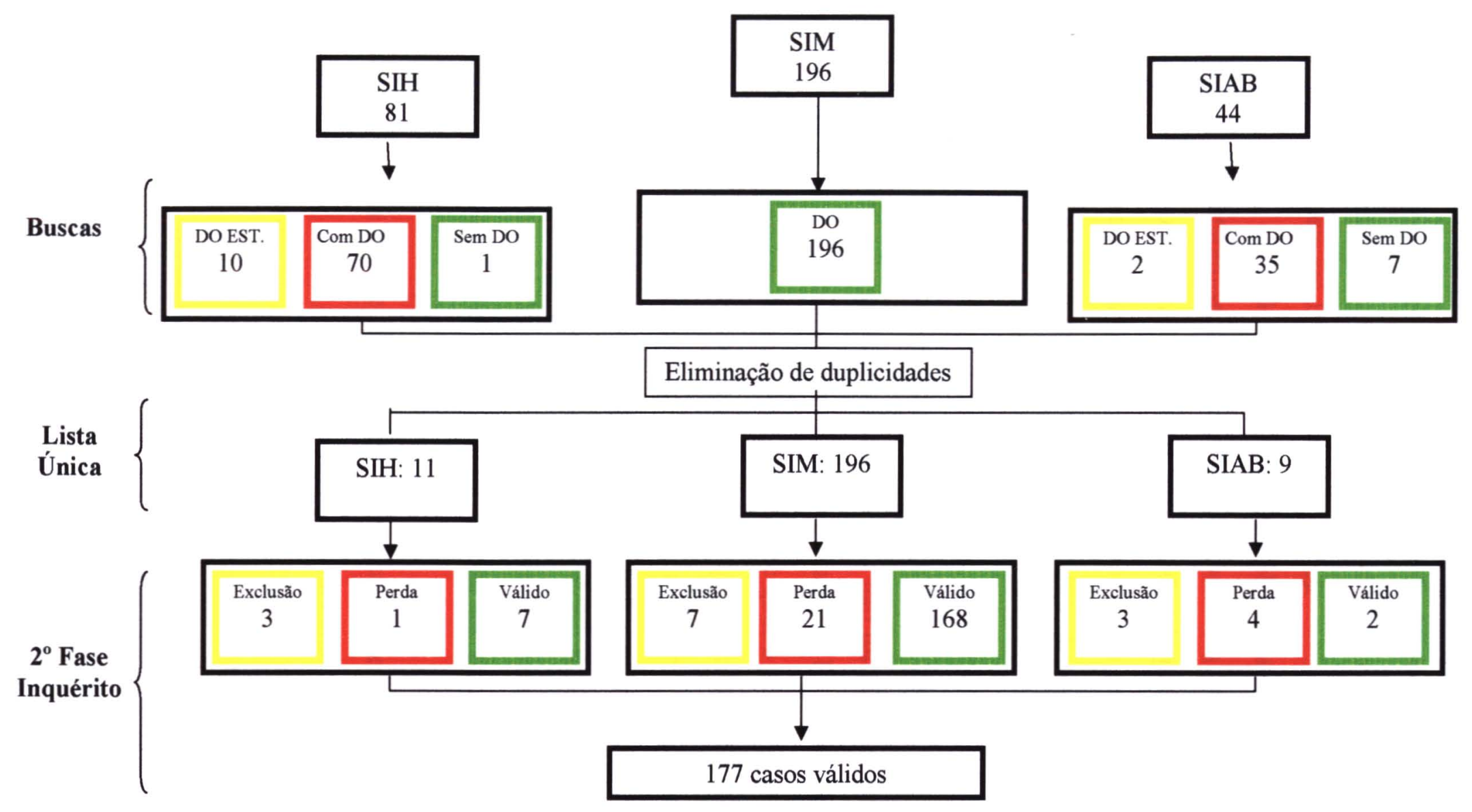

Figura 7. Casos da lista única de óbitos de mulheres em idade fértil segundo fonte de informação selecionados na Fase 2 (PADRÃO-OURO). Aracaju (SE), 2001. 
Dos 11 casos do SIH que não estavam presentes entre os casos oficiais do SIM (mulheres de 10 a 49 residentes em Aracaju, em 2001), houve três exclusões, uma perda e sete casos válidos, o que significa que o SIH contribuiu com um percentual menor de casos (sete em 190 casos, ou seja, 3,7\%).

Quanto ao motivo da exclusão dos casos, em um deles tratava-se de paciente do sexo masculino e dois trataram-se de não residentes. Houve um caso em que não se obteve a DO, nem tampouco outra informação, foi considerado perda, por haver a possibilidade de ocorrer erro de digitação da variável motivo de saída hospitalar. Seria recomendável que os eventos únicos (nascimentos e óbitos) tivessem informações mais precisas em qualquer dos SIS, como o número da DO entre os campos, no caso do desfecho ser o óbito, a exemplo do que vem sendo recomendado pelo próprio Ministério da Saúde no caso de nascidos vivos (Brasil 2002).

Dos nove casos informados pelo SIAB, em sete que não foi possível resgatar a DO, e em dois as mesmas foram resgatadas na base estadual do SIM. Somente dois deles trataram-se de casos válidos, e houve três exclusões e quatro perdas. Portanto, o SIAB contribuiu com $1,1 \%$ dos casos para a melhora quantitativa dos casos de óbito. Entre os motivos de exclusão houve um caso relativo a paciente viva, e um por tratar-se de óbito do recém nascido e não da mãe que havia sido erroneamente informada como caso de óbito (cabe ressaltar que para o recém nascido havia DO presente no SIM), e o outro a idade não pertencia aos limites estabelecidos pelo presente estudo. Quanto às quatro perdas, o motivo foi não ter sido encontrado o endereço ou qualquer outra informação.

Este resultado aponta que se faz necessária a aplicação de metodologia de inquérito para os casos de óbitos informados por este sistema, quando não é encontrada a DO. Neste sentido, MELLO JORGE e GOTLIEB. (2001) recomendam uma rotina de procedimentos que inclui visita domiciliar, o preenchimento de formulário padronizado para o esclarecimento destes casos, antes da inclusão dos mesmos no SIM. Também mostra a necessidade de capacitação das Equipes de Saúde do PACS/PSF, em especial dos agentes de saúde, quanto á importância de manterem dados corretos no SIAB. Cabe ressaltar que, por outro lado, em um caso em que a DO não fora captada anteriormente pelo SIM (informado pelo SIAB), em decorrência desta investigação, a mesma foi localizada e inclusa no sistema e que 
entre as perdas houve um caso em que havia incompatibilidade do sexo informado na DO-ORIGINAL e após a busca nas fontes do PACS/PSF e construção da lista única, pode-se verificar que se tratava de paciente do sexo feminino, e portanto que houve falha na digitação no SIM.

Entre os 196 casos informados pelo SIM (base municipal), após a elaboração do PADRÃO-OURO, observou-se que 168 tratavam-se de casos válidos, com 21 perdas e 7 exclusões. Portanto, dos casos em que se obteve informações adicionais (casos válidos somados às exclusões) em 4,0\% deles a informação no SIM foi considerada incorreta. Entre os motivos de exclusão destacaram-se: um paciente do sexo masculino e seis não residentes.

Este resultado aponta que o SIM, embora seja o sistema de informação em saúde mais antigo, suas informações ainda precisam ser aprimoradas, o que foi demonstrado em diversos estudos (MELLO JORGE et. al 2002, BAGGIO 2002, OLIVEIRA 2002). LAURENTI et. al (2003), em pesquisa nas capitais brasileiras, dos 3080 casos analisados, excluiram 5,7\% dos casos, por haver incompatibilidade entre as informações da DO ORIGINAL e após o inquérito, que incluiu visita domiciliar. Entre os motivos apontados pelos autores havia casos de não residentes, ou o sexo ou a idade incompatíveis com as exigidas pelo estudo.

Por outro lado o uso a Fase 3 (uso dos SIS) pode gerar distorções, um exemplo é o SIAB: como nesta fase, o propósito foi aceitar a informação, os sete casos foram incluídos, assim como o caso procedente do SIH (Figura 8 e Tabela 24). Entre os motivos de exclusão destacaram-se: um caso com idade incompatível (SIMSIAB), outro com sexo incompatível (SIM-SIH) e os dez restantes por terem informação de município de residência que não Aracaju. Nota-se que, nesta fase, um caso presente apenas no SIM foi excluido pois se verificou erro de digitação da variável municipio de residência. 
Tabela 24. Procedência dos casos da NOVA-DO segundo fonte quantitativa e resultado da terceira fase (SIS). Aracaju (SE), 2001.

\begin{tabular}{lrrr}
\hline Fonte & \multicolumn{2}{c}{ Tipo de Caso } & Total \\
\cline { 2 - 4 } & Exclusões & Válidos & 105 \\
\hline SIM & 1 & 104 & 7 \\
SIAB & - & 7 & 1 \\
SIH & - & 1 & 66 \\
SIM-SIH & 10 & 56 & 23 \\
SIM-SIAB & 1 & 22 & 14 \\
SIM-SIH-SIAB & - & 14 & 216 \\
\hline Total & 12 & 204 & \\
\hline
\end{tabular}

Utilizando apenas os SIS, exceto nos casos cuja fonte foi o SIM e o SIH, houve captação de um número maior de casos. Estes casos nem sempre refletem a realidade, ocorrendo problemas de várias naturezas: as informações foram incorretas (SIAB), a declaração do endereço não foi consistente (SIM e SIH), ocorreram erros na digitação (SIH e SIM) ou ainda erros no preenchimento da DO. Portanto, do ponto de vista quantitativo, ainda que os SIS tenham contribuído para a melhora da informação (dos 177 casos válidos, nove foram agregados partir dos mesmos, ou seja $5,1 \%$ ), seu uso deve ser feito com cautela e sempre acompanhado da fase de inquérito. 


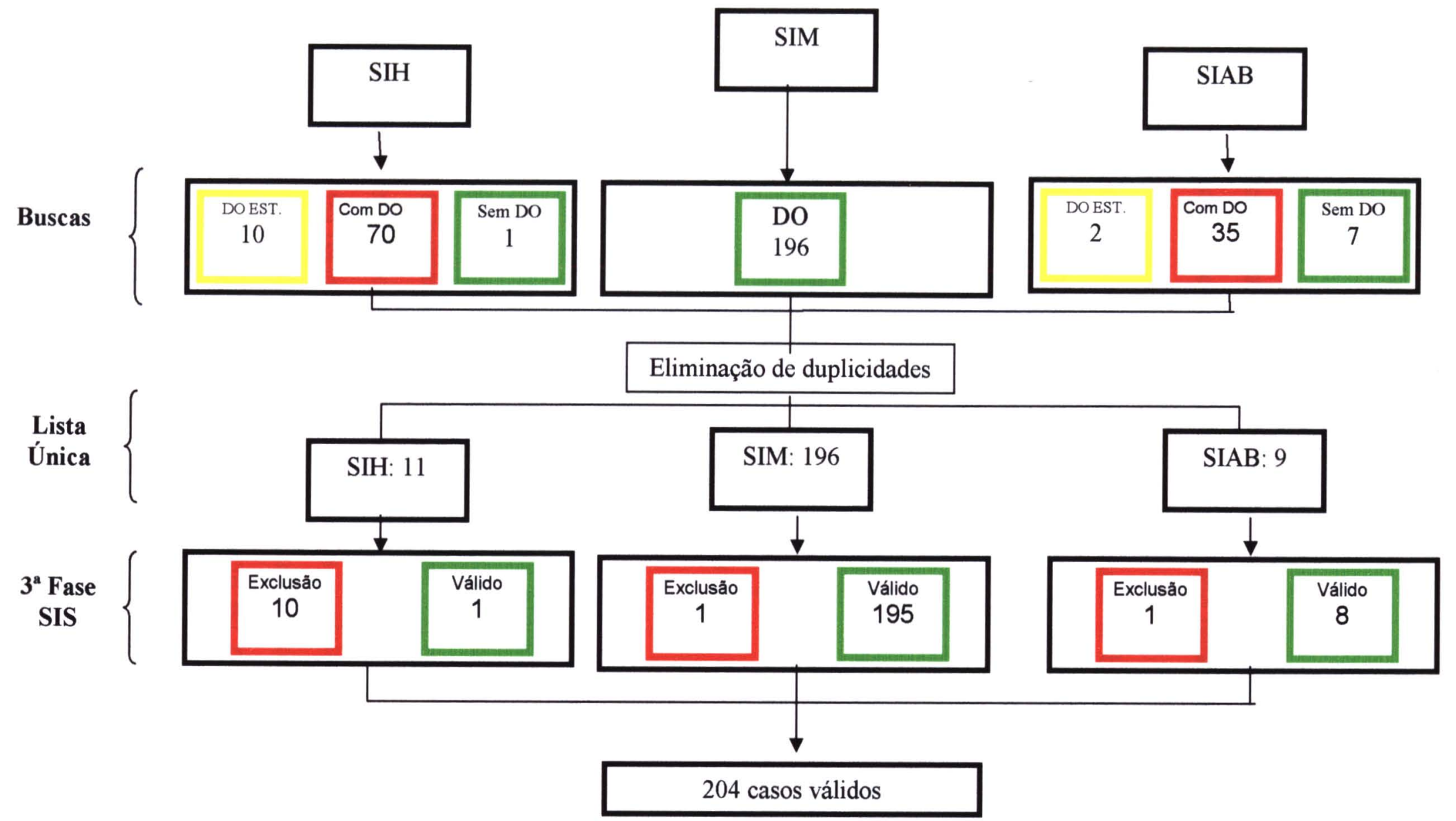

Figura 8. Casos de óbitos de mulheres em idade fértil segundo fonte de informação selecionados na Fase 3 (NOVA-DO). Aracaju (SE), 2001. 


\subsubsection{Ganho qualitativo da informação}

A partir da lista única foram realizadas buscas em fontes alternativas. Nesta fase o objetivo foi estabelecer o PADRÃO-OURO como parâmetro de comparação para a fase posterior.

Dos casos presentes na lista única, procedeu-se à busca de informações adicionais, utilizando o levantamento em prontuários hospitalares, IML, domicílio e unidades de saúde que prestaram assistência à paciente em momento anterior ao óbito. Em 177 foram obtidas informações adicionais e foi possível construir o PADRÃO-OURO.

Em 169 casos houve concordância entre o município informado na $\mathrm{DO} e$ aquele obtido nas fontes alternativas; em sete casos houve discordância, e, em um caso não foi possivel localizar a DO. Houve um caso cuja fonte de informação foi o SIAB e após o retorno ao serviço de saúde que emitiu a DO, foi realizado o resgate da mesma e sua inclusão no SIM

Dos casos provenientes do SIH em que houve conflito quanto ao município de residência, após investigação nas fontes alternativas observou-se que os mesmos eram residentes em Aracaju e permaneceram no estudo. Ainda que esta comprovação não tenha sido realizada por meio de visita domiciliar, sabe-se que a principal fonte utilizada para a complementação da DO, pelos serviços responsáveis pelo SIM, são as anotações constantes do prontuário médico.

De fato, pesquisa recente realizada em todas as capitais do país (LAURENTI et. al 2003) utilizaram metodologia de visita domiciliar para todos os casos de óbitos de mulheres em idade fértil, porém estas ações devem ser pontuais, uma vez que poucos municípios possuem Comitês de Investigação de Mortalidade Materna atuantes, com capacidade operacional para realizar tal inquérito. Entretanto, se por um lado a metodologia permitiu a exclusão das não residentes, por outro não permitiu a inclusão das residentes em que o endereço estava incorreto na DO.

Quanto à contribuição dos Sistemas de Informação em Saúde - SIS - para a melhora da informação dos óbitos em 2001, nesta fase o objetivo foi verificar a possibilidade do uso dos SIS para a melhoria das informações qualitativas dos óbitos. 
Foram selecionados da lista única 196 casos de óbitos em que se obteve a DO, somados a oito casos em que não se obteve a DO. Estes oito casos foram todos codificados como mortes por causa indeterminada, sugerindo uma melhora quantitativa do SIM. Dos 196 em que a DO informava município de residência Aracaju, em 93 foi possível obter alguma informação adicional nos SIS consultados $(49,7 \%)$ e, conforme referido anteriormente, esta informação quando se tratou de uma causa, foi inserida na Parte 2 da DO-ORIGINAL como forma de complementála e quando se tratasse de informação referente à gravidez parto e puerpério foram preenchidos os campos 43 ou 44 da DO. A Tabela 25 mostra a distribuição de causas obtidas.

Tabela 25. Distribuição dos casos de óbito de mulheres em idade fértil ( $\mathrm{n}^{\mathbf{0}} \mathrm{e} \%$ ) segundo causa básica e a captação de informação adicional (NOVADO) sobre causa de óbito nos SIS a . Aracaju (SE), 2001.

\begin{tabular}{lrrrr}
\hline Causa Básica & \multicolumn{2}{c}{ NOVA-DO } & \multicolumn{2}{r}{ Total } \\
\cline { 2 - 5 } & Sim & Não & $N^{\circ}$ & $\%$ \\
\hline D. Infecciosas e Parasitárias & 1 & 5 & 6 & 3,1 \\
Neoplasias & 30 & 26 & 56 & 28,6 \\
D. Sangue & 2 & 2 & 4 & 2,0 \\
D. Endócrinas & 5 & 3 & 8 & 4,1 \\
Transtornos Mentais & 1 & 1 & 2 & 1,0 \\
D. Sistema Nervoso & 2 & 2 & 4 & 2,0 \\
D. Ouvido & 1 & - & 1 & 0,5 \\
D. Ap. Circulatório & 25 & 20 & 45 & 23,0 \\
D. Ap. Respiratório & 4 & 5 & 9 & 4,6 \\
D. Ap. Digestivo & 3 & 3 & 6 & 3,1 \\
D. Osteomuscular & 3 & 2 & 5 & 2,6 \\
D. Ap. Geniturinário & 1 & 3 & 4 & 2,0 \\
Gravidez, Parto ou Puerpério & 2 & 1 & 3 & 1,5 \\
Malformações Congênitas & 1 & - & 1 & 0,5 \\
Mal Definidas & 2 & 11 & 13 & 6,6 \\
C. Externas & 11 & 18 & 29 & 14,8 \\
\hline Total & 94 & 102 & 196 & 100,0 \\
\hline
\end{tabular}

a: excluidos oito casos sem DO-ORIGINAL.

Observa-se que em 102 casos não houve possibilidade de complementar a DO com informação dos SIS no tocante às causas de morte. Destes casos, 64 foram 
óbitos hospitalares, e não foi resgatada informação adicional, ou porque a AIH não foi localizada, ou por se tratar de óbitos ocorridos em hospitais não conveniados com a rede SUS, ou ainda por não ter havido tempo para gerar uma internação, tendo ocorrido o óbito no pronto atendimento hospitalar (Tabela 26).

Tabela 26. Distribuição dos casos de óbitos de mulheres em idade fértil (n ${ }^{\circ}$ e \%) segundo local de ocorrência do óbito e a captação de informação adicional sobre causa de óbito nos SIS. Aracaju (SE), 2001.

\begin{tabular}{lrrrrrrr}
\hline Local de Ocorrência & \multicolumn{3}{c}{ DO Complementada } & \multicolumn{2}{c}{ Total } \\
& \multicolumn{2}{c}{ Sim } & \multicolumn{2}{c}{ Não } & & \\
\cline { 2 - 7 } & $\mathrm{n}^{\mathbf{0}}$ & $\%$ & $\mathrm{n}^{\mathbf{0}}$ & $\%$ & $\mathrm{n}^{\mathbf{0}}$ & $\%$ \\
\hline Hospital & 84 & 89,4 & 64 & 62,7 & 148 & 75,5 \\
Domicilio & 4 & 4,3 & 23 & 22,5 & 27 & 13,8 \\
Via Pública & 4 & 4,3 & 8 & 7,8 & 12 & 6,1 \\
Outros & 2 & 2,1 & 7 & 6,9 & 9 & 4,6 \\
\hline Total & 94 & 100,0 & 102 & 100,0 & 196100,0 \\
\hline
\end{tabular}

Quando foram comparadas as distribuições de causas da NOVA-DO e a DOORIGINAL, observou-se que apenas cinco grupos de causa da CID 10 sofreram alterações: houve aumento dos casos de neoplasias, das doenças do aparelho circulatório e das doenças endócrinas e diminuição dos casos de doenças do sistema nervoso, e das mal definidas. Entretanto, as alterações foram muito pequenas, variando entre 2,0 e $14,0 \%$, o que pode ser atribuído a três fatores: ao critério muito conservador para a correção da causa básica na DO-ORIGINAL; ao preenchimento da variável Motivo da Internação, no $\mathrm{SIH}$, se tratar, em geral, de sintomas, com predominio das causas mal-definidas (o que não alterou a $\mathrm{DO}$ ). Ou ainda ao fato de terem sido analisados apenas os 42 dias que antecederam o óbito e, portanto, o motivo da internação estaria muito ligado às causas de morte (Tabela 27).

Possivelmente, o uso de metodologias como a proposta por BRAMELD (1998), em que foram analisadas as internações até um ano antes da morte, poderiam mudar o quadro observado e, aliado a isto, a melhor forma de análise seria o estudo segundo causas múltiplas de morte (PUFFER e GRIFFTH 1968). 
Tabela 27. Distribuição dos casos de óbitos de mulheres em idade fértil $\left(\mathrm{n}^{\circ}\right.$ e \%) segundo causa básica na DO-ORIGINAL e na NOVA-DO (SIS) ${ }^{\mathrm{a}}$ e ganho de informações (relação A/B). Aracaju (SE), 2001.

Causa Básica

\begin{tabular}{cccc}
$\begin{array}{c}\text { DO-ORIGINAL } \\
\text { A }\end{array}$ & \multicolumn{2}{c}{ NOVA-DO } \\
\hline$n^{0}$ & $\%$ & $n^{\circ}$ & $\%$
\end{tabular}

D. Infecciosas e Parasitárias

Neoplasias

D. Sangue

D. Endócrinas

Transtornos Mentais

D. Sistema Nervoso

D. Ouvido

D. Ap. Circulatório

D. Ap. Respiratório

D. Ap. Digestivo

D. Osteomuscular

D. Ap. Geniturinário

Gravidez, Parto ou Puerpério

Malformações Congênitas

Mal Definidas

C. Externas

TOTAL

a: excluídos oito casos sem DO-ORIGINAL.

\begin{tabular}{rrrrr}
6 & 3,1 & 6 & 3,1 & 1,00 \\
55 & 28,1 & 56 & 28,6 & 1,02 \\
4 & 2,0 & 4 & 2,0 & 1,00 \\
7 & 3,6 & 8 & 4,1 & 1,14 \\
2 & 1,0 & 2 & 1,0 & 1,00 \\
6 & 3,1 & 4 & 2,0 & 0,67 \\
1 & 0,5 & 1 & 0,5 & 1,00 \\
44 & 22,4 & 45 & 23,0 & 1,02 \\
9 & 4,6 & 9 & 4,6 & 1,00 \\
6 & 3,1 & 6 & 3,1 & 1,00 \\
5 & 2,6 & 5 & 2,6 & 1,00 \\
4 & 2,0 & 4 & 2,0 & 1,00 \\
3 & 1,5 & 3 & 1,5 & 1,00 \\
1 & 0,5 & 1 & 0,5 & 1,00 \\
14 & 7,1 & 13 & 6,6 & 0,93 \\
29 & 14,8 & 29 & 14,8 & 1,00 \\
196 & 100,0 & 196 & 100,0 & 1,00 \\
\hline
\end{tabular}

\subsubsection{Análise da concordância da causa básica de óbito}

Nesta etapa será analisada a concordância entre a DO-ORIGINAL e o PADRÃO-OURO (177 casos), posteriormente o percentual de concordância entre a DO-ORIGINAL e a NOVA-DO e o PADRÃO-OURO e, por fim, serão analisados os casos comuns às fases dois e três ( 83 casos).

Dos 177 casos analisados (em um caso não foi localizada a DO-ORIGINAL), observou-se uma concordância crescente à medida que se agregaram mais as causas, o que é esperado:

Concordância de subcategorias de 4 caracteres: $38,6 \%$

- Concordância de categorias de 3 caracteres: $46,6 \%$ 
- Concordância de capítulos: $72,7 \%$

Estudo recente, de óbitos hospitalares por causas não violentas em pacientes do sexo masculino em Aracaju, em 2001, mostrou concordância segundo capítulo de $69,2 \%$ e de categorias igual a $53,4 \%$, isto é, valores bem próximos aos encontrados neste estudo (MENESES 2003).

Quanto à concordância das causas de óbito, observou-se aumento dos óbitos nos capítulos dos transtornos mentais $(1,1 \%$ para $2,8 \%$ ), da gravidez, parto $\mathrm{e}$ puerpério $(1,1 \%$ para $4,0 \%)$, das doenças do ouvido $(0,6 \%$ para $1,1 \%$ ), e das doenças do aparelho geniturinário $(2,3 \%$ para $4,0 \%)$, e diminuição dos capítulos das mal formações $(0,6 \%$ para $0,0 \%)$, das mal definidas $(6,8 \%$ para $2,3 \%)$ e das doenças do sangue $(1,7 \%$ para $0,6 \%)$, conforme Tabela 28 . Neste tipo de análise não houve modificações importantes nos capítulos de maior freqüência.

Tabela 28. Distribuição ( ${ }^{\circ}$ e \%) segundo causa básica na DO-ORIGINAL e causa básica observada no PADRÃO-OURO e relação entre os capítulos. Aracaju (SE), 2001 ${ }^{\mathrm{a}}$.

\begin{tabular}{|c|c|c|c|c|c|}
\hline \multirow[t]{2}{*}{ Causa Básica } & \multicolumn{2}{|c|}{$\begin{array}{l}\text { DO-ORIGINAL } \\
\text { (A) }\end{array}$} & \multicolumn{2}{|c|}{$\begin{array}{l}\text { PADRÃO OURO } \\
\text { (B) }\end{array}$} & \multirow[t]{2}{*}{$\mathrm{B} / \mathrm{A}$} \\
\hline & $\mathrm{N}$ & $\%$ & $\mathrm{~N}$ & $\%$ & \\
\hline D. Infecciosas e Parasitárias & 5 & 2,8 & 5 & 2,8 & $\overline{1,0}$ \\
\hline Neoplasias & 50 & 28,4 & 50 & 28,4 & 1,0 \\
\hline D. Sangue & 3 & 1,7 & 1 & 0,6 & 0,3 \\
\hline D. Endócrinas & 7 & 4,0 & 6 & 3,4 & 1,0 \\
\hline Transtornos Mentais & 2 & 1,1 & 5 & 2,8 & 2,5 \\
\hline D. Sistema Nervoso & 5 & 2,8 & 2 & 1,1 & 0,4 \\
\hline D. Ouvido & 1 & 0,6 & 2 & 1,1 & 2,0 \\
\hline D. Ap. Circulatório & 40 & 22,7 & 41 & 23,3 & 1,0 \\
\hline D. Ap. Respiratório & 6 & 3,4 & 5 & 2,8 & 1,0 \\
\hline D. Ap. Digestivo & 5 & 2,8 & 7 & 4,0 & 1,4 \\
\hline D. Osteomuscular & 5 & 2,8 & 5 & 2,8 & 1,0 \\
\hline D. Ap. Geniturinário & 4 & 2,3 & 7 & 4,0 & 1,8 \\
\hline Gravidez, Parto ou Puerpério & 2 & 1,1 & 7 & 4,0 & 2,3 \\
\hline Malformações Congênitas & 1 & 0,6 & - & - & $I^{B}$ \\
\hline Mal Definidas & 12 & 6,8 & 4 & 2,3 & 0,3 \\
\hline C. Externas & 28 & 15,9 & 29 & 16,5 & 1,0 \\
\hline Total & 176 & 100,0 & 176 & 100,0 & 1,0 \\
\hline
\end{tabular}


Quanto à sensibilidade (Tabelas 29 e 30), esta variou entre 20,0 e $100,0 \%$. Os casos em que a opinião do investigador (PADRÃO-OURO) e o documento original, na análise por capítulos, apresentaram maior concordância, isto é, pelos maiores valores de sensibilidade, ocorreram para os capítulos das neoplasias $(92,0 \%)$, causas externas $(93,1 \%)$ e doenças do sangue $(100,0 \%)$. Os menores valores foram referentes aos capitulos das doenças do aparelho respiratório $(20,0 \%)$, das maternas $(28,6 \%)$, das doenças infecciosas e parasitárias juntamente com os transtornos mentais e comportamentais (ambas com 40,0\%).

Tabela 29. Distribuição ( $\mathrm{n}^{\circ}$ e \%) segundo capítulos da DO-ORIGINAL e do PADRÃO-OURO. Aracaju (SE), $2001^{\mathrm{a}}$.

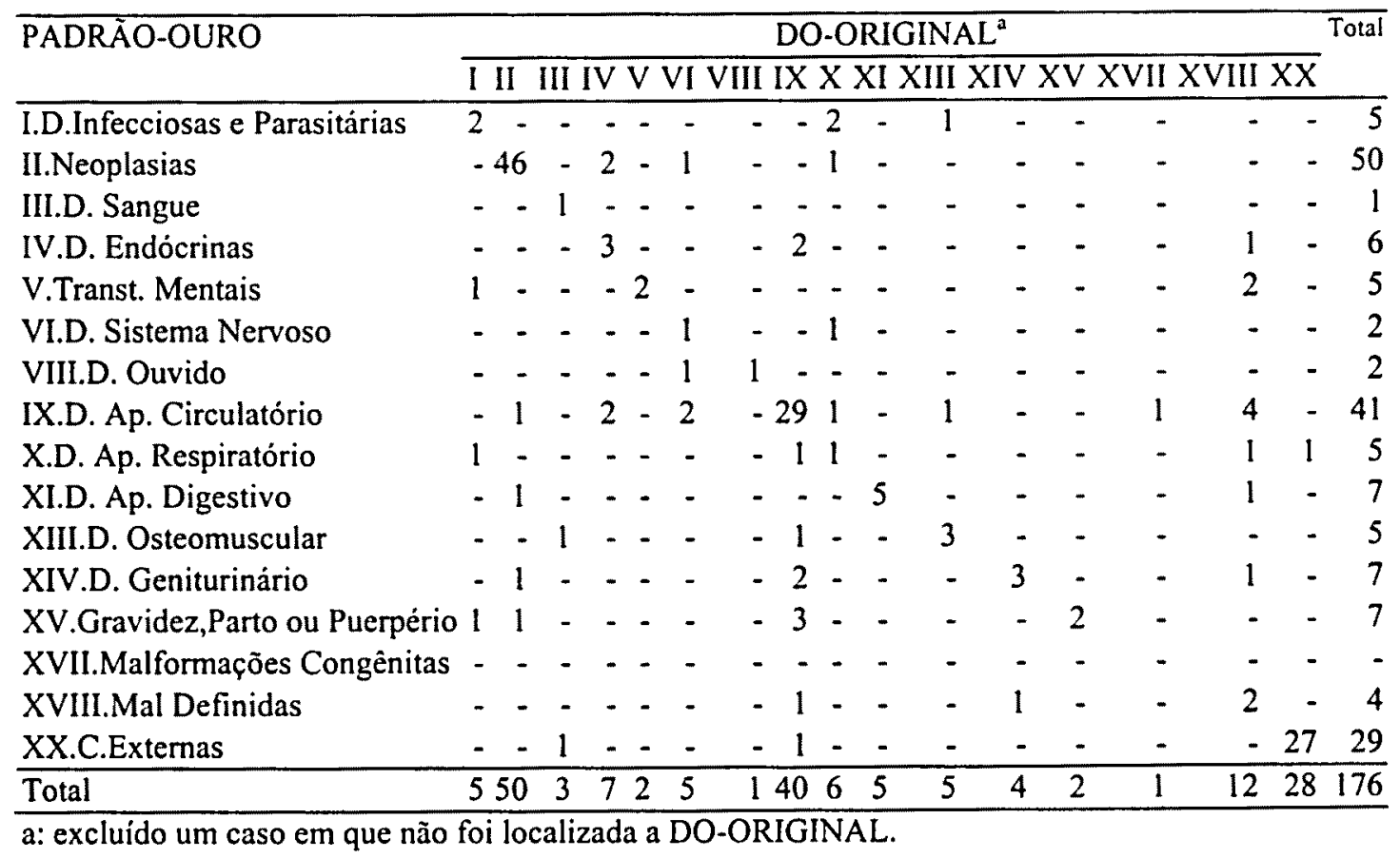

Observa-se que o valor de Kappa apresentou concordância fraca em cinco capitulos, em oito capitulos, a concordância foi considerada intermediária, e em três, foi considerada excelente, o que reflete uma baixa concordância entre o PADRÃOOURO e a DO-ORIGINAL (Tabela 31 ).

No caso dos capítulos das doenças do aparelho respiratório e das doenças mal definidas, os valores de Kappa foram dos mais baixos (15,6\% e $22,4 \%$ ), sendo os mais altos referentes aos capitulos das neoplasias $(88,8 \%)$ e o das causas externas 
(93,7\%) Quanto ao capitulo referente à gravidez, parto e puerpério o valor de Kappa foi $43,4 \%$, mais elevado do que ao obtido por RIBEIRO (1999), que analisou óbitos maternos segundo duas fontes de informação para mortes maternas no Município de São Paulo obtendo valores de 6\%, em 1994, e 33\%, em 1995.

Tabela 30. Teste de Sensibilidade e estatística Kappa segundo capítulos na DOORIGINAL e no PADRÃO-OURO . Aracaju (SE), 2001.

\begin{tabular}{lrr}
\hline Causa Básica & Sensibilidade & Kappa \% \\
\hline D. Infecciosas e Parasitárias & 40,0 & 38,2 \\
Neoplasias & 92,0 & 88,8 \\
D. Sangue & 100,0 & 49,6 \\
D. Endócrinas & 50,0 & 44,1 \\
Transtornos Mentais & 40,0 & 56,4 \\
D. Sistema Nervoso & 50,0 & 27,4 \\
D. Ouvido & 50,0 & 66,4 \\
D. Ap. Circulatório & 70,7 & 63,1 \\
D. Ap. Respiratório & 20,0 & 15,6 \\
D. Ap. Digestivo & 71,4 & 82,8 \\
D. Osteomuscular & 60,0 & 58,8 \\
D. Ap. Geniturinário & 42,9 & 53,2 \\
Gravidez, Parto ou Puerpério & 28,6 & 43,4 \\
Malformações Congênitas & - & - \\
Mal Definidas & 50,0 & 22,4 \\
C. Externas & 93,1 & 93,7 \\
\hline a: & &
\end{tabular}

a: excluído um caso em que não foi localizada a DO-ORIGINAL.

Quanto à posição, segundo capítulos, não houve modificação no tocante às três primeiras causas de morte, entretanto, as doenças do aparelho digestivo que ocupavam o $9^{\circ}$ posto passaram para $04^{\circ}$ posto, as doenças do aparelho geniturinário do $11^{\circ}$ para $\circ 5^{\circ}$ posto e as causas maternas do $14^{\circ}$ para o $6^{\circ}$ posto (Tabela 31 ). Este resultado é semelhante aos obtidos por LAURENTI et. al (1990a) e por SIQUEIRA et. al (1999). Após a construção do atestado refeito, as três primeiras causas não tiveram alteração de posição. No entanto, nos estudos citados, o $4^{\circ}$ posto foi ocupado pelas doenças infecciosas e as causas maternas passaram do $8^{\circ}$ para o $5^{\circ}$ posto. Possivelmente, tais diferenças sejam devidas ao fato de que estes estudos referiramse aos anos de 1986 e 1989, ambos conduzidos no Município de São Paulo. 
Tabela 31. Posição do capitulo na DO-ORIGINAL e no PADRÃO-OURO ${ }^{a}$. Aracaju (SE), 2001.

Causa Básica

DO-ORIGINAL PADRÃO-OURO

\begin{tabular}{|c|c|c|c|c|}
\hline & $n^{\circ}$ & Posição & $\mathrm{n}^{\circ}$ & Posição \\
\hline D. Infecciosas e Parasitárias & 5 & $7^{\circ}$ & 5 & $9^{\circ}$ \\
\hline Neoplasias & 50 & $1^{\circ}$ & 50 & $1^{\circ}$ \\
\hline D. Sangue & 3 & $12^{\circ}$ & 1 & $15^{\circ}$ \\
\hline D. Endócrinas & 7 & $5^{\circ}$ & 6 & $7^{\circ}$ \\
\hline Transtornos Mentais & 2 & $13^{\circ}$ & 5 & $11^{\circ}$ \\
\hline D. Sistema Nervoso & 5 & $8^{\circ}$ & 2 & $13^{\circ}$ \\
\hline D. Ouvido & 1 & $15^{\circ}$ & 2 & $14^{\circ}$ \\
\hline D. Ap. Circulatório & 40 & $2^{\circ}$ & 41 & $2^{\circ}$ \\
\hline D. Ap. Respiratório & 6 & $6^{\circ}$ & 5 & $8^{\circ}$ \\
\hline D. Ap. Digestivo & 5 & $9^{\circ}$ & 7 & $4^{\circ}$ \\
\hline D. Osteomuscular & 5 & $10^{\circ}$ & 5 & $10^{\circ}$ \\
\hline D. Ap. Geniturinário & 4 & $11^{\circ}$ & 7 & $5^{\circ}$ \\
\hline Gravidez, Parto ou Puerpério & 2 & $14^{\circ}$ & 7 & $6^{\circ}$ \\
\hline Malformações Congênitas & 1 & $16^{\circ}$ & - & $16^{\circ}$ \\
\hline Mal Definidas & 12 & $4^{\circ}$ & 4 & $12^{\circ}$ \\
\hline C. Externas & 28 & $3^{\circ}$ & 29 & $3^{\circ}$ \\
\hline
\end{tabular}

a: excluído um caso em que não foi localizada a DO-ORIGINAL.

No presente trabalho, as causas mal definidas passaram do $4^{\circ}$ posto para o $12^{\circ}$ posto. Estudos realizados recentemente, utilizando metodologia similar à utilizada na fase de inquérito também foi verificada queda importante das causas mal-definidas. BAGGIO (2002) na Regional de Marilia observou que foi possivel tornar $68,2 \%$ das causas mal definidas em bem definidas e OLIVEIRA (2002), em municipios do Mato Grosso, observou melhora da informação em $64,5 \%$ do total de casos analisados. No presente estudo $66,7 \%$ dos casos do capítulo das doenças mal definidas passaram para outros capítulos. Resultados similares também foram obtidos por MELLO JORGE et. al (2002a), em um estudo que envolveu 15 municípios brasileiros, inclusive Aracaju, onde se obteve 71,0\% de melhora do diagnóstico das causas mal definidas. Ainda que o presente estudo seja restrito aos óbitos de mulheres em idade fértil, o mesmo também aponta que o uso de metodologia simples pode contribuir para a melhora da qualidade da informação sobre mortalidade.

Quanto à análise da concordância das causas, entre a DO-ORIGINAL e a NOVA-DO e o PADRÃO-OURO não foram observadas diferenças significantes 
entre as duas primeiras. Vale ressaltar que a metodologia utilizada para a construção da NOVA-DO não se mostrou satisfatória, conforme discutido anteriormente. O que se conclui é que, no tocante às causas de óbito, pouco foi esclarecido com a construção da NOVA-DO, sendo, portanto, o PADRÃO-OURO, a melhor ferramenta. Na Tabela 32 observa-se que a diferença da concordância entre a DOORIGINAL e a NOVA-DO assume valores muito próximos, em relação ao PADRÃO-OURO, o que vale dizer que, praticamente, não foram observadas modificações nos grupos de causas na fase em que se construiu a NOVA-DO.

Tabela 32. Concordância da causa básica na DO-ORIGINAL, na NOVA-DO com o PADRÃO-OURO. Aracaju (SE), 2001.

\begin{tabular}{lccc}
\hline Concordância & $\begin{array}{c}\text { DO-ORIGINAL } \\
\text { (A) }\end{array}$ & $\begin{array}{c}\text { NOVA-DO } \\
\text { (B) }\end{array}$ & $\begin{array}{c}\text { Diferença } \\
\text { (A-B) }\end{array}$ \\
\hline Subcategorias de 4 caracteres & 34,1 & 32,9 & 1,2 \\
Categorias de 3 caracteres & 42,4 & 41,2 & 1,2 \\
Capitulos & 72,9 & 72,9 & - \\
\hline
\end{tabular}

Finalmente, com o objetivo de comparar os resultados das duas fases, foram selecionados apenas os casos de óbitos de mulheres em idade fértil em que foi possível resgatar a informação em ambas as fases e que tinham como característica serem residentes no município. Foram então analisados 83 casos comuns: observouse que a diferença obtida entre a NOVA-DO e a DO-ORIGINAL, foi muito pequena, conforme referido anteriormente. Não foram observadas mudanças nas posições das causas entre a DO-ORIGINAL e a NOVA-DO. No entanto, quando são analisadas as mudanças entre a DO-ORIGINAL e o PADRÃO-OURO, observa-se que os principais capítulos de causas de óbito (neoplasias, doenças do aparelho circulatório e as causas externas) não mudaram de posto, e em doze capítulos houve mudança de posto.

Destacaram-se as mortes maternas (do $10^{\circ}$ para o $4^{\circ}$ posto), os transtornos mentais (do $12^{\circ}$ para o $9^{\circ}$ posto) e as doenças do aparelho geniturinário (do $13^{\circ}$ para o $10^{\circ}$ posto). Entre os que perderam posição destacaram-se as doenças do aparelho respiratório (do $6^{\circ}$ para o $11^{\circ}$ posto), as doenças sangue (do $9^{\circ}$ para o $15^{\circ}$ posto), e as 
doenças do sistema nervoso (do $5^{\circ}$ para o $8^{\circ}$ posto). Observa-se (Tabela 33 ) que na análise destes 83 casos, o maior ganho foi nas causas maternas (200,0\%) e no capitulo dos transtornos mentais e doenças do aparelho geniturinário (ambos de $100 \%)$.

Tabela 33. Distribuição $\left(\mathrm{n}^{\circ} \mathrm{e} \%\right.$ ) dos óbitos em mulheres em idade fértil segundo causa básica na DO-ORIGINAL, na NOVA-DO e no PADRÃO-OURO. Aracaju (SE), 2001.

\begin{tabular}{|c|c|c|c|c|c|c|c|c|}
\hline \multirow[t]{2}{*}{ Causa Básica } & \multicolumn{2}{|c|}{$\begin{array}{l}\text { DO-ORIGINAL } \\
\text { (A) }\end{array}$} & \multicolumn{2}{|c|}{$\begin{array}{l}\text { NOVA-DO } \\
\text { (B) }\end{array}$} & \multicolumn{2}{|c|}{$\begin{array}{l}\text { PADRÃO } \\
\text { OURO (C) }\end{array}$} & \multirow[t]{2}{*}{$\mathrm{C} / \mathrm{A}$} & \multirow[t]{2}{*}{$\mathrm{C} / \mathrm{B}$} \\
\hline & $\mathrm{N}^{\circ}$ & $\%$ & $\mathrm{~N}^{\circ}$ & $\%$ & $\mathrm{~N}^{\mathrm{o}}$ & $\%$ & & \\
\hline D. Infecciosas e Parasitárias & - & - & - & - & 1 & 1,2 & $\mathrm{I}^{\mathrm{a}}$ & $\mathrm{I}^{\mathrm{a}}$ \\
\hline Neoplasias & 25 & 30,1 & 26 & 31,3 & 25 & 30,1 & 1,0 & 1,0 \\
\hline D.Sangue & 2 & 2,4 & 2 & 2,4 & - & - & - & - \\
\hline D. Endócrinas & 4 & 4,8 & 5 & 6,0 & 4 & 4,8 & 1,0 & 0,8 \\
\hline Transtornos Mentais & 1 & 1,2 & 1 & 1,2 & 2 & 2,4 & 2,0 & 2,0 \\
\hline D. Sistema Nervoso & 3 & 3,6 & 2 & 2,4 & 2 & 2,4 & 0,7 & 1,0 \\
\hline D. Ouvido & - & - & - & - & 1 & 1,2 & $\mathrm{I}^{\mathrm{a}}$ & $\mathrm{I}^{\mathrm{a}}$ \\
\hline D. Ap. Circulatório & 23 & 27,7 & 23 & 27,7 & 21 & 25,3 & 0,9 & 0,9 \\
\hline D. Ap. Respiratório & 3 & 3,6 & 3 & 3,6 & 1 & 1,2 & 0,3 & 0,3 \\
\hline D. Ap. Digestivo & 3 & 3,6 & 3 & 3,6 & 3 & 3,6 & 1,0 & 1,0 \\
\hline D. Osteomuscular & 3 & 3,6 & 3 & 3,6 & 4 & 4,8 & 1,3 & 1,3 \\
\hline D. Ap. Geniturinário & 1 & 1,2 & 1 & 1,2 & 2 & 2,4 & 2,0 & 2,0 \\
\hline Gravidez, Parto ou Puerpério & 2 & 2,4 & 2 & 2,4 & 6 & 7,2 & 3,0 & 3,0 \\
\hline Malformações Congênitas & 1 & 1,2 & 1 & 1,2 & - & - & - & - \\
\hline Mal Definidas & 2 & 2,4 & 1 & 1,2 & 1 & 1,2 & 0,5 & 1,0 \\
\hline C. Externas & 10 & 12,0 & 10 & 12,0 & 10 & 12,0 & 1,0 & 1,0 \\
\hline Total & 83 & 100,0 & 83 & 100,0 & 83 & 100,0 & 1,0 & 1,0 \\
\hline
\end{tabular}

a: valor indefinido.

\subsubsection{Perfil epidemiológico dos óbitos de mulheres em idade fértil}

Quanto ao município de ocorrência, dos 177 casos em que foi possivel a construção do PADRÃO-OURO, 175 se deram em Aracaju e os dois restantes em outros municipios de Sergipe, ambos por causa externa. Quanto ao local de ocorrência, $81,9 \%$ foram hospitalares e $9,6 \%$ domiciliares. Dentre os óbitos domiciliares, em 6 casos a causa básica foi neoplasia, apontando que o domicilio 
pode ter sido o local de escolha da paciente ou dos seus familiares para a ocorrência da morte (Tabela 34).

Tabela 34. Distribuição dos óbitos de mulheres em idade fértil segundo local de ocorrência $\left(n^{\circ}\right.$ e \%). Aracaju (SE), 2001.

\begin{tabular}{lrr}
\hline Local & $\mathrm{N}^{\circ}$ & $\%$ \\
\hline Hospital & 145 & 81,9 \\
Domicilio & 17 & 9,6 \\
Via Pública & 9 & 5,1 \\
Outros & 6 & 3,4 \\
\hline Total & 177 & 100,0 \\
\hline
\end{tabular}

A distribuição segundo idade mostrou que a média foi 35,6 anos e a mediana foi de 38,0 anos (Tabela 35). A maior concentração de óbitos em idades mais avançadas, como é esperado, também foi encontrado por outros estudos (ALBUQUERQUE et. al 1997, FAÚNDES et. al 2000).

Tabela 35. Número, \% e \% acumulado dos óbitos de mulheres em idade fértil segundo faixa etária. Aracaju (SE), 2001.

\begin{tabular}{lrrr}
\hline Faixa etária & $N^{\circ}$ & $\%$ & $\%$ Acumulado \\
\hline 10 a 14 & 4 & 2,3 & 2,3 \\
15 a 19 & 15 & 8,5 & 10,7 \\
20 a 24 & 11 & 6,2 & 16,9 \\
25 a 29 & 17 & 9,6 & 26,6 \\
30 a 34 & 17 & 9,6 & 36,2 \\
35 a 39 & 35 & 19,8 & 55,9 \\
40 a 44 & 40 & 22,5 & 78,4 \\
45 a 49 & 38 & 21,5 & 100,0 \\
\hline Total & 177 & 100,0 & - \\
\hline
\end{tabular}

As causa de morte mais freqüentes (Tabela 36$)$ foram as neoplasias $(28,8 \%)$, as doenças do aparelho circulatório $(23,2 \%)$ e as causas externas $(16,4 \%)$. Quando se analisam estes grupos de causas, observa-se que entre as neoplasias destacaram-se as 
de mama, de genital feminino e do aparelho digestivo. A relação entre as neoplasias de mama e de colo de útero foi de 1,8 .

A segunda causa de morte foi representada pelas doenças do aparelho circulatório $(23,2 \%)$. Prevaleceram as DCV $(43,9 \%)$, seguidas das DIC e da hipertensão arterial (HA) (ambas com 14,6\%). A relação entre as DCV e as DIC foi de 3,3, apontando que havia deficiências no manejo dos pacientes hipertensos, especialmente por se tratar de um grupo etário relativamente jovem.

Quanto à terceira causa de óbito, estas foram representadas pelas causas externas $(16,4 \%)$, Sobressaíram-se como os tipos mais importantes: as agressões $(41,4 \%)$ e os acidentes de transporte $(34,5 \%)$. Das agressões, chamaram a atenção os ferimentos por arma de fogo (66,7\% dos casos de agressões). Entre eles, em dois casos em que a mulher foi vitima de bala perdida, sendo que uma estava no seu local de trabalho. MELLO JORGE et. al (2002b) verificaram para o conjunto das capitais brasileiras que entre as mulheres em idade fértil a principal causa de morte também foram as agressões, seguidas dos acidentes de trânsito, tendo sido observado o mesmo padrão na região Nordeste.

Quanto aos acidentes de transporte destacaram-se os atropelamentos (seis casos), e um destes referia-se a atropelamento de ciclista. Cabe lembrar, que pelo relevo pouco ondulado do Municipio, aliado às condições sócio econômicas, o modo de transporte "bicicleta" é muito utilizado, e ao mesmo tempo a carência de vias de transporte adequadas, levam a este tipo de acidente.

Chamou a atenção, o fato das neoplasias serem a primeira causa de morte e não as doenças do aparelho circulatório, uma vez que diversos estudos utilizando metodologia semelhante observaram que as doenças do aparelho circulatório foram a primeira causa de morte (MELLO JORGE et. al 2002a; LAURENTI et. al 1990a; SIQUEIRA et. al 1999). Este resultado foi coincidente com os obtidos dois estudos recentes (TANAKA e MITSUIKI 1999; LAURENTI et. al 2003): o primeiro realizado em 15 municípios e o segundo nas capitais de 25 estados e no Distrito Federal. Uma hipótese explicativa seria o fato de ter havido 18 perdas, em que não se obtiveram informações adicionais, e como se trabalhou com um pequeno número de casos, estas perdas poderiam causar impacto no perfil de mortalidade observado, ou 
ainda os resultados estariam apontando uma nova tendência da mortalidade neste grupo.

Tabela 36. Distribuição do número de óbitos de mulheres em idade fértil segundo causa e idade. Aracaju (SE), 2001.

\begin{tabular}{|c|c|c|c|c|c|c|c|c|c|}
\hline \multirow[t]{2}{*}{ Causa Básica } & \multirow{2}{*}{\multicolumn{8}{|c|}{ Idade }} & \multirow{2}{*}{ Total } \\
\hline & $\overline{10 \mathrm{a}_{14}}$ & & a 24 & a 29 & & 5 a39 & & & \\
\hline D.Infecciosas e Parasitárias & 1 & - & 1 & - & 1 & 1 & - & 1 & 5 \\
\hline Neoplasias & - & 1 & 2 & 3 & 6 & 7 & 14 & 18 & 5 \\
\hline D. Sangue & - & 1 & - & - & - & - & - & - & \\
\hline D. Endócrinas & - & - & - & 1 & . & - & 1 & 4 & \\
\hline Transtornos Mentais & - & - & - & 1 & 1 & 1 & 2 & - & \\
\hline D. Sistema Nervoso & - & - & - & 1 & . & - & - & 1 & 2 \\
\hline D. Ouvido & - & 2 & - & - & 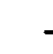 & - & - & - & 2 \\
\hline D. Ap. Circulatório & - & 3 & - & 4 & 2 & 12 & 11 & 9 & 4 \\
\hline D. Ap. Respiratório & - & 2 & 1 & - & 1 & - & - & 1 & 5 \\
\hline D. Ap. Digestivo & - & - & - & - & 1 & 3 & 2 & 1 & 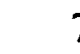 \\
\hline D. Osteomuscular & 1 & 2 & - & - & - & 2 & - & - & 5 \\
\hline D. Ap. Geniturinário & - & 1 & - & - & - & 2 & 4 & - & th \\
\hline Gravidez, Parto ou Puerpério & - & - & - & 3 & 1 & 3 & - & - & 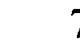 \\
\hline Mal Definidas & . & - & 1 & - & 1 & - & 1 & 1 & 4 \\
\hline C Externas & 2 & 3 & 6 & 4 & 3 & 4 & 5 & 2 & 29 \\
\hline Total & 4 & 15 & 11 & 17 & 17 & 35 & 40 & 38 & 177 \\
\hline
\end{tabular}

Quanto à distribuição dos óbitos segundo idade e as principais causas de morte, observou-se que existiu um padrão de causas por faixa etária (Tabela 37). Entre as menores de 20 anos destacaram-se as doenças infecciosas, as doenças do sangue, as doenças do ouvido e do sistema osteomuscular. Entre as mulheres com 35 anos e mais, destacaram-se, as doenças endócrinas e metabólicas, e as doenças do aparelho circulatório e digestivo. Por outro lado, as causas externas e as neoplasias estiveram presentes em todas as faixas etárias, sendo esta última, mais freqüente nas idades mais avançadas. 
Tabela 37. Distribuição acumulada dos óbitos de mulheres em idade fértil segundo causa e idade. Aracaju (SE), 2001.

\begin{tabular}{lrrrrrrrrr}
\hline Causa Básica & \multicolumn{7}{c}{ Idade } \\
\cline { 2 - 9 } & $10 \mathrm{a} 14$ & $15 \mathrm{a} 19$ & $20 \mathrm{a} 24$ & $25 \mathrm{a} 29$ & $30 \mathrm{~A} 34$ & 35 a 39 & 40 a 44 & 45 a 49 \\
\hline D.Infecciosas e Parasitárias & 20,0 & 20,0 & 40,0 & 40,0 & 60,0 & 80,0 & 80,0 & 100,0 \\
Neoplasias & - & 2,0 & 5,9 & 11,8 & 23,5 & 37,3 & 64,7 & 100,0 \\
D. Sangue & - & 100,0 & 100,0 & 100,0 & 100,0 & 100,0 & 100,0 & 100,0 \\
Endócrinas & - & - & - & 16,7 & 16,7 & 16,7 & 33,3 & 100,0 \\
Transtornos Mentais & - & - & - & 20,0 & 40,0 & 60,0 & 100,0 & 100,0 \\
D. Sistema Nervoso & - & - & - & 50,0 & 50,0 & 50,0 & 50,0 & 100,0 \\
D. Ouvido & - & - & 100,0 & 100,0 & 100,0 & 100,0 & 100,0 & 100,0 & 100,0 \\
D. Ap. Circulatório & - & 7,3 & 7,3 & 17,1 & 22,0 & 51,2 & 78,0 & 100,0 \\
D. Ap. Respiratório & - & 40,0 & 60,0 & 60,0 & 80,0 & 80,0 & 80,0 & 100,0 \\
D. Ap. Digestivo & - & - & - & - & 14,3 & 57,1 & 85,7 & 100,0 \\
D. Osteomuscular & 20,0 & 60,0 & 60,0 & 60,0 & 60,0 & 100,0 & 100,0 & 100,0 \\
D. Ap. Geniturinário & - & 14,3 & 14,3 & 14,3 & 14,3 & 42,9 & 100,0 & 100,0 \\
Gravidez, Parto ou Puerpério & - & - & - & 42,9 & 57,1 & 100,0 & 100,0 & 100,0 \\
Mal Definidas & - & - & 25,0 & 25,0 & 50,0 & 50,0 & 75,0 & 100,0 \\
C. Externas & 6,9 & 17,2 & 37,9 & 51,7 & 62,1 & 75,9 & 93,1 & 100,0 \\
\hline Total & 2,3 & 10,7 & 16,9 & 26,6 & 36,2 & 55,9 & 78,5 & 100,0 \\
\hline
\end{tabular}

O coeficiente de mortalidade foi de 103,8 óbitos por cem mil mulheres na idade fértil, podendo ser considerado como valor mínimo, pois conforme referido, houve 26 perdas. Segundo idade, os coeficientes foram crescentes, variando de 17,1 por cem mil mulheres de 10 a 14 anos a 272,8 por cem mil mulheres de 40 a 49 anos (Figura 9). Este gradiente crescente do coeficiente foi descrito por outros estudos (LAURENTI et. al 1990a; ALBUQUERQUE et. al 1997; HADDAD e SILVA 2000).

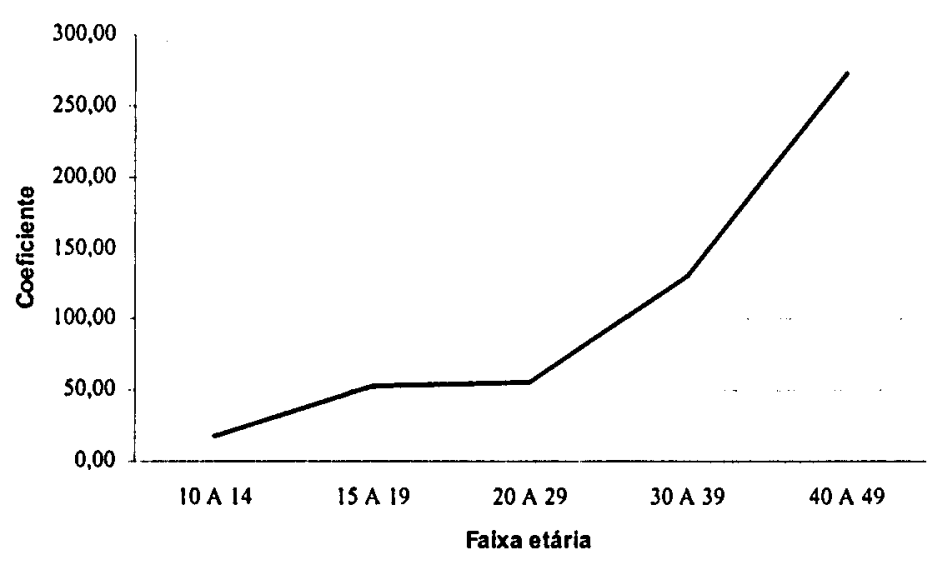

Figura 9. Coeficiente de mortalidade por cem mil mulheres em idade fértil segundo idade. Aracaju (SE), 2001. 


\subsection{Análise dos óbitos ocorridos durante o ciclo gravídico-puerperal em $2001^{6}$}

Os resultados a seguir serão apresentados da seguinte maneira: primeiramente será mostrado o ganho quantitativo, o ganho qualitativo e, em seguida, os resultados obtidos com a soma das metodologias no tocante à concordância sobre a presença de gravidez até um ano antes do óbito e a causa básica, bem como as características epidemiolỏgicas dos casos.

\subsubsection{Ganho quantitativo da informação}

A partir dos casos em que foi possível elaborar o PADRÃO-OURO foram selecionados aqueles cuja causa básica se referisse à morte materna ou que havia a informação sobre a presença de gravidez até um ano antes do óbito tendo sido selecionados nove casos.

Após a elaboração do PADRÃO-OURO verificou-se que destes nove casos sete foram confirmados $\mathrm{e}$ dois foram excluídos, pois embora houvesse preenchimento da variável presença de gravidez no momento do óbito no documento original, este fato não foi constatado nas fontes consultadas. Além disto, mais quatro casos foram identificados com presença de gravidez até um ano antes do óbito. Portanto, somavam 11 casos.

Retomando a lista de casos em que foi possível elaborar o PADRÃO-OURO, e utilizando os SIS foram resgatados os casos em que havia a presença de gravidez até um ano antes do óbito. O SINASC contribuiu com quatro casos, o SIH com dois casos, o SIM (óbitos fetais e infantis) com um caso, e as planilhas do SIAB informaram um caso. Eliminando-se as duplicidades, os SIS contribuíram com seis casos. Destes, em três já havia informação no documento original (e confirmados pela elaboração do PADRÃO-OURO), em um foi resgatada a informação sobre presença de gravidez a partir do PADRÃO-OURO (não foi resgatada a DO-

\footnotetext{
${ }^{6}$ Inclusive no puerpério tardio.
} 
ORIGINAL), e, em dois casos foi resgatada a informação apenas pelos SIS (NOVADO).

Portanto, somados os casos que informavam a presença de gravidez até um ano antes do óbito e após a eliminação de duplicidades, totalizaram 13 casos válidos.

Destes 13 casos, somente em sete havia alguma informação na DOORIGINAL sobre a presença de gravidez até um ano antes do óbito, sendo que em três a causa era materna. Portanto, considerando o ganho quantitativo, ou seja, a recuperação da informação sobre a presença de gravidez até um ano antes do óbito, representou $46,2 \%$.

Cabe lembrar que a metodologia para a construção da lista única seguida da elaboração do PADRÃO-OURO possibilitou a captação de um caso de óbito relacionado ao ciclo gravidico-puerperal, em que, após várias tentativas o documento não foi recuperado, o que correspondeu a $7,7 \%$ dos casos. Além disto, a elaboração do PADRÃO-OURO permitiu excluir um caso presente na lista única que se referia a óbito materno de não residente, cuja DO-ORIGINAL estava erroneamente preenchida como residente em Aracaju. 


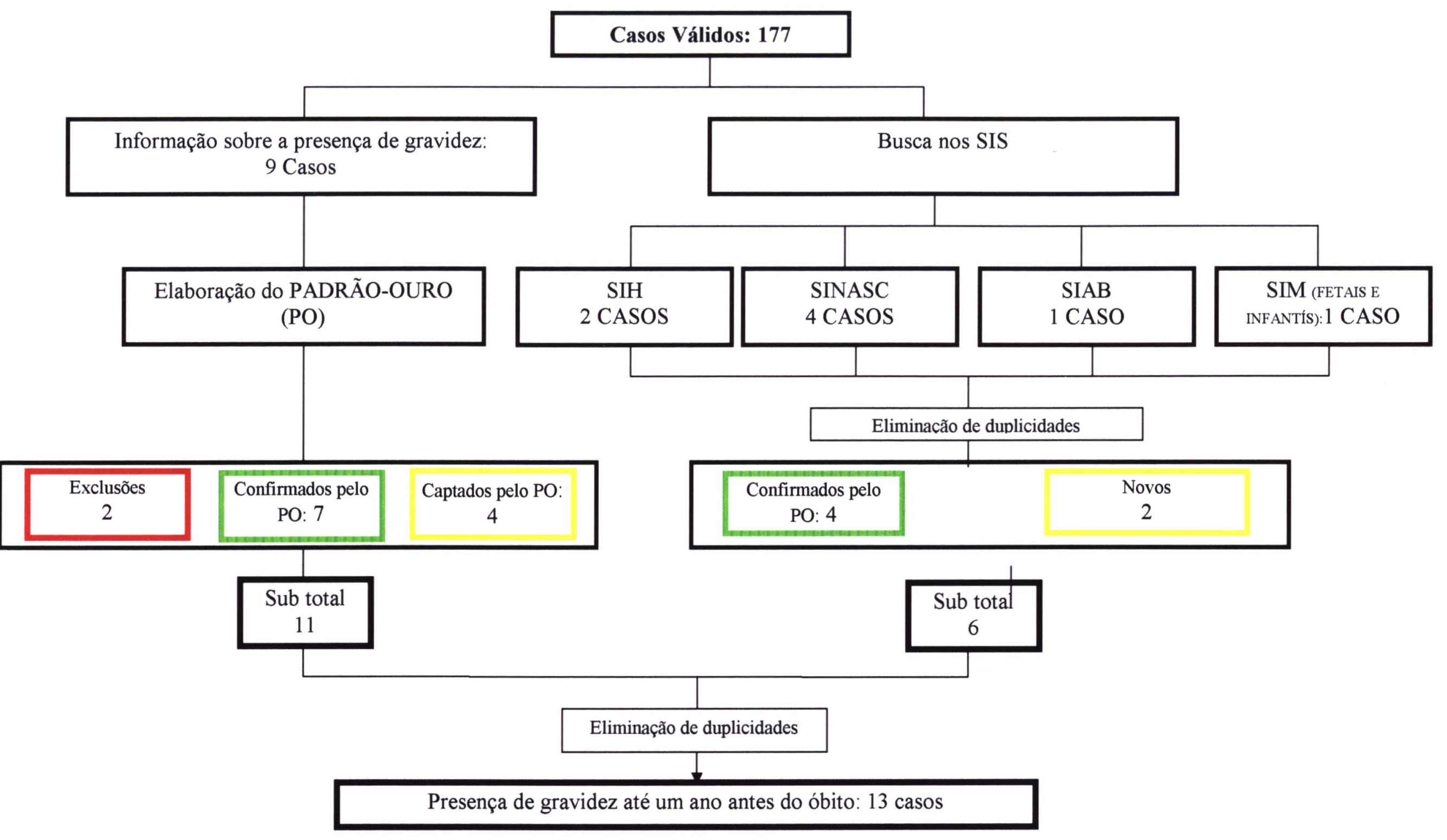

Figura 10. Casos de mulheres em idade fértil com resgate informação de gravidez, parto ou puerpério até um ano antes do óbito, segundo fonte da informação. Aracaju (SE), 2001. 


\subsubsection{Ganho qualitativo da informação}

Observou-se a informação de presença de gravidez até um ano antes do óbito em 13 casos, sendo que quatro ocorreram durante a gravidez, cinco no puerpério e quatro no puerpério tardio (Tabela 38). Dos seis casos em que houve resgate da informação, dois foram captados apenas pelo PADRÃO-OURO e dois apenas pela NOVA-DO e dois pelas duas técnicas.

Tabela 38. Momento do óbito em mulheres no ciclo gravídico-puerperal ${ }^{a}$ segundo causa de morte no PADRÃO-OURO. Aracaju (SE), 2001.

\begin{tabular}{|c|c|c|c|c|}
\hline \multirow[t]{2}{*}{ Causa Básica } & \multicolumn{3}{|c|}{ Momento do Óbito } & \multirow[t]{2}{*}{ Total } \\
\hline & Grávida & $\begin{array}{l}\text { Até } 42 \text { dias após o } \\
\text { término da gravidez }\end{array}$ & $\begin{array}{l}\text { De } 43 \text { a } 364 \text { dias completos } \\
\text { após o término da gravidez }\end{array}$ & \\
\hline Neoplasias & - & - & 3 & 3 \\
\hline D. Ap. Circulatório & - & - & 1 & 1 \\
\hline D. Ap. Respiratório & 1 & - & - & 1 \\
\hline Gravidez,Parto ou Puerpério & 2 & 5 & - & 7 \\
\hline C. Externas & 1 & - & - & 1 \\
\hline Total & 4 & 5 & 4 & 13 \\
\hline
\end{tabular}

a: Até um ano após o término da gestação.

Conforme referido, em sete casos havia menção no SIM da presença de gravidez, parto ou puerpério (Tabela 39) sendo três enquanto causa básica e em quatro estavam preenchidos os campos 43 ou 44 ou a parte 2 do atestado. Dos seis casos em que não havia menção no SIM, em dois deles a informação foi proveniente apenas do PADRÃO-OURO (um óbito em grávida e outro um no periodo puerperal), isto significa que as informações constavam dos prontuários das pacientes, e que no preenchimento da DO foram omitidas. Os dois casos derivados apenas dos SIS ocorreram no período puerperal tardio. Houve um caso captado pelos SIS e pelo PADRÃO-OURO cujo óbito ocorreu no período puerperal tardio. Houve finalmente um caso que não foi possível resgatar a DO, tratava-se de um caso de óbito não materno, ocorrido no período puerperal tardio. 
Tabela 39. Informação sobre a presença de gravidez, parto ou puerpério na DOORIGINAL segundo causa da morte no PADRÃO-OURO. Aracaju (SE), 2001.

\begin{tabular}{lcccr}
\hline Causa Básica & \multicolumn{2}{c}{ Informação na DO-ORIGINAL } & Total \\
\cline { 2 - 5 } & \multicolumn{2}{c}{ Presente } & Ausente & \\
\cline { 2 - 5 } & $\begin{array}{r}\text { Causa } \\
\text { Básica }\end{array}$ & $\begin{array}{r}\text { Outro } \\
\text { Local }^{\mathbf{a}}\end{array}$ & & \\
\hline Neoplasias & - & - & 3 & 3 \\
D. Ap. Circulatório & - & - & 1 & 1 \\
D. Ap. Respiratório & - & - & 1 & 1 \\
Gravidez, Parto ou Puerpério & 3 & 3 & 1 & 7 \\
C. Externas & - & 1 & 6 & 13 \\
\hline Total & 3 & 4 & & \\
\hline
\end{tabular}

a: Campos 43, ou 44, ou Parte 2.

Quanto à contribuição dos SIS (Figura 11): foram identificados seis casos com informação de gravidez, parto ou puerpério até um ano antes do óbito. As fontes de informação foram: o SINASC (quatro casos), o SIH (dois casos), o SIM (um caso de óbito fetal) e o SIAB (um caso). Destes, a fonte em dois foram o SINASC e o SIH, em dois o SINASC, em um, o SIM e em outro o SIAB.

Após a eliminação de duplicidades com os sete casos presentes na DO-ORIGINAL, houve captação de mais três casos referentes ao período puerperal tardio, o que representa um aumento de $42,9 \%$, considerando apenas os casos previamente informados pelo SIM.

JOCUMS et. al (1995), utilizando linkage com declarações de nascidos vivos e de óbitos fetais, verificaram que de 32 mortes observadas, apenas em 15 delas a fonte foi o atestado de óbito $(53,1 \%)$ e as restantes foram identificadas a partir dos bancos de dados de nascidos vivos e óbitos fetais, e confirmadas por investigação.

Dos seis casos em que houve o resgate da informação a partir do uso dos SIS, apenas um deles tratava-se de causa materna, e após a elaboração do PADRÃO-OURO três foram classificados como maternos (Tabela 40). 
Tabela 40. Informação sobre a presença de gravidez, parto ou puerpério na DOORIGINAL segundo causa da morte no PADRÃO-OURO dos casos resgatados pelos SIS. Aracaju (SE), 2001.

\begin{tabular}{|c|c|c|c|c|c|}
\hline \multirow[t]{2}{*}{ PADRÃO-OURO } & \multicolumn{4}{|c|}{ DO-ORIGINAL } & Total \\
\hline & 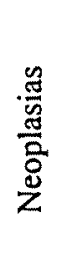 & 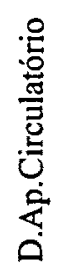 & 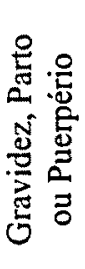 & 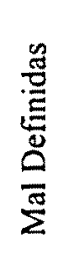 & \\
\hline Neoplasias & 2 & - & - & - & 2 \\
\hline D. Ap. Circulatório & - & - & - & 1 & 1 \\
\hline Gravidez, Parto ou Puerpério & - & 2 & 1 & & 3 \\
\hline Total & 2 & 2 & 1 & 1 & 6 \\
\hline
\end{tabular}

Quanto a contribuição do PADRÂO-OURO houve a inclusão de mais quatro casos, e confirmação de sete, o que representa um aumento de $57,1 \%$, considerando apenas os sete casos previamente informados pelo SIM. Dos quatro casos resgatados, um em gestante e outro, no puerpério, e dois no puerpério tardio. Finalmente, quanto às causas, em um destes quatro casos a causa passou a ser materna. Cabe lembrar, que em um caso não havia DO. 


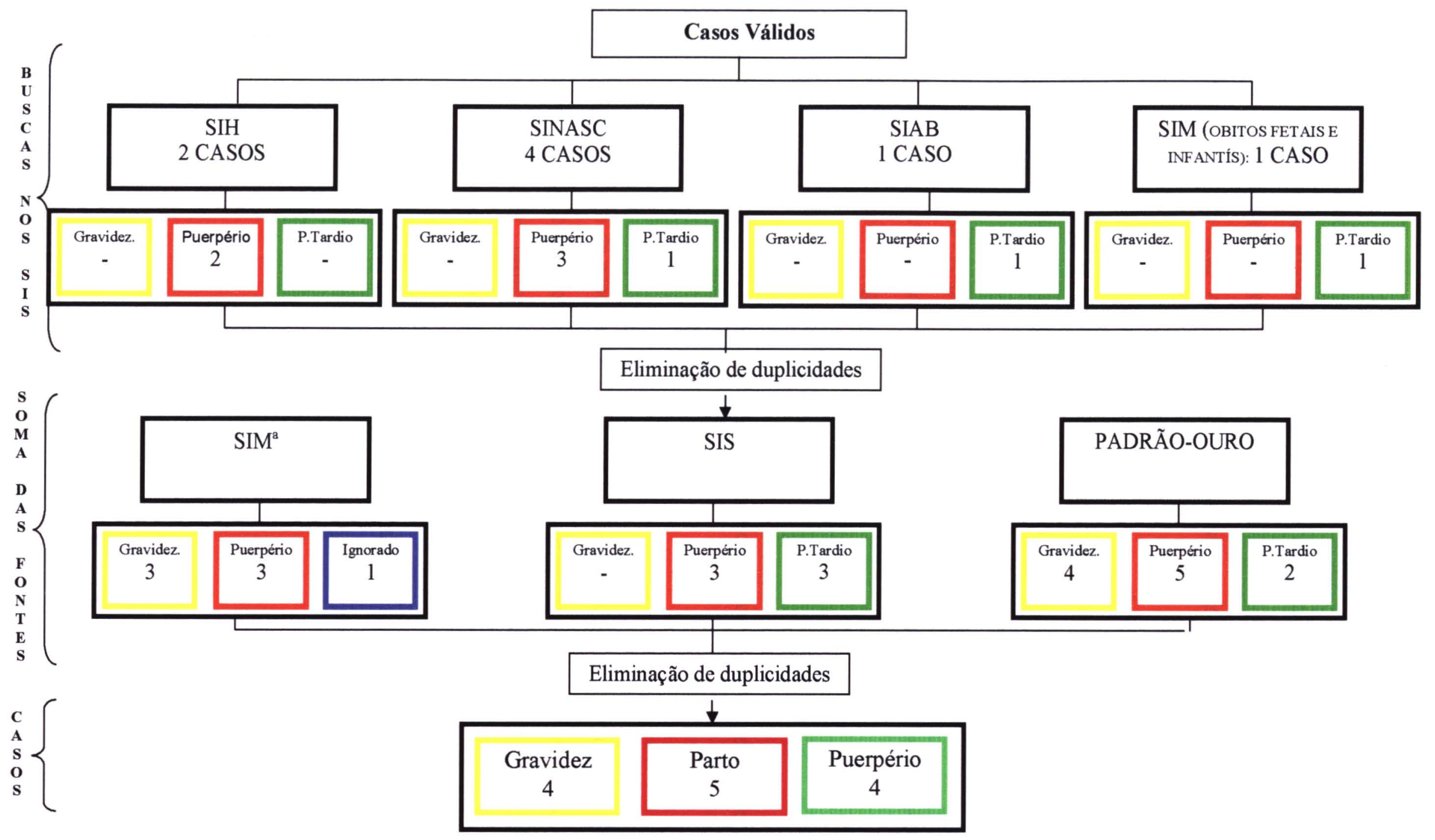

Figura 11. Casos de óbitos de mulheres de 10 a 49 anos até um ano após o término da gravidez, segundo fonte e momento do óbito. Aracaju (SE), 2001

a: informação presente em qualquer parte da DO (causa ou campos 43 ou 44). 
Pode-se observar que os SIS se mostraram como ferramenta sensivel para detectar a presença da gravidez até um ano antes do óbito. Entretanto, os casos devem ser analisados através do uso de outras metodologias, como a busca em fontes alternativas, para que seja verificado o nexo causal entre o óbito e uma causa materna.

Quanto ao aumento da captação de casos, observa-se que as duas metodologias mostraram-se satisfatórias, sendo que o uso dos SIS mostrou-se mais sensivel para captar casos no período puerperal tardio, enquanto o PADRÃO-OURO durante a gravidez e o puerpério. Entretanto, o melhor resultado foi obtido a partir da soma dos casos da NOVA-DO e do PADRÃO-OURO, o que correspondeu a um ganho de $85,7 \%$ de casos (isto é, de mais seis casos somados aos sete casos válidos observados no documento original).

\subsubsection{Análise da concordância dos óbitos relacionados à gravidez, ao parto e ao puerpério}

Para o conjunto de casos válidos em que havia a presença da gravidez até um ano antes do óbito, comparou-se a distribuição quanto ao momento do óbito $\mathrm{e}$ segundo causa básica, utilizando o PADRÃO-OURO, a NOVA-DO e a DOORIGINAL, segundo a concordância entre elas.

Dos 13 casos observados, o grau de concordância entre a informação sobre presença de gravidez, parto ou puerpério (inclusive até um ano antes do óbito) foi $30,0 \%$ menor na DO-ORIGINAL e $10,0 \%$ menor NOVA-DO em relação ao PADRÃO-OURO (Tabela 41). 
Tabela 41. Concordância da informação presença de gravidez, parto ou puerpério na DO-ORIGINAL, na NOVA-DO com o PADRÃO-OURO. Aracaju (SE), 2001.

\begin{tabular}{|c|c|c|c|c|c|c|c|c|}
\hline \multirow[t]{2}{*}{ Presença da informação } & \multicolumn{2}{|c|}{$\begin{array}{l}\text { DO-ORIGINAL } \\
\text { (A) }\end{array}$} & \multicolumn{2}{|c|}{$\begin{array}{l}\text { NOVA-DO } \\
\text { (B) }\end{array}$} & \multicolumn{2}{|c|}{$\begin{array}{l}\text { PADRÃO-OURO } \\
\text { (C) }\end{array}$} & \multirow[t]{2}{*}{$\mathrm{C} / \mathrm{A}$} & \multirow[t]{2}{*}{$\mathrm{C} / \mathrm{B}$} \\
\hline & $n^{\circ}$ & $\%$ & $\mathrm{n}^{\circ}$ & $\%$ & $n^{\circ}$ & $\%$ & & \\
\hline$\overline{\mathrm{Sim}}$ & 7 & 58,3 & 10 & 76,9 & 11 & 84,6 & 1,6 & 1,1 \\
\hline Grávida & 3 & 25,0 & 2 & 15,4 & 4 & 30,8 & 1,3 & 2,0 \\
\hline Até 42 dias & 4 & 33,3 & 4 & 30,8 & 5 & 38,5 & 1,3 & 1,3 \\
\hline De 43 a 364 dias & - & - & 4 & 30,8 & 2 & 15,4 & $\mathrm{l}^{\mathrm{b}}$ & 0,5 \\
\hline Não & 5 & 41,7 & 3 & 23,1 & 2 & 15,4 & 0,4 & 0,7 \\
\hline Total & 12 & 100,0 & 13 & 100,0 & 13 & 100,0 & 1,1 & 1,0 \\
\hline
\end{tabular}

a: informada em qualquer campo da DO.

b: valor indefinido.

Observou-se que os SIS informaram a presença de gravidez até um ano antes do óbito num valor inferior ao PADRÃO-OURO. Do ponto de vista da concordância da causa básica houve um aumento das causas relacionadas à presença de gravidez até um ano antes do óbito quando se considera a DO-ORIGINAL ou a NOVA-DO em relação ao PADRÃO-OURO (Tabela 42).

Tabela 42. $\quad N^{\circ}$ de óbitos segundo causa básica na DO-ORIGINAL, na NOVA-DO e no PADRÃO-OURO, entre mulheres que estiveram grávidas até um ano antes do óbito e razão entre eles. Aracaju (SE), 2001.

\begin{tabular}{lcccrr}
\hline Causa Básica & $\begin{array}{c}\text { DO-ORIGINAL } \\
\text { (A) }\end{array}$ & $\begin{array}{c}\text { NOVA-DO } \\
\text { (B) }\end{array}$ & PADRÃO OURO (C) & C/A & C/B \\
\hline Neoplasias & 3 & 3 & 3 & 1,0 & 1,0 \\
D. Ap. Circulatório & 3 & 3 & 1 & 0,3 & 0,3 \\
D. Ap. Respiratório & - & - & 1 & $\mathrm{I}^{\mathrm{b}}$ & $\mathrm{I}^{\mathrm{b}}$ \\
Gravidez, Parto ou Puerpério & 3 & 3 & 7 & 2,3 & 2,3 \\
Mal Definidas & 1 & 3 & - & - & - \\
C. Externas & 2 & 1 & 1 & 0,5 & 1,0 \\
\hline Total & 12 & 13 & 13 & 1,1 & 1,0 \\
\hline
\end{tabular}

a: excluído um caso em que a DO-ORIGINAL não foi localizada.

b: valor indefinido.

No tocante às causas de morte, houve aumento das causas matemas $(230,0 \%)$ e diminuição das causas do aparelho circulatório (70,0\%). A subinformação sobre os óbitos maternos foi de $57,1 \%$ (três casos na DO-ORIGINAL para sete casos pós- 
investigação). Este resultado é similar ao obtido por MELLO JORGE et. al (2002a), no estudo que envolveu 11 municípios brasileiros, em que a subinformação foi de $63,5 \%$. A relação obtida pelos autores entre a existência de morte por causa materna e presença de gravidez nos últimos doze meses, e que antecedeu o óbito, foi $68,8 \%$, valor superior ao encontrado neste estudo.

Dos casos analisados, observou-se apenas 50,0\% de concordância segundo capitulos da DO, inferior à encontrada quando foram analisados todos os casos de morte de mulheres em idade fértil $(72,6 \%)$, o que sugere que nos casos em que o óbito envolve a presença de gravidez, as DOs são mais mal preenchidas que nos demais óbitos (Tabela 43). Dos seis casos em que houve concordância entre os capitulos, em quatro deles também houve concordância nas subcategorias de três algarismos, e em dois deles, houve concordância quanto às categorias de quatro algarismos.

Tabela 43. Distribuição dos óbitos com resgate da informação sobre gravidez, parto ou puerpério (inclusive tardio) segundo causas na DO-ORIGINAL e no PADRÃO-OURO ${ }^{a}$. Aracaju (SE), 2001.

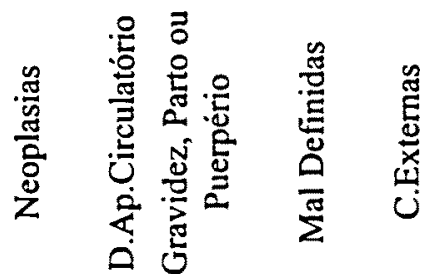

\begin{tabular}{lcccccr}
\hline Neoplasias & 2 & - & - & - & - & 2 \\
D. Ap. Circulatório & - & - & - & 1 & - & 1 \\
D. Ap. Respiratório & - & - & - & - & 1 & 1 \\
Gravidez, Parto ou Puerpério & 1 & 3 & 3 & - & & 7 \\
C. Externas & - & - & - & - & 1 & 1 \\
\hline Total & 3 & 3 & 3 & 1 & 2 & 12 \\
\hline
\end{tabular}

a: excluído um caso em que não se obteve a DO-ORIGINAL. 


\subsubsection{Perfil epidemiológico das mortes durante o ciclo gravídico- puerperal $^{7}$}

Dos óbitos relacionados ao ciclo gravídico-puerperal todos ocorreram em Aracaju. A média de idade foi 31,6 anos e a mediana foi de 30,0 anos, sendo a variação entre 18 e 42 anos (Tabela 44). A maior proporção de óbitos ocorreu entre os 25 e 29 anos (30,8\%). Na faixa de 15 a 19 anos ocorreram $15,4 \%$ dos óbitos, entretanto não foram considerados maternos.

Ainda que este evento seja raro, alguns autores verificaram a presença de óbitos maternos na idade de 10 a 14 anos. No presente estudo tal evento não ocorreu. Entretanto, SOARES et. al (sd) e MELLO JORGE et. al (2002a) obtiveram casos nesta idade, sendo que os óbitos em menores de 20 anos foram respectivamente $17,0 \%$ e $12,8 \%$. No presente estudo não se observou morte materna entre as grávidas menores de 20 anos. Os óbitos ocorreram todos após os 24 anos, sendo que nas faixas dos 25 aos 29 anos e dos 35 aos 39 anos ocorreram 85,8\% dos casos. Evidentemente que como foi observado um número muito pequeno de casos, este valor é sujeito a flutuações.

Tabela 44. Distribuição em $\mathrm{n}^{\circ}$, e \% dos óbitos em mulheres grávidas até um ano antes do óbito segundo causa e idade. Aracaju(SE), 2001.

\begin{tabular}{|c|c|c|c|c|c|c|}
\hline \multirow[t]{3}{*}{ Idade } & \multicolumn{4}{|c|}{ Causa de óbito } & \multicolumn{2}{|c|}{ Total } \\
\hline & \multicolumn{2}{|c|}{ Materna } & \multicolumn{2}{|c|}{ Não materna } & & \\
\hline & $\mathrm{n}^{\mathrm{o}}$ & $\%$ & $\mathrm{n}^{\circ}$ & $\%$ & $\mathrm{n}^{\circ}$ & $\%$ \\
\hline 15 a 19 & - & - & 2 & 33,3 & 2 & 15,4 \\
\hline 20 a 24 & - & - & - & - & - & - \\
\hline 25 a 29 & 3 & 42,9 & 1 & 16,7 & 4 & 30,8 \\
\hline 30 a 34 & 1 & 14,3 & - & - & 1 & 7,7 \\
\hline 35 a 39 & 3 & 42,9 & - & - & 3 & 23,1 \\
\hline 40 a 44 & - & - & 3 & 50,0 & 3 & 23,1 \\
\hline Total & 7 & 100,0 & 6 & 100,0 & 13 & 100,0 \\
\hline
\end{tabular}

\footnotetext{
${ }^{7}$ Inclusive no puerpério tardio.
} 
Considerando o total casos, quanto ao local de ocorrência a maior parte deles $(84,6 \%)$ verificou-se em estabelecimentos de saúde, um no domicílio e outro na via pública. Dentre os óbitos que ocorreram no período puerperal (cinco casos), a morte ocorreu entre um e 41 dias após o término da gravidez, sendo o intervalo de tempo médio 13,2 dias. Entre os que ocorreram entre 43 e 364 dias completos após o término da gravidez (quatro casos), o intervalo de tempo médio foi de 179,7 dias, variando entre 108 e 311 dias. Dos óbitos maternos, dois ocorreram durante a gravidez $(28,6 \%)$, cinco deles ocorreram no período puerperal $(71,4 \%)$, não havendo óbitos no período puerperal tardio. O tempo entre o final da gravidez e o óbito (BERG et. al 2003) foi estimado: 76,5\% dos óbitos ocorreram em até 42 dias, 10,7\% entre 43 dias e 364 completos e apenas $12,9 \%$ dos casos morreram durante a gravidez.

A distribuição espacial dos casos de óbitos maternos revelou que os casos foram provenientes dos seguintes bairros: Centro (1), Santos Dumont (2), Bugio (1), Ponto Novo (1), Farolândia (1) e Santo Antônio (1) todos caracterizados por serem bairros de baixa renda média familiar mensal, isto é, entre duzentos e trinta e quatro reais (Bugio) e oitocentos e cinqüenta reais (Centro), de acordo com dados do último censo (IBGE 2001). Por outro lado, em todos eles existem serviços de saúde prestadores de atenção básica (Figura 12). 


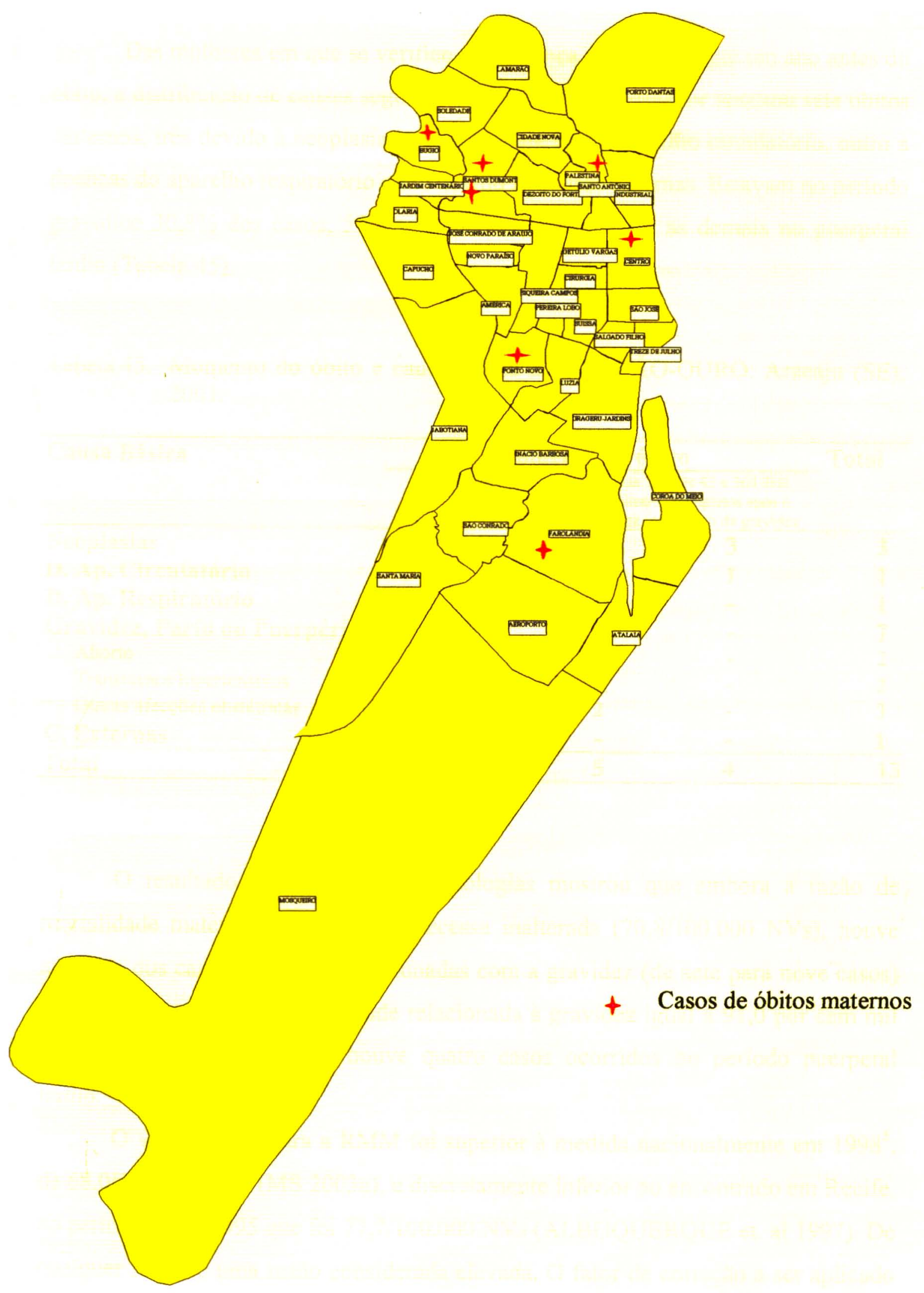

Figura 12 Distribuição dos óbitos maternos segundo bairro de residência. Aracaju (SE), 2001. 
Das mulheres em que se verificou a presença de gravidez até um ano antes do óbito, a distribuição de causas segundo a opinião do investigador apontou sete óbitos maternos, três devido à neoplasias, outro a doenças do aparelho circulatório, outro a doenças do aparelho respiratório e um devido às causas externas. Estavam no periodo gravídico $30,8 \%$ dos casos, $53,8 \%$ no período puerperal e as demais no puerperal tardio (Tabela 45).

Tabela 45. Momento do óbito e causa básica no PADRÃO-OURO. Aracaju (SE), 2001.

\begin{tabular}{|c|c|c|c|c|}
\hline \multirow[t]{2}{*}{ Causa Básica } & \multicolumn{3}{|c|}{ Momento do óbito } & \multirow[t]{2}{*}{ Total } \\
\hline & Grávida & $\begin{array}{l}\text { Até } 42 \text { dias } \\
\text { após o término } \\
\text { da gravidez }\end{array}$ & $\begin{array}{l}\text { De } 43 \text { a } 364 \text { dias } \\
\text { completos após o } \\
\text { término da gravidez }\end{array}$ & \\
\hline Neoplasias & - & - & 3 & 3 \\
\hline D. Ap. Circulatório & - & - & 1 & 1 \\
\hline D. Ap. Respiratório & 1 & - & - & 1 \\
\hline Gravidez, Parto ou Puerpério & 2 & 5 & - & 7 \\
\hline Aborto & 1 & 1 & - & 2 \\
\hline Transtomos hipertensivos & & 2 & - & 2 \\
\hline Outras afeç̧ões obstétricas & 1 & 2 & - & 3 \\
\hline C. Externas & 1 & - & - & 1 \\
\hline Total & 4 & 5 & 4 & 13 \\
\hline
\end{tabular}

O resultado da soma das metodologias mostrou que embora a razão de mortalidade materna (RMM) permanecesse inalterada $(70,8 / 100.000 \mathrm{NVs})$, houve aumento dos casos de mortes relacionadas com a gravidez (de sete para nove casos) o que gerou a razão de mortalidade relacionada à gravidez igual a 91,0 por cem mil nascidos vivos. Além disto, houve quatro casos ocorridos no período puerperal tardio.

O valor obtido para a RMM foi superior à medida nacionalmente em $1998^{8}$, de 68,0/100.000 NVs (MS 2003a), e discretamente inferior ao encontrado em Recife, no período 1994-1995 que foi 77,7/100.000 NVs (ALBUQUERQUE et. al 1997). De qualquer forma é uma razão considerada elevada. $O$ fator de correção a ser aplicado neste ano seria de 2,3, inferior ao preconizado pelo Ministério da Saúde para a região

8 Obtida a partir dos resultados de 10 UFs, situadas nas Regiões Sul, Sudeste e Centro-Oete, cuja cobertura do SIM entre os óbitos femininos de 10 a 49 anos é maior que $90 \%$ (MS, 2000). 
Nordeste (MS 1994c) e ao obtido por MELLO JORGE et. al (2002a) para 11 municipios brasileiros, dentre eles Aracaju cujos resultados apontam para um fator de correção de 2,75. O fato de ter sido observado um fator de correção menor, possivelmente seja devido à magnitude da mortalidade materna nas capitais ser menor que a dos municipios do interior. $O$ valor obtido no presente estudo foi próximo ao obtido por LAURENTI et. al (2003) em estudo recente, que verificaram, entre as capitais da Região Nordeste, que o fator deveria ser 2,05.

Dos óbitos maternos, quatro podem ser consideradas mortes obstétricas diretas (prevaleceram os abortos e os transtornos hipertensivos) e três indiretas, cuja razão é 1,3. Esta relação é inferior à obtida no Paraná (BRAGA et. al 1992) que foi de 5,1 óbitos diretos para cada óbito indireto, mas o MS (2001d) aponta uma tendência de aumento dos óbitos maternos indiretos. Entretanto, em estudo mais recente realizado no Paraná (SOARES et. al sd) os autores obtiveram apenas $26,0 \%$ dos óbitos indiretos valor inferior ao obtido no presente estudo. Quanto às mortes relacionadas com a gravidez, observaram-se 9 casos o que gerou a razão de mortalidade relacionada à gravidez igual a 91,0 por cem mil nascidos vivos, valor idêntico ao obtido no presente estudo.

LAURENTI et. al (1990b) ao analisarem 953 casos de óbitos de mulheres em idade fértil verificaram que em $10,0 \%$ deles a morte ocorreu até um ano após o termino da gestação (96 casos), sendo 56 classificáveis como maternos e 40 como não maternos $(42,1 \%)$. No estudo, os autores discutem a existência de doenças cuja condição poderia piorar ou ser desencadeada pelo estado gestacional. LAURENTI et. al (2003) em pesquisa nas capitais brasileiras, observaram 199 casos em que havia presença de gravidez, sendo que $47,2 \%$ foram mortes maternas. No presente estudo, do total de mulheres grávidas até um ano antes do óbito, 46,7\% trataram-se de mortes maternas.

Cada uma das fases contribuiu para o incremento dos casos, de forma que a metodologia de busca em sistemas de informação pode ser considerada complementar ao inquérito em fontes alternativas, especialmente na detecção de casos onde havia presença de gravidez até um ano antes do óbito.

O uso dos SIS tem potencial de melhorar a qualidade da informação sobre as mortes ocorridas até um ano após o término da gestação, conforme MELLO JORGE 
et. al (2001). A agregação de informações provenientes dos SIS permitiria o melhor conhecimento da magnitude do problema, que somadas às politicas públicas voltadas para as gestantes como o Programa de Humanização no Pré-Natal e Nascimento, recentemente introduzido no nosso meio (2000) possibilitará o melhor enfrentamento da mortalidade materna (BRASIL 2000c).

Cabe ressaltar que em 2002 foi introduzida, no Sistema de Informação do Programa de Humanização no Pré-Natal e Nascimento (SISPRENATAL), uma variável relativa ao tipo de interrupção no PHPN, que incluiu o óbito como uma das classes da variável, que fará deste sistema mais uma fonte de informação dos óbitos em mulheres grávidas, restrita à população dependente do SUS (DATASUS 2002). É fato também que caberá aos municípios a manutenção e o investimento em esforços para que a qualidade dos dados deste novo sistema seja adequada.

A incorporação dos SIS como ferramenta a serviço da saúde pública é um desafio a ser enfrentado pelos municipios do país. Diversas discussões já estão em andamento, especialmente no tocante à retro-alimentação de forma ágil das informações contidas no SIM e no SINASC, para os municípios. Se por um lado a lógica da digitação dos eventos por ocorrência foi uma decisão acertada (BRASIL 2000a e 2000b), no sentido de manter quantitativamente os bancos de dados, falta hoje uma política para que os municípios se apropriem dos bancos de dados referentes aos seus habitantes. O mesmo pensamento é valido no caso do SIH.

A preocupação com a desfragmentação dos SIS, nível municipal, não é temática recente (MORAES et. al 1992). A transformação dos SIS em ferramenta a serviço da saúde pública requer uma integração permanente entre os setores responsáveis pelos distintos sistemas e do desenvolvimento de ferramentas que agilizem o fluxo de informações.

BERG et. al (2003) verificaram que houve aumento da RMM nos Estados Unidos entre 1991 (10,3/100.000 NVs) e 1997 (12,9/100.000 NVs) e atribuem esta melhora da qualidade da informação a dois fatores: a introdução na DO das variáveis que permitem identificar a presença de gravidez entre os óbitos de mulheres em idade fértil e ao uso nacional e sistemático das técnicas de linkage com os bancos de nascidos vivos e óbitos fetais. 
De fato, um dos pontos da nova agenda para a redução dos óbitos maternos é o reforço aos sistemas de vigilância a morbi-mortalidade maternas, sendo necessário o estabelecimento e a execução de mecanismos para fortalecer os sistemas de informação e vigilância para que haja o acompanhamento dos êxitos alcançados na redução das mortes maternas (OPS 2002), portanto, o primeiro passo é, dar visibilidade, para a magnitude do problema.

A mudança do uso das informações, ou seja, do enfoque apenas administrativo ou demográfico para o enfoque epidemiológico (DRUMOND JÚNIOR 2001) implica em mudanças na lógica da produção e disponibilização das informações.

No caso das mortes de mulheres em idade fértil, partem dos comitês (municipais ou estaduais) de mortalidade materna as propostas de novos fluxos de informação e novas rotinas no sentido de utilizar os SIS. Entretanto, caberia à esfera federal centralizar estas propostas e garantir sua implantação. Ainda que nos manuais dos comitês de morte materna (MS 1994c; MS 2001b) sejam sugeridas as buscas nos diferentes SIS, fica a cargo dos municipios ou dos estados a implementação destas medidas.

Os casos provenientes das distintas fontes devem ser o instrumento de análise dos comitês de mortalidade materna, possibilitando verificar as máscaras regionais e um novo conjunto de casos (além das mortes maternas), aqueles que se referem a doenças que embora não diretamente relacionadas com o estado gravídico-puerperal, mas que na sua presença poderiam estar aumentando a mortalidade entre as mulheres. Para tanto, desenhos de estudo analíticos devem ser conduzidos, na tentativa de verificar esta hipótese. 
5. CONSIDERAÇOES FINAIS E CONCLUSÕES 
Foram estudados 4299 óbitos de mulheres em idade fértil de residentes em Aracaju, no período de 1979 a 2001. Observou-se tendência de queda do coeficiente de mortalidade. As principais causas de óbito foram as doenças do aparelho circulatório (sendo que as doenças cérebro-vasculares somadas às doenças isquêmicas do coração representaram $51,1 \%$ destes) as neoplasias (de mama e colo de útero representaram $38,4 \%$ do total) e as causas externas (entre as quais se destacaram os acidentes de transporte seguidos pelos de causa ignorada, com respectivamente $32,8 \%$ e $26,8 \%$ ). Parte dos óbitos deveu-se a patologias evitáveis: como as mortes maternas, as mortes por neoplasia de mama e colo de útero e por doenças cérebro-vasculares.

No tocante às mortes maternas foram observados 192 casos no período. A razão de mortalidade materna apresentou tendência de queda, entretanto, apresentou também muitas flutuações no número anual de casos, o que indica que a qualidade da informação foi insatisfatória (ou seja, uma captação muito irregular de mortes maternas anuais). Na tentativa de corrigir a RMM foram utilizados dois fatores de correção, o que resultou num intervalo de valores máximos e mínimos, dentro do qual estaria a verdadeira RMM. Por exemplo, em 2000-2001 a taxa esteve entre 49,0 e 277,0 óbitos maternos por cem mil nascidos vivos, cuja amplitude é muito grande, o que impede o conhecimento da real magnitude do problema. Entre as causas de morte materna, ocorridas entre 1979 e 2001, destacaram-se os transtomos hipertensivos $(25,0 \%)$ e os abortos $(22,4 \%)$, causas consideradas evitáveis.

A metodologia de busca de informações quantitativas em mais de uma fonte mostrou-se adequada, porém dependente de sistematização e de articulação entre os diversos setores das secretarias de saúde responsáveis pelos distintos Sistemas de Informação. Os 196 casos informados pelo SIM passaram a $216 \mathrm{com}$ a complementação pelas distintas fontes, o que representou um aumento de 10,2\%, entretanto esta contribuição diminuiu para $4,7 \%$ após a elaboração do PADRÃOOURO.

$O$ uso das informações do SIAB deve ser feito de forma muito criteriosa, posto que alguns casos referidos como tal mostraram-se incorretos. Portanto, os casos de óbitos informados, que não forem encontrados no SIM, devem ser devolvidos à unidade de saúde da família que os notificou, para a coleta de 
informações adicionais, tais como: o cemitério em que foi enterrado, o cartório em que foi registrado o óbito, o hospital onde o mesmo ocorreu, antes que sejam incorporados ao sistema.

Por outro lado, em dois casos as informações foram resgatadas pelo SIAB, não tendo sido encontradas as respectivas DOs no SIM. Em um deles, houve possibilidade de retorno à unidade de saúde que emitiu o documento, o resgate do mesmo, e sua inclusão no SIM. Quanto ao outro caso (óbito domiciliar), apesar de várias tentativas, não foram obtidas informações que possibilitassem que $o$ documento fosse resgatado (acredita-se que o mesmo tenha sido emitido).

As informações do SIH mostraram-se adequadas do ponto de vista quantitativo; entretanto, da mesma maneira que foi sugerida a inclusão do número da DN na AIH, no caso dos partos na rede SUS (BRASIL 2002), seria interessante que neste documento também constasse o número da $\mathrm{DO}$, nos casos em que o motivo de saída hospitalar foi o óbito, o que daria mais consistência ao sistema.

Houve um caso em que não foi localizada a DO e o SIH informava que o tipo de saída foi óbito. Como não se obteve êxito em comprovar tal fato, o caso foi excluído da análise, visto que poderia tratar-se de erro no preenchimento do campo da AIH. Por outro lado, foram resgatados sete casos, sendo que em dois deles não foram captados pelo SIM por se tratar de erros na digitação do sexo na DO e os seis restantes por conterem inconsistências no endereço anotado na $\mathrm{DO}$ e na fonte utilizada para a construção do PADRÃO-OURO.

$\mathrm{O}$ inquérito em fontes alternativas, como o que foi utilizado neste estudo, pode também entrar na rotina dos setores responsáveis pelo SIM e, aliado à busca sistemática nos SIS, pode tornar-se uma ferramenta importante tanto para a melhora da causa básica de óbito das MIF, quanto para o esclarecimento das mortes maternas. Em 2001, as patologias mais freqüentes foram as neoplasias $(28,8 \%)$, as doenças do aparelho circulatório $(23,2 \%)$ e as causas externas $(16,4 \%)$. A metodologia para esclarecimento das causas de óbito de MIF utilizando os SIS mostrou-se pouco esclarecedora.

No tocante aos óbitos durante a gravidez ou até um ano após o seu término, o SINASC representou boa fonte para a captação dos casos de óbito ocorridos no 
periodo de 43 a 364 dias após o término da gravidez, devendo ser incorporada uma rotina de resgate da informação neste sistema.

A busca de óbitos fetais e de menores de um ano, no SIM, também possibilitou a coleta de informações adicionas relativas à presença de gravidez até um ano antes do óbito. Cabe lembrar, entretanto, que, tanto no SIM como no SINASC, a busca deve ser realizada no banco de dados correspondente não só ao ano do óbito, mas também no ano anterior. Os casos resgatados utilizando o SIH trataram-se de duplicação (já haviam sido resgatados pelo SINASC). Houve um caso proveniente das planilhas do SIAB. O uso dos SIS como ferramenta auxiliar para detectar casos de gravidez até um ano antes do óbito evidenciou-se bastante adequada. De 7 casos presentes no SIM em que havia este tipo de informação passou-se para 10 casos após a busca nos SIS.

O PADRÃO-OURO mostrou-se também como o método adequado; dos casos para os quais foi possivel estabelecer a causa básica, as mortes maternas aumentaram de três para sete. Além disto, foram observados 11 casos de óbitos entre mulheres que estiveram grávidas até um ano antes do óbito.

Entretanto, é quando se somam os resultados da Fase PADRÃO-OURO da e Fase SIS que se obtém o maior valor: 13 óbitos de mulheres que estiveram grávidas até um ano antes do óbito, sendo sete maternos (RMM de 70,8/100.000 NVs). O resultado deste trabalho aponta que as metodologias utilizadas (uso dos SIS e construção do PADRÃO-OURO) devem ser complementares e nunca excludentes.

Recomenda-se, portanto, o uso combinado das Fases SIS e PADRÃO-OURO. Os SIS melhoraram a quantidade das informações de óbitos de MIF e os relativos à gravidez com baixo custo. $O$ inquérito complementou a Fase SIS e melhorou a qualidade das informações. A metodologia é factível, tornando as informações mais fidedignas. Entretanto, todo este esforço será perdido se não gerar incorporação e correção estatística das DOs e conseqüente aprimoramento do SIM. Portanto, faz-se necessário desenvolver rotinas que sejam utilizadas sistematicamente e adotadas tanto pelos responsáveis pelas investigações dos comitês de morte materna quanto pelos gestores do SIM.

Além disto, os resultados obtidos levam a algumas reflexões: a adoção do conceito de morte materna no periodo puerperal tardio e por seqüelas de causa 
obstétrica direta (OMS 1995), traz uma discussão sobre a necessidade de inclusão de especificações do quarto caráter para os casos codificados como 096 e 097.

Outra questão que não pode ser desconsiderada é que devem ser aprimoradas as estratégias de, continuamente, capacitar médicos e estudantes de medicina para a melhora do preenchimento da DO.

Finalmente, para os casos de óbito de MIF por qualquer causa que não as definidas como maternas, são necessários estudos analíticos que objetivem verificar se a presença da gravidez até um ano antes do óbito, se constitui em fator de risco para a morte. 
REFERÊNCIAS 
Albuquerque RM de, Cecatti JG, Hardy E. Faúndes A. Mortalidade materna em Recife: causas de óbitos. Cad Saúde Pública [periódico on line] 1997; 13(1). Disponivel em <URL:http:/www.scielo.br/> [2001 mar 05]

Allen MH, Chavkin W, Marinoff J. Ascertainment of maternal deaths in New York City. Am J Public Health 1991; 81(3):380-2.

Almeida MF de, Mello Jorge MHP de. O uso da técnica de "Linkage" de sistemas de informações em estudos de coorte sobre mortalidade neonatal. Rev Saúde Pública 1996; 30(2): 141-7.

Baggio MCR. A qualidade da informação de mortalidade em alguns municípios da Regional de Marília-SP: correção de distorções por meio de técnicas simples. São Paulo; 2002. [Tese de Doutorado - Faculdade de Saúde Pública da USP].

Benedetti TJ, Starzyk O, Frost F. Misclafition of maternal deaths in Washington State. Morb Mortal Wkly Rep 1986 35(39): 621-3.

Berg CJ, Chang J, Callagnhan WM, Whiehead SJ. Pregnancy-related mortality in the United States, 1991-1997. Obstetr Gynecol 2003; 101(2):289-296.

Bouvier-Colle MH; Varnoux N; Costes P; Hatton F Reasons for the underreporting of maternal mortality in France, as indicated by a survey of all deaths among women of childbearing age. Int J Epidemiol 1991; 20(3):717-21.

Braga LFCO, Nazareno ER, Fanini ML, Soares VMN, Hireta VM. Relatório do comitê de morte materna do Paraná, 1991. Inf Epidemiol SUS 1992; 1(7):31-49.

Brameld KJ, Holman CD, Bass AJ, Codde JP, Rouse IL Hospitalisation of the elderly during the last year of life: an application of record linkage in Western Australia 1985-1994 J Epidemiol Community Health 1998; 52(11): 740-4.

Brasil. Constituição da República Federativa do Brasil. Brasilia: Senado Federal; 1988.

Brasil. Decreto lei $931410 \mathrm{dez}$ 1997. Dispõe sobre a gratuidade do registro de nascimento e óbito. Diário Oficial da República Federativa do Brasil, Brasília 1997.

Brasil. Portaria n.474, de 31 de agosto de 2000. Regulamenta a coleta de dados, fluxo e periodicidade de envio das informações sobre óbitos para o Sistema de Informações sobre Mortalidade - SIM. Diário Oficial da República Federativa do Brasil. Brasília, 4 set 2000a. Seção 1, p 33.

Brasil. Portaria n.475, de 31 de agosto de 2000. Regulamenta a coleta de dados, fluxo e periodicidade de envio das informações sobre nascidos vivos para o Sistema de Informações sobre Nascidos vivos - SINASC. Diário Oficial da República Federativa do Brasil. Brasília, 4 set 2000b. Seção 1, p 34.

Brasil. Portaria GM n.569, de 08 de junho de 2000. Institui a implantação Programa de Humanização no Pré-Natal e Nascimento - PHPN. Diário Oficial da República Federativa do Brasil. Brasilia, 2000c. Seção I, p 4.

Brasil. Portaria n.938, de 21 de maio de 2002. Regulamenta o incentivo ao registro civil de nascimento. Diário Oficial da República Federativa do Brasil. Brasília, 2002. Seção I , p 24 . 
Carvalho DM. Grandes sistemas nacionais de informação em saúde: revisão e discussão da situação atual. Inf Epidemiol SUS 1997; 4(4): 8-45.

Conselho Nacional de Saúde. Portaria $\mathrm{n}^{\circ} 256$, de $1^{\circ}$ out 1997 . Define o Óbito Materno nos Estados e Municípios, como evento de Notificação Compulsória para a Vigilância Epidemiológica. Brasília; 1997.

[DATASUS] Departamento de Informática do SUS. SISPRENATAL [Programa de computador]. Versão 2.0. Brasília: Ministério da Saúde/DATASUS; 2002.

Dye TD; Gordon H; Held B; Tolliver NJ; Holmes AP Retrospective maternal mortality case ascertainment in West Virginia, 1985 to 1989. Am J Obstet Gynecol 1992; 167(1):72-6,

Drumond Júnior M. Epidemiologia e saúde pública: reflexões sobre os usos da epidemiologia nos serviços do sistema único de saúde em nível municipal. Campinas; 2001. [Tese de Doutorado - Faculdade de Ciências Médicas da UNICAMP].

Escrivão Jr A, Lira MMT de A. PRO-AIM Programa de Aprimoramento das Informações de Mortalidade no município de São Paulo. Saúde Debate 1990; 30:725.

Faúndes A, Parpinelli MA, Cecatti JG. Mortalidade de mulheres em idade fértil em Campinas, São Paulo (1985-1994). Cad Saúde Pública [on line] 2000; 16 (3). Disponível em <URL:http:/www.scielo.br/> [2002 dez 05]

Goldacre MJ. Cause-specific mortality: understanding uncertain tips of the disease iceberg J Epidemiol Community Health 1993; 47(6): 491-6.

Gomes FA. Sistema de informações hospitalares do Sistema Único de Saúde (SIH-SUS): contribuição para o estudo da mortalidade materna no Brasil. Ribeirão Preto; 2002. [Tese de Doutorado - Escola de Enfermagem de Ribeirão Preto da USP].

Gordis L. Assessing the validity and reliability of diagnostic and screening tests. In: Epidemiology. Philadelphia: WB Saunders Company;1996. p.58-76.

Graham W; Brass W; Snow RW Estimating maternal mortality: the sisterhood method. Stud Fam Plann 1989; 20(3):125-35.

Haddad N, Silva MB da. Mortalidade feminina em idade reprodutiva no Estado de São Paulo, Brasil, 1991-1995: causas básicas de óbito e mortalidade materna. Rev Saúde Pública [on line] 2000; 34 (1). Disponivel em <URL:http:/www.scielo.br/> [2002 dez 05]

Hosne WS, Vieira S. Pesquisa médica: a ética e a metodologia. São Paulo: Pioneira; 1998.

[IBGE] Instituto Brasileiro de Geografia e Estatística. Estatísticas de Registro Civil: 1979-2001. Rio de Janeiro, 1981-2003; v.6-v.28.

[IBGE] Instituto Brasileiro de Geografia e Estatística.. Pesquisa nacional por amostra de domicílios: 1998. Fundação IBGE: 2000. Disponível em <URL:http:/www.ibge.gov.br/> [2001 mai 05]. 
[IBGE] Instituto Brasileiro de Geografia e Estatística. Censo demográfico 2000. Características da população e dos domicílios: resultados do universo [CDROOM]. Fundação IBGE: Rio de janeiro, 2001.

Jekel JF, Elmore JG, Katz DL. Entendendo e reduzindo erros em medicina clinica In: Epidemiologia, bioestatística e medicina preventiva. Porto Alegre: Artmed; 1999. p: $99-112$.

Jocums S, Mitchel Jr EF, Entman SS, Piper JM. Monitoring maternal mortality using vital records linkage. Am J Prev Méd 1995; 11 (2):75-8.

Kendrick S, Clarke J. The scottish record linkage system. Health Bull 1993; 51(2):72-9.

Laurenti R, Buchalla CM, Lólio CA, Santo AH, Mello Jorge MHP de. Mortalidade de mulheres em idade fértil no Município de São Paulo (Brasil), 1986. I Metodologia e resultados gerais. Rev Saúde Pública 1990a; 24(2): 128-33.

Laurenti R, Buchalla CM, Lólio CA, Santo AH, Mello Jorge MHP de. Mortalidade de mulheres em idade fértil no Município de São Paulo (Brasil), 1986. II. Mortes por causas maternas. Rev Saúde Pública 1990b; 24(6): 468-72.

Laurenti R, Mello Jorge MHP de, Gotlieb SLD. Reflexões sobre a mensuração da mortalidade materna. Cad Saúde Pública [on line] 2000a; 16 (1). Disponivel em < URL:http:/www.scielo.br/> [2001 mar 05]

Laurenti R, Mello Jorge MHP de, Gotlieb SLD. Mortes maternas no Brasil: análise do preenchimento da variável da declaração de óbito. Inf Epidemiol SUS 2000b; $9(1): 43-50$.

Laurenti R, Mello Jorge MHP de, Gotlieb SLD. Estudo da mortalidade de mulheres de 10 a 49 anos, com ênfase na mortalidade materna. São Paulo; 2003. [Relatório parcial do Projeto de pesquisa Gravidez, Parto e Puerpério - Departamento de Epidemiologia - Faculdade de Saúde Pública da USP].

Lira MMT de, Drumond Júnior M. Anos potenciais de vida perdidos no Brasil em 1980 e 1997. In: FUNASA. Estudos epidemiológicos. Brasília; 2000. p. 9-46.

Lotufo, PA. Mortalidade pela doença cérebro-vascular no Brasil. Rev Bras Hipertensão 2000; 7(4)387-391.

Mathias TA de F, Soboll ML de MS. Confiabilidade de diagnósticos nos formulários da autorização de internação hospitalar. Rev Saúde Pública 1998; 32(6): 526-32.

Mello Jorge MHP de, Gotlieb SLD, Soboll ML de MS, Almeida MF, Latorre MRDO. Avaliação do sistema de informação de nascidos vivos e o uso dos seus dados em epidemiologia e estatísticas de saúde. Rev Saúde Pública 1993; 27 supl: $2-45$.

Mello Jorge MHP de, Gotlieb SLD, Oliveira H. O sistema de informação sobre nascidos vivos: primeira avaliação dos dados brasileiros. Inf Epidemiol SUS 1996, 5 (2): 15-48.

Mello Jorge MHP de, Gotlieb SLD. O sistema de informação de Mortalidade: Problemas e propostas para seu enfrentamento. São Paulo; 1998. [Relatório Cientifico - Faculdade de Saúde Pública da USP]. 
Mello Jorge MHP de, Gotlieb SLD. O sistema de informação da atenção básica como fonte de dados para os sistemas de informações sobre mortalidade e sobre nascidos vivos. Inf Epidemiol SUS 2001; 10 (1): 7-18.

Mello Jorge MHP de, Gotlieb SLD, Laurenti R. A saúde no Brasil: análise do período 1996 a 1999. São Paulo: Parma, 2001.

Mello Jorge MHP de, Gotlieb SLD, Laurenti R. O sistema de informação sobre mortalidade: Problemas e propostas para seu enfrentamento. I- Morte por causas naturais. Rev Bras Epidemiol 2002a; 5(2): 197-211.

Mello Jorge MHP de, Gotlieb SLD, Laurenti R. O sistema de informação sobre mortalidade: Problemas e propostas para seu enfrentamento. II- Morte por causas externas Rev Bras Epidemiol 2002b; 5(2): 212-23.

Meneses DG. Análise das causas de óbito não violentas em adultos jovens do sexo masculino, no município de Aracaju, em 2001. Aracaju, 2003. [Monografia de conclusão de curso de graduação - Departamento de Medicina - Universidade Federal de Sergipe].

Moraes IHM, Eduardo MB de P, Soboll ML de MS. Informação em saúde e gestão democrática. Brasilia; 1992. [9 $9^{\circ}$ Conferência Nacional de Saúde: texto de apoio].

[MS] Ministério da Saúde. Portaria n 663, de 22 de março de 1994. Institui o dia 28 de maio como o Dia Nacional de Redução da Mortalidade Materna. Diário Oficial da União da República Federativa do Brasil. Brasília; 1994a.

[MS] Ministério da Saúde. Portaria n ${ }^{\circ} 773$, de 7.04.94. Cria a Comissão Nacional de Mortalidade Materna, Diário Oficial da União da República Federativa do Brasil. Brasília; $1994 b$.

[MS] Ministério da Saúde. Secretaria de Assistência à Saúde Departamento de Assistência e Promoção à Saúde. Coordenação materno-infantil. Manual dos Comitês de Mortalidade Materna. Brasília; 1994c.

[MS] Ministério da Saúde. Fundação Nacional de Saúde. In: Movimento de autorização hospitalar: arquivos reduzidos 1998. Manual da AIH. [CD-ROM]. DATASUS. Rio de Janeiro; 1998.

[MS] Ministério da Saúde. Fundação Nacional de Saúde. Manual de preenchimento da declaração de nascido vivo. 3 ed. Brasília; 1999a.

[MS] Ministério da Saúde. Fundação Nacional de Saúde. Manual de preenchimento da declaração de óbito. 3 ed. Brasília; $1999 \mathrm{~b}$.

[MS] Ministério da Saúde. Secretaria de Assistência à Saúde. Coordenação de Atenção Básica. Avaliação da implantação e funcionamento do Programa de Saúde da Família - PSF. Relatório preliminar [Monografia on line] Brasília, Nov 1999c. Disponivel em < URL:http:/www.saude.gov.br/> [2001 abr 05]

[MS] Ministério da Saúde. Portaria $n^{\circ} 1399$ de 1999. Regulamenta a NOB SUS 01/96 no que se refere às competências da União, Estados, Municípios e Distrito Federal, na área de epidemiologia e controle de doenças, define a sistemática de financiamento e dá outras providências. Diário Oficial da União da República Federativa do Brasil. Brasília, 15 dez 1999d. 
[MS] Ministério da Saúde. Fundação Nacional de Saúde. Sistema de Informação de mortalidade, 1979-98. [CD-ROM]. Rio de Janeiro: DATASUS; 2000.

[MS] Ministério da Saúde. Fundação Nacional de Saúde. Plano de aprimoramento do Sistema de Informação de mortalidade. Brasilia; 2001a. [Documento preliminar].

[MS] Ministério da Saúde. Secretaria de Políticas de Saúde. Área Técnica de saúde da mulher. Manual dos Comitês de Mortalidade Materna. $2^{a}$ ed. Brasília: Ministério da Saúde; 2001b.

[MS] Ministério da Saúde. Fundação Nacional de Saúde. Importância do Sistema de Informação sobre Mortalidade (SIM) e Nascidos Vivos (SINASC) para os profissionais do programa de saúde da família. Brasilia; $2001 \mathrm{c}$.

[MS] Ministério da Saúde. Secretaria de Políticas de Saúde. Área Técnica de Saúde da Mulher. Mortalidade materna: situação nas capitais. Brasília; 2001d [Relatório técnico].

[MS] Ministério da Saúde. Portaria n 1943 de 18 de outubro de 2001. Regulamenta as doenças de notificação compulsória, em todo o território nacional. Diário Oficial da União da República Federativa do Brasil. Brasília, 24 out 2001 e.

[MS] Ministério da Saúde. Fundação Nacional de Saúde. Banco de dados dos Sistemas de Informação de mortalidade (SIM) e nascidos vivos (SINASC), 19962000. [CD-ROM]. Rio de Janeiro: DATASUS; 2002a.

[MS] Ministério da Saúde Secretaria Executiva.Departamento de Informática do SUS. SINAN WINDOWS: Sistema de Informação de Agravos de Notificação.[programa de computador] Brasília; $2002 \mathrm{~b}$.

[MS] Ministério da Saúde. Rede intergerencial de informações para a saúde. IDB 2000 Brasil: Indicadores e dados básicos para a saúde.Brasília; 2002c.

[MS] Ministério da Saúde. Informações em saúde. DATASUS; 2003a. Disponível em <URL:http:/tabnet.datasus.gov.br/tabnet/tabnet.htm> [2003 jan 05].

[MS] Ministério da Saúde. Portaria $\mathrm{n}^{\circ} 653$ de 28 de maio de 2003b. Regulamente a notificação compulsória dos óbitos maternos. Diário Oficial da União da República Federativa do Brasil. Brasília, 30 mai 2003b.

Nunes A, Santos, JRS, Barata, RB, Viana SM. Medindo as desigualdades em saúde no Brasil: uma proposta de monitoramento. Brasília: Organização Pan-Americana de Saúde/Instituto de Pesquisa Econômica Aplicada; 2001.

Okabe I. Uso da técnica "linkage" e da análise fatorial de correspondência múltipla no estudo de mortalidade infantil. In: Anais do $6^{\circ}$ Congresso Brasileiro de Saúde Coletiva; 2000 ago-set 28-01, Salvador, Brasil. Salvador: ISC; 2000, 1041. [CDROM]

Oliveira LR. Avaliando o Sistema de Informações sobre Mortalidade em Mato Grosso. São Paulo; 2002. [Dissertação de Mestrado - Faculdade de Saúde Pública da USP].

[OMS] Organização Mundial da Saúde. Manual da classificação estatística internacional de doenças, lesões e causas de óbitos: $9^{\mathrm{a}}$ rev. 1975. São Paulo: Centro da OMS para Classificação de Doenças em Português; 1978. 
[OMS] Organização Mundial da Saúde. Classificação estatística internacional de doenças e problemas relacionados à saúde: $10^{2}$ rev. 1995. São Paulo: Centro Colaborador da OMS para Classificação de Doenças em Português. Universidade de São Paulo; 1995.

[OPAS] Organización Pan Americana de la Salud. Organización Mundial de la Salud. 26 Conferencia sanitária Pan americana.Estrategias regional para la reducción de la mortalidad y la morbidad maternas; 2002 set 26-27; Washington, D.C.; 2002.

Puffer RR, Griffth GW. Caracteristicas de la mortalidad urbana. Washington, D.C.: Organizacion Panamericana de la Salud; 1968. (OPAS - Publicación Cientifica, 151)

Ribeiro, AF: Mortalidade materna no Município de São Paulo: análise segundo diferentes fontes, 1994 e 1995. São Paulo; 1999. [Dissertação de Mestrado Faculdade de Saúde Pública da USP].

Rosen G. Uma história da saúde pública. Rio de Janeiro, HUCITEC; 1994.

Salanave B, Bouvier-Colle MH, Varnoux N, Alexander S, Macfarlane A, MOMS Group A. Classification differences and maternal mortality: a European study. Int $\mathbf{J}$ Epidemiol 1999; 28(1):64-9.

Santos JLF dos. Projetor [Programa de computadorl]. São Paulo; 1992.

[SAS] Secretaria de Assistência à Saúde, Coordenação de Saúde da Comunidade. SIAB: manual do sistema de informação de atenção básica. Brasília: Ministério da Saúde; 1998.

[SES] Secretaria de Estado da Saúde de Sergipe. UNICEF. Diagnóstico materno infantil no Estado de Sergipe. Aracaju; 1994.

[SES] Secretaria de Estado da Saúde de Sergipe. Banco de dados dos Sistemas de Informação de mortalidade (SIM) e nascidos vivos (SINASC), 2000-2001. Estado de Sergipe. Aracaju; 2002.

Silva da FS, Sugmyama CY, Oliveira MSM, Petris AJ, Andrade SM de, Oliveira EA et al. Sistemas de Informações:instrumento de planejamento para a redução de desigualdades. In: Silva da FS. A construção do SUS a partir do município. São Paulo: HUCITEC; 1996. p.12-28.

Silva LK, Russomano FB. Sub-registro da mortalidade materna no Rio de Janeiro, Brasil: comparação de dois sistemas de informação. Bol Oficina Sanit Panam 1996; 120(1):36-43.

Siqueira AAF de, Rio EMB, Tanaka AC d'A, Schor N, Alvarenga AT, Almeida LC. Mortalidade feminina na região Sul do Município de São Paulo: qualidade de certificação médica dos óbitos. Rev Saúde Pública 1999; 33(5): 499-04.

Soares FGB, Selonke F, Francisco LF, Felchner BG, Bem RS, Soares MAS. Mortalidade materna: importância do comitê de mortalidade materna, estudo de 66 óbitos maternos no biênio de 1999-2000 na $2^{\mathrm{a}}$ Regional de Saúde do Paraná. Curitiba; sd. [Universidade Federal do Paraná].

Stanton C, Hill K, Abouzhar C, Wardlaw T. Modeling maternal mortality in developing World. WHO/UNICEF, 1995 
Tanaka AC d'A. Maternidade dilema entre nascimento e morte. São Paulo: HUCITEC. Rio de Janeiro: ABRASCO; 1995.

Tanaka AC d'A, Mitsuiki L. Estudo da magnitude da mortalidade materna em 15 cidades brasileiras. [Monografia on line] Brasília, Nov 1999. Disponível em <URL:http:/www.saude.gov.br/> [2001 jan 05]

Tanaka AC d'A, Mitsuiki L. Mortalidade materna em 15 cidades brasileiras. Ciência Saúde Coletiva 2000; 5 supl:324. [Apresentado no $6^{\circ}$ Congresso Brasileiro de Saúde Coletiva: 2000; ago-set 28-01, Salvador, Brasil.]

Theme-Filha MM, Silva RI, Noronha CP. Mortalidade materna no Município do Rio de Janeiro, 1993 a 1996. Cad Saúde Pública [on line]1999; 15 (2). Disponível em <URL:http:/www.scielo.br/> [2002 dez 05]

Vasconcelos AMN. A qualidade das estatísticas de óbitos no Brasil. Rev Bras Estud Popul 1998; 15(1):115-124.

Walker GLA, McCaw AM, Ashley DEC, Bernard GW. Maternal mortality in Jamaica. Lancet 1986; 1:486-488.

[WHO] World Health Organization. Maternal and a perinatal conditions. [on line] 2001a. Avaliable on <URL:http:/www.who.int/inf-new/mate.htm> [2001 mai 05]

[WHO] World Health Organization. Maternal mortality in 1995: estimates developed by WHO, UNICEF, UNFPA. Geneva: WHO; $2001 \mathrm{~b}$. 
ANEXOS 
Anexo 1. Razões

Razão de mortalidade materna:

óbitos maternos (diretos e indiretos) $\times 100.000$

nascidos vivos

Razão de mortalidade materna tardio

óbitos maternos tardios $x 100.000$

nascidos vivos

Razão de mortalidade obstétrica direta

óbitos maternos diretos $\times 100.000$

nascidos vivos

Razão de mortalidade obstétrica indireta

óbitos maternos indiretos $x 100.000$

nascidos vivos

Razão de mortalidade relacionada com a gravidez

óbitos relacionados com a gravidez $\times 100.000$

nascidos vivos

Fonte: OMS 1995. 
Anexo 2. Causas presumiveis de morte materna

\begin{tabular}{|c|c|c|}
\hline Causa & CID 9r & CID $10 \mathrm{r}$ \\
\hline Hemorragia & 459.0 & R58 \\
\hline Insuficiência Hepática Aguda & 570 & $\mathrm{~K} 72.0$ \\
\hline Choque Séptico & 785.5 & A41.9 \\
\hline Septicemia Sepis Ou Sepse & 038.9 & A41.9 \\
\hline Choque Toxêmico & 785.5 & $\mathrm{~A} 48.3$ \\
\hline CIVD & 286.6 & D65 \\
\hline Epilepsia & 345.9 & G40.9 \\
\hline Hipertensão Intracraniana Aguda & 401.9 & G93.2 \\
\hline Insuficiência Cardiaca Por Estenose Mitral & 394.2 & $\mathrm{I} 05.2$ \\
\hline Hipertensão Arterial & 428.9 & $\mathrm{I10}$ \\
\hline Infarto Agudo do Miocárdio & $410 \mathrm{X}$ & $\mathrm{I} 21.9$ \\
\hline Miocardiopatia & 425.4 & 142.9 \\
\hline ICC & 428.0 & 150.0 \\
\hline \begin{tabular}{|l} 
Falência Miocárdica \\
\end{tabular} & 428.9 & I50.9 \\
\hline AVC & 436 & I64 \\
\hline Embolia Pulmonar & 415.1 & I74.9 \\
\hline \begin{tabular}{|l} 
Tromboembolismo \\
\end{tabular} & 444.9 & I74.9 \\
\hline \begin{tabular}{|l|} 
Broncopneumonia \\
\end{tabular} & $485 . \mathrm{X}$ & $\mathrm{J} 18.8$ \\
\hline \begin{tabular}{|l|} 
Pneumonia \\
\end{tabular} & 486 & $\mathrm{~J} 18.9$ \\
\hline \begin{tabular}{|l|} 
Edema Agudo De Pulmão \\
\end{tabular} & 518.4 & $\mathrm{~J} 81$ \\
\hline \begin{tabular}{|l|} 
Pelviperitonite \\
\end{tabular} & 614.5 & K65.0 \\
\hline \begin{tabular}{|l|} 
Peritonite \\
\end{tabular} & 567.9 & K65.0 \\
\hline Insuficiência Renal Aguda & 584.9 & $\mathrm{~N} 17.9$ \\
\hline \begin{tabular}{|l|} 
Endometrite \\
\end{tabular} & 615.9 & $\mathrm{~N} 71.9$ \\
\hline Endomiometrite & 615.9 & N71.9 \\
\hline \begin{tabular}{|l|} 
Insuficiência Cardio-respiratória Falência \\
Respiratória Parada Cardíaca Parada Respiratória \\
Ou Parada Cardio-respiratória \\
\end{tabular} & 799.1 & R09.2 \\
\hline \begin{tabular}{|l} 
Crise Convulsiva \\
\end{tabular} & 780.3 & R56.8 \\
\hline Choque Hipovolêmico & 785.5 & R57.1 \\
\hline \begin{tabular}{|l} 
Choque Endotóxico \\
\end{tabular} & 785.5 & R57.8 \\
\hline \begin{tabular}{|l|} 
Choque Neurogênico \\
\end{tabular} & 785.5 & R57.8 \\
\hline \begin{tabular}{|l|} 
Choque \\
\end{tabular} & 785.5 & R57.9 \\
\hline $\begin{array}{l}\text { Choque Hemorrágico Hemorragia Sangramento } \\
\text { SOE }\end{array}$ & 459.0 & R58.0 \\
\hline Toxemia & 799.8 & R68.8 \\
\hline \begin{tabular}{|l|} 
Sem Assistência Médica \\
\end{tabular} & 798.9 & R98 \\
\hline \begin{tabular}{|l|} 
Causa Desconhecida \\
\end{tabular} & 799.9 & R99 \\
\hline Choque Anafilático & 995.0 & T78.2 \\
\hline Choque Anestésico & 968 & T88.2 \\
\hline
\end{tabular}

Fonte: MINISTÉRIO DA SAÚDE, 2001. 
Anexo 3. Instrumentos de coleta de dados utilizados no inquérito 


\section{F1 - QUANTI}

FORMULÁRIO PARA OBTENÇÃO DE INFORMAÇÕES SOBRE ÓBITOS NÃO

CONSTANTES DO SIM/MS

Para preenchimento em nível central

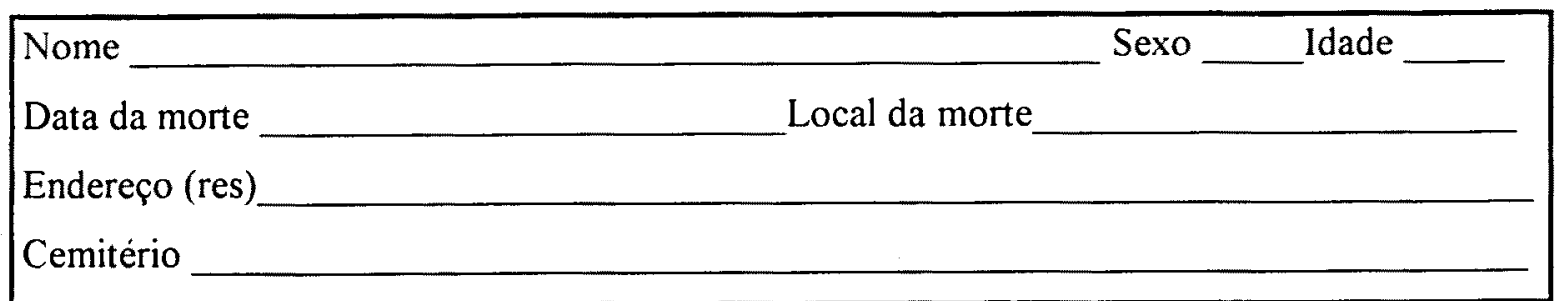

\section{Para o início da entrevista, ver instrutivo}

Para preenchimento em domicílio

Nome
Sexo $\_$Idade $\_$Data de nascimento
Data da morte __ Local da morte
Endereço (res)

- A morte foi registrada no Cartório?

$\operatorname{Sim} \square \quad$ Não $\square \quad$ Ignora $\square$

Se sim, qual? Municipio

Se não, porquê??

Onde foi enterrado?

Se a morte ocorreu no domicílio preencher o formulário F2, conforme o esquema.

Data Entrevistador

\section{CONCLUSÃO}

Encaminhamento: Fazer outro formulário? Sim $\square \quad$ Não

Se sim, qual? 


\section{F2. FORMULÁRIo PARA COLETA dE INFORMAÇÃo SOBRE ÓBITOS EM DOMICÍLIO (para causas mal definidas, residuais dos capítulos e presumíveis)}

Para preenchimento em nivel central

\begin{tabular}{|ll|}
\hline Nome & Sexo __ Idade \\
Data da morte & Local da morte \\
Endereço (res) & \\
Cemitério & \\
\hline
\end{tabular}

\section{Para o início da entrevista, ver instrutivo}

\section{Para preenchimento em domicílio}

\begin{tabular}{|l|}
\hline Nome \\
Sexo $\_$Idade $\_$Data de nascimento \\
Data da morte $\_$Local da morte \\
Endereço (res)
\end{tabular}

Durante o ano que passou (um ano antes da morte), ... foi atendido por médico, hospital ou
Posto de Saúde?
$\operatorname{Sim} \square$
Não $\square$
Ignora $\square$

$\mathrm{Se} \mathrm{Sim}$, preencha o quadro abaixo

\begin{tabular}{|l|l|l|l|l|l|l|}
\hline $\begin{array}{c}\text { Nome do hospital, clínica, } \\
\text { médico, etc. }\end{array}$ & $*$ & Data & $\begin{array}{c}\text { Dias no } \\
\text { hospital }\end{array}$ & Motivo & $* * *$ \\
\hline 1$)$ & & & & & & \\
$2)$ & & & & & \\
\hline 3$)$ & & & & & \\
\hline
\end{tabular}

* Tipo: $\quad \mathbf{M}=$ médico particular, convênio $\mathbf{H}=$ hospital $\mathbf{P S}=$ Posto de Saúde, Centro de Saúde

** Número de consultas

*** Esses atendimentos tinham algo a ver com a doença que levou à morte? $\mathbf{S}=\operatorname{SIM} \mathbf{N}=$ NÃO

- Se mulher entre 10 e 49 anos:

Estava grávida no momento da morte? $\operatorname{Sim} \square \quad$ Não $\square \quad$ Ignora $\square$

Se sim, duração da gestação: meses

Esteve grávida nos 12 meses que precederam a morte? Sim $\square \quad$ Não $\square$ Ignora $\square$ Se sim, o produto foi ?

$\square$ Nascido vivo $\square$ Nascido morto $\square$ Aborto $\square$ Ignorado

Onde foi atendida? Data 
Vamos falar um pouco sobre a doença que levou à morte

- Como começou a doença

- Descrição

da

doença

(detalhar)

Se se tratar de acidente/violência, detalhar ao máximo o tipo de acidente e o tipo de lesão.

- Quanto tempo ficou doente?

- Fez tratamento caseiro? Sim $\square \quad$ Não $\square \quad$ Ignora $\square \quad$ Qual?

- Teve assistência médica? Sim $\square \quad$ Não $\square \quad$ Ignora $\square \quad$ Se sim, onde?

Endereço

- E o que mais foi feito?

- Tomou remédio? Sim $\square \quad$ Não $\square \quad$ Ignora $\square \quad$ Se sim, qual?

- Que doença levou à morte?

- Onde morreu? Domicílio $\square \quad$ Hospital $\square \quad$ Ignora $\square \quad$ Outro lugar $\square$

Se hospital, qual e onde?

- A Sra. acha que essa morte poderia ter sido evitada?

Se

sim,

como?

Data

1

Entrevistador

\section{CONCLUSÃo}

Encaminhamento: Fazer outro formulário? Sim $\square$

Não

Se sim, qual? 
F3. FORMULÁRIO PARA COLETA DE INFORMAÇÕES HOSPITALARES SOBRE ÓBITOS (causas mal definidas, residuais dos capítulos e presumiveis)

Para preenchimento em nivel central

\begin{tabular}{|l|l|}
\hline Nome & Sexo __ Idade \\
Data da morte & Local da morte $\_$ \\
Endereço (res) & \\
Cemitério & \\
\hline
\end{tabular}

\section{Para o início da entrevista, ver instrutivo}

Para preenchimento no hospital

Nome
Sexo $\_$Idade $\_$Data de nascimento
Data da morte __ Local da morte
Endereço (res)

Data de entrada no hospital Data de saida

Condições do paciente à admissão

Resumo da anamnese (sintomas)

Resumo da evolução do paciente

\section{Exames}

a) Laboratório

\begin{tabular}{|l|l|l|}
\hline Tipo & Data & Resultado \\
\hline & & \\
\hline & & \\
\hline
\end{tabular}


b) Raio $X$

\begin{tabular}{|l|l|l|}
\hline Tipo & Data & Resultado \\
\hline & & \\
\hline & & \\
& & \\
\hline
\end{tabular}

c) Citologia/biópsia (descrever o material e resultado)

d) Operações e achados

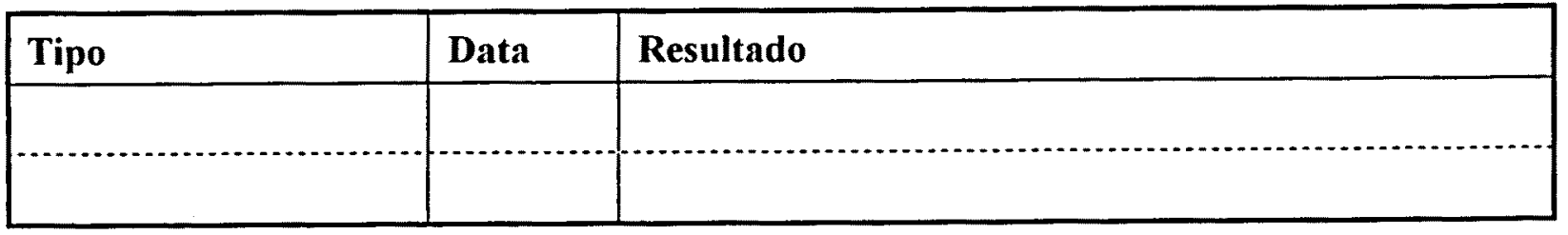

e) Diagnósticos clínicos

f) Autópsia? Sim $\square$ Não $\square$ Resultado:

Para óbitos femininos de 10 a 49 anos, verificar se consta informação sobre a presença de gravidez, parto e puerpério nos 12 meses que precederam a morte.

- Se mulher entre 10 e 49 anos:

Estava grávida no momento da morte? Sim $\square \quad$ Não $\square \quad$ Ignora $\square$

Se sim, duração da gestação: meses

Esteve grávida nos 12 meses que precederam a morte? $\operatorname{Sim} \square \quad$ Não $\square \quad$ Ignora $\square$ Se sim, o produto foi?

$\square$ Nascido vivo $\square$ Nascido morto $\square$ Aborto $\square$ Ignorado

Onde foi atendida? Data

Condições da mãe momento da alta

DADOS SOBRE O ÓBITO:

O que consta no Prontuário:

Data 1 _ _ Entrevistador

\section{CONCLUSÃo}

Encaminhamento: Fazer outro formulário? Sim $\square \quad$ Não $\square$

Se sim, qual? 
F4. FORMULÁRIO PARA COLETA DE INFORMAÇÃO SOBRE ÓBITOS DOMICILIARES QUE TIVERAM ALGUMA ASSISTÊNCIA MÉDICA ANTERIOR COM MÉDICO, CS, PS OU ASSEMELHADO.

Para preenchimento em nível central

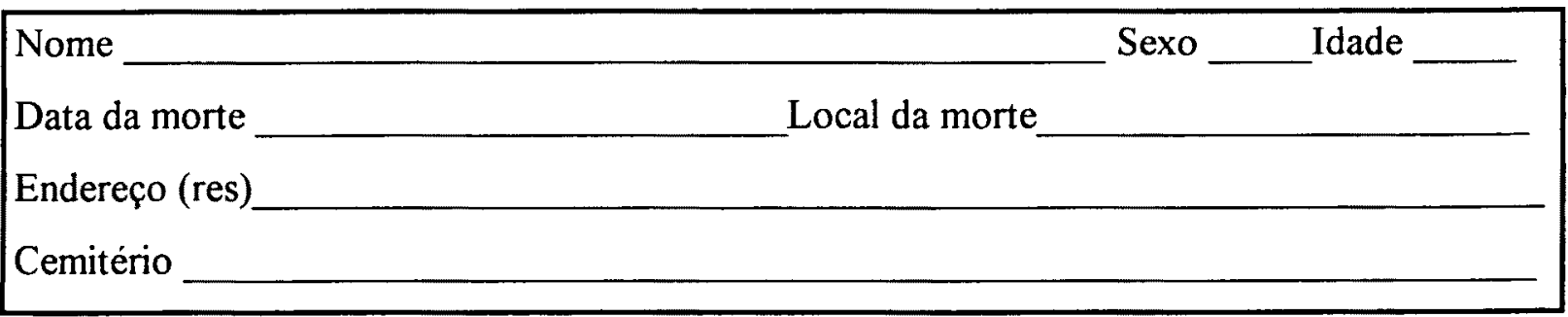

\section{Para o início da entrevista, ver instrutivo}

Para preenchimento no local do atendimento

Nome
Sexo _ Idade __ Data de nascimento
Data da morte _ Local da morte
Endereço (res)
1. Houve atendimento a essa pessoa?
$\operatorname{Sim} \square$
Não $\square$
Ignora $\square$
2. Se sim,
Quando?

Quantas vezes?

Qual o diagnóstico?

Houve confirmação por exames complementares? $\quad$ Sim $\square \quad$ Não $\square \quad$ lgnora $\square$ Quais?

Qual foi a doença responsável pela morte? Ignora $\square$

Entrevista feita com (anotar nome do médico ou Centro de Saúde que fez o atendimento)

Data Entrevistador 
F5. FORMULÁRIO PARA COLETA DE INFORMAÇÃO SOBRE CAUSAS EXTERNAS (IML - DP)

Para preenchimento em nível central

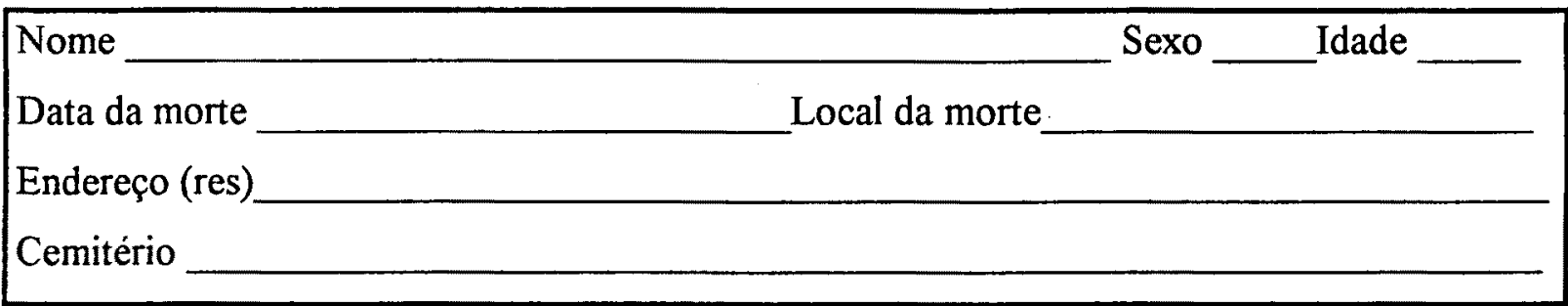

\section{Para o início da entrevista, ver instrutivo}

Para preenchimento em instituição

Nome
Sexo $\_$Idade $\_$Data de nascimento
Data da morte __ocal da morte
Endereço (res)__

\section{INFORMAÇÃO DA DP}

Data do evento Data da morte

Tipo de causa externa (o mais detalhado possivel)

OBS

\section{INFORMAÇÃO DO IML}

Data da morte

Natureza da lesão

Tipo de causa externa (descrição do acidente/violência)

OBS

Data Entrevistador 


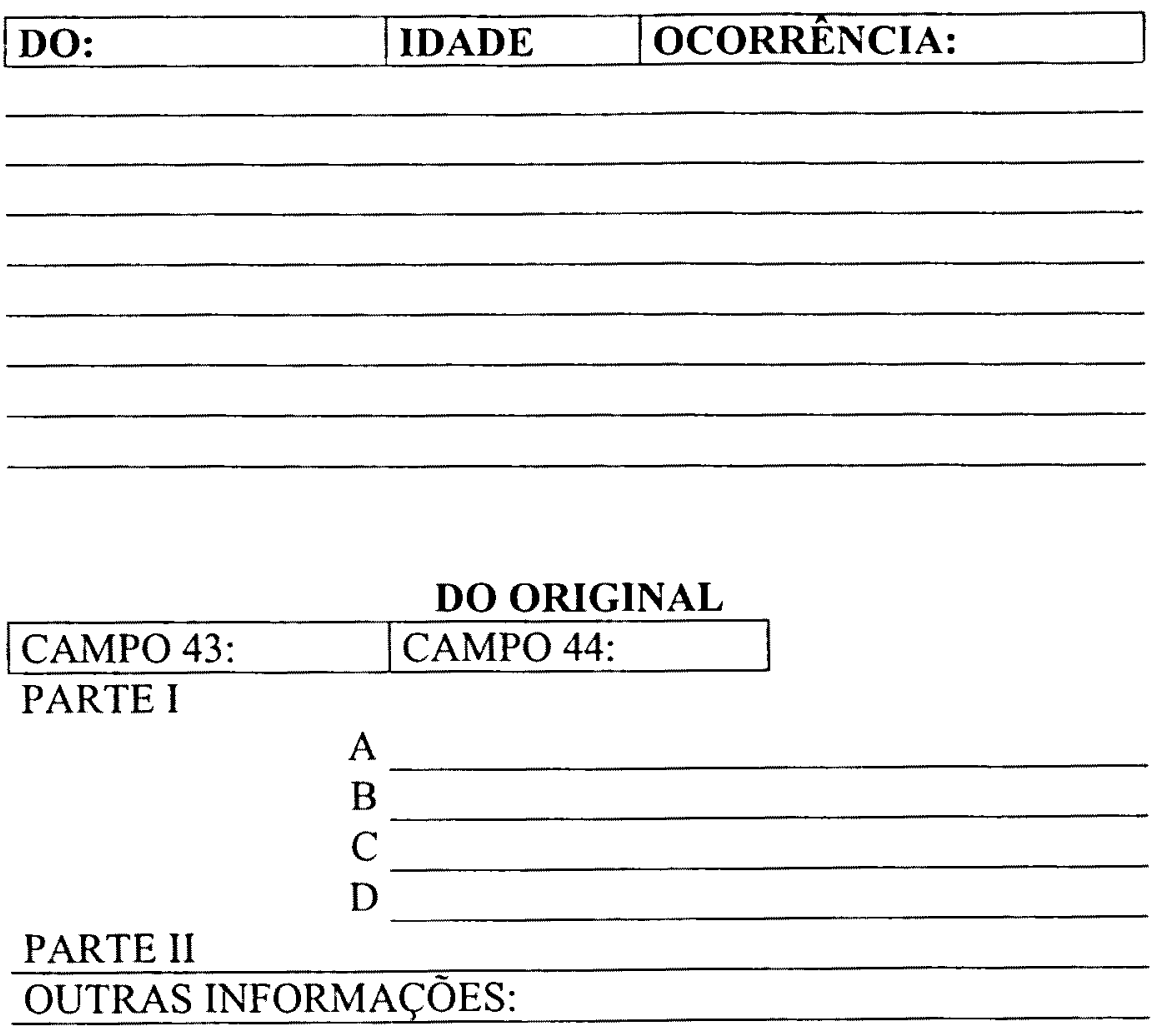

CAUSA BÁSICA

CAMPO 43:

CAMPO 44:
PARTE I

A

B

C

D

PARTE II OUTRAS INFORMAÇÕES:

\section{CAUSA BÁSICA (OI):}

FORMULÁRIOS UTILIZADOS

\begin{tabular}{|l|l|l|l|l|}
\hline F1 & F2 & F3 & F4 & F5 \\
\hline
\end{tabular}

\begin{tabular}{|l|l|}
\multicolumn{1}{c}{ NOVA-DO } \\
\hline CAMPO 43: & CAMPO 44: \\
\hline
\end{tabular}

PARTE I

A

B

C

$\mathrm{D}$

PARTE II

OUTRAS INFORMAÇÕES:

CAUSA BÁSICA (SIS):

SISTEMAS DE INFORMAÇÃO

\begin{tabular}{|l|l|l|l|}
\hline SIM & SIAB & SINASC & SIH \\
\hline
\end{tabular}


Anexo 4. Instrumentos de coleta de dados junto ao SIAB 


\begin{tabular}{|c|c|c|c|c|}
\hline & $\begin{array}{l}\text { SECRETARIA MUNICIPAL DE SAUDE DE ARACAJU } \\
\text { SISTEMA DE INFORMAÇÃO DE ATENÇÃO BÁSICA }\end{array}$ & & MÊS|_L_ & ANO LLLL \\
\hline MUNICÍPIO (nome) & MUNICIPIO (código): & | SEGMENTOLLا_L & UNIDADE L_Lا_Lا_L & ÁREA LLLL \\
\hline
\end{tabular}

\begin{tabular}{|c|c|c|c|c|c|c|c|c|c|c|}
\hline \multicolumn{11}{|c|}{ NOTIFICAÇÃO DE ÓBITOS } \\
\hline & $\begin{array}{c}\text { Data } \\
\text { do } \\
\text { Óbito }\end{array}$ & Nome & Nome da Mãe & Endereço & $\begin{array}{l}\text { Município de } \\
\text { Ocorrência }\end{array}$ & $\begin{array}{l}\text { Sexo } \\
(\mathrm{M} / \mathrm{F})\end{array}$ & Idade & $\begin{array}{c}\text { Local de } \\
\text { Ocorr. } \\
\text { (Hosp/Resid) }\end{array}$ & $\begin{array}{l}\text { Causa } \\
\text { Referida }\end{array}$ & Numero DO \\
\hline 1 & & & & & & & & & & \\
\hline 2 & & & & & & & & & & \\
\hline 3 & & & & & & & & & & \\
\hline 4 & & & & & & & & & & \\
\hline 5 & & & & & & & & & & \\
\hline 6 & & & & & & & & & & \\
\hline 7 & & & & & & & & & & \\
\hline 8 & & & & & & & & & & \\
\hline 9 & & & & & & & & & & \\
\hline 10 & & & & & & & & & & \\
\hline
\end{tabular}




\section{ESTADO DE SERGIPE}

PREFEITURA MUNICIPAL DE ARACAJU

SECRETARIA MUNICIPAL DE SAÚDE

INVESTIGAÇÃO DE ÓBITOS NÃO ENCONTRADOS NO SIM

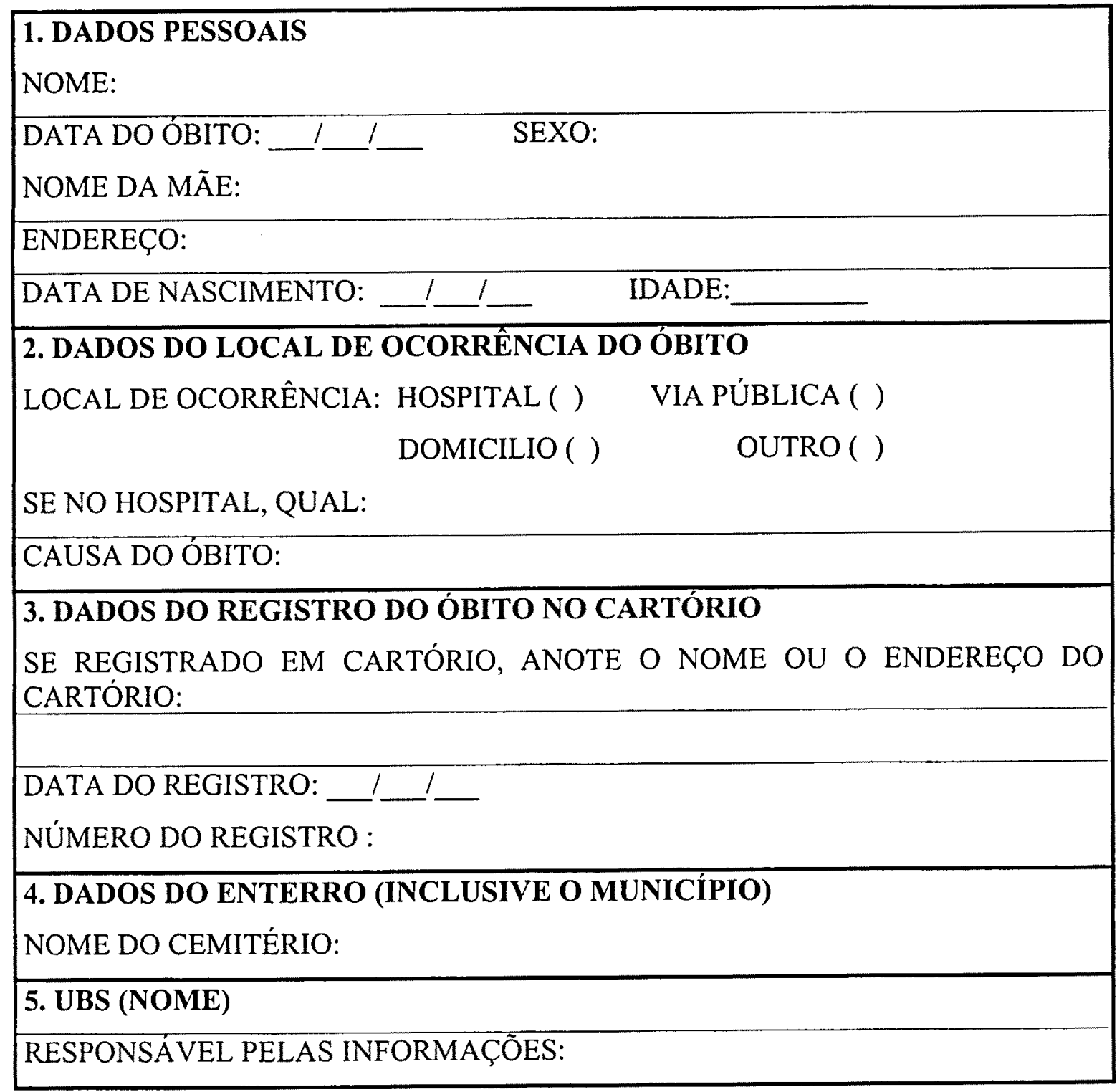

Fonte: SMS, Aracaju. 
Anexo 5: Formulário D1: informações para casos não conhecidos pelo SIM

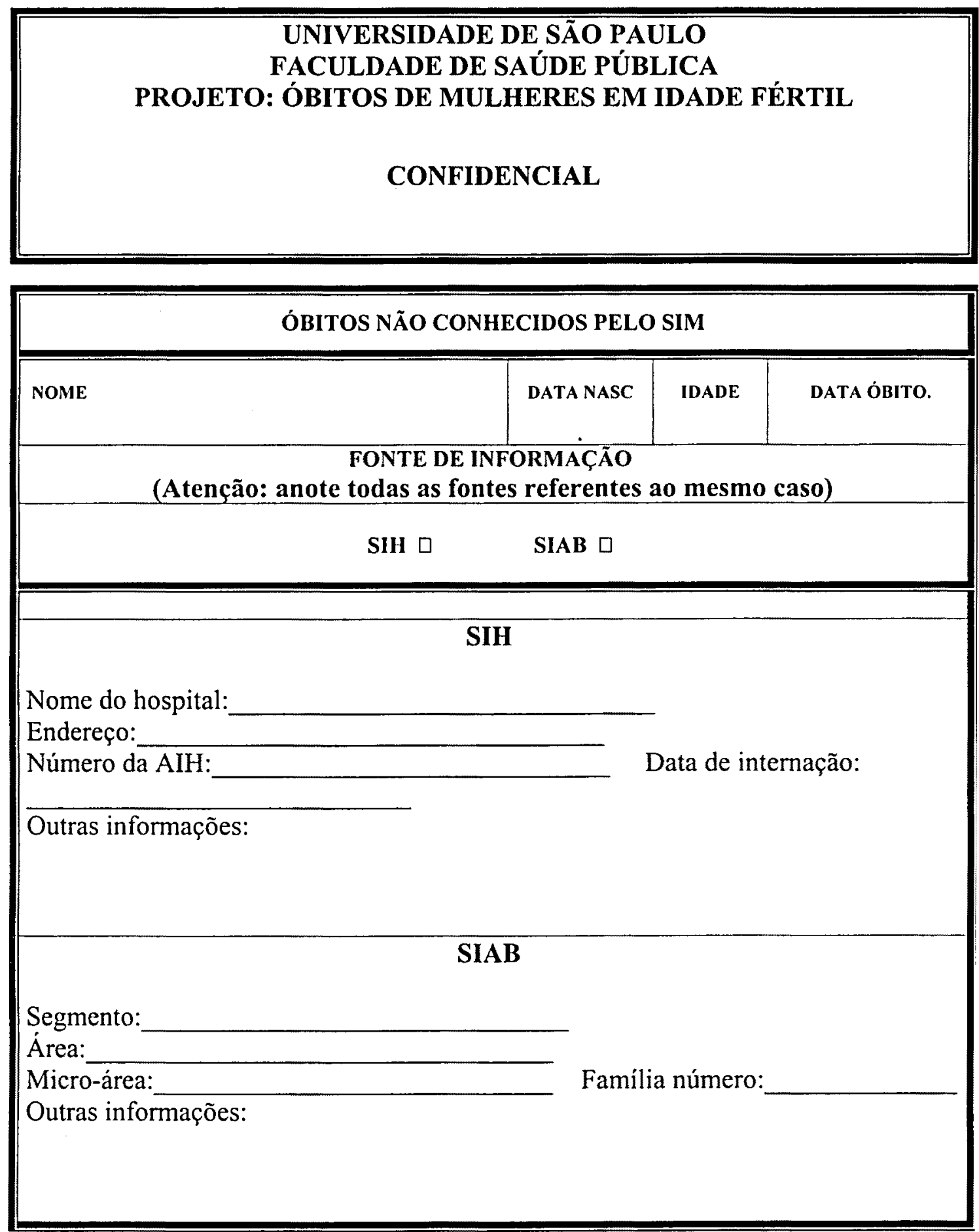




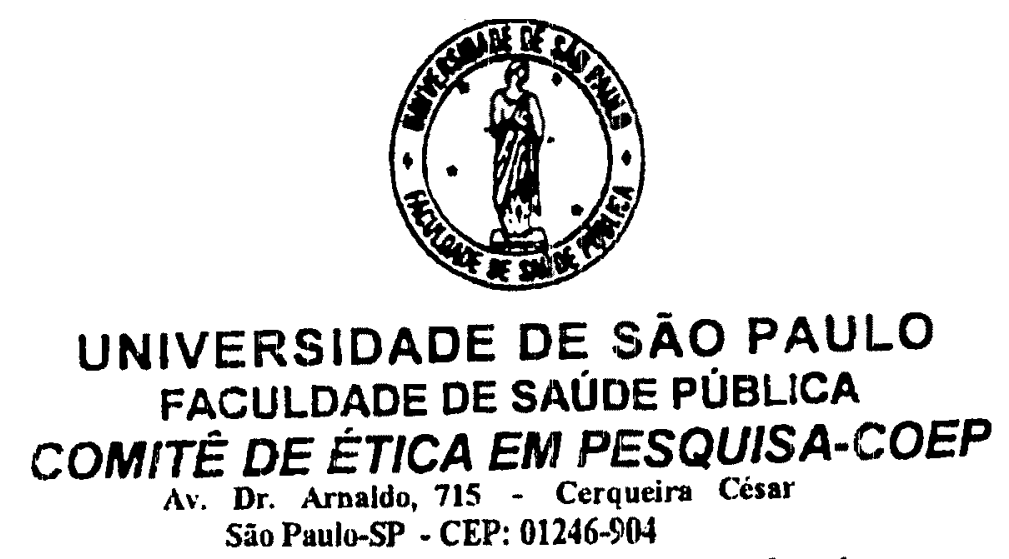

Telefone: (0xx11) 3066-7779 - e-mail: mdgracas@usp.br

\section{Of.COEP/115/01}

27 de julho de 2001

Pelo presente, informo que o Comitê de Ética em Pesquisa da Faculdade de Saúde Pública da Universidade de São Paulo-COEP, analisou e aprovou, em sua 5. ${ }^{2} / 00$ Sessão Ordinária, de 10.07.01, de acordo com os requisitos da Resolução CNS/196/96, o Protocolo de Pesquisa n. ${ }^{\circ} 497$, intitulado: "ÓBITOS DE MULHERES EM IDADE FÉRTIL: EM BUSCA DE BASES DE DADOS DE APOIO À MELHORA DA INFORMAÇÃO", apresentado pela pesquisadora Anna Klara Bohland.

Atenciosamente,

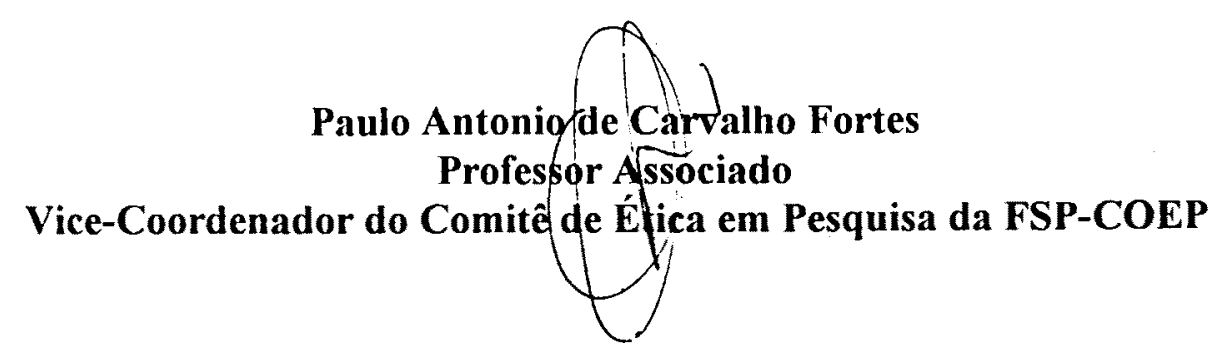


Anexo 6: Parecer do CEP-FSP-USP 
Bom dia senhor(a)

Estamos realizando uma pesquisa sobre a saúde das mulheres. Tivemos informação que nesta casa ocorreu um caso de morte da SRA: , e gostaríamos que o $\mathrm{SR}(\mathrm{a})$ respondesse algumas perguntas.

Nossa pesquisa tem o interesse de saber o que realmente aconteceu com a falecida: como ficou doente, se ia ao médico, onde era atendida, se tomava medicamentos e para quais doenças e qual foi a última vez que ela ficou grávida.

Da nossa parte garantimos que estas informações serão mantidas em total sigilo.

A sua cooperação será muito importante para nós, por que os resultados desta pesquisa podem ajudar a melhorar a saúde das outras mulheres.

Podemos começar ???

Se não $=>$ agradeça e encerre.

Se $\operatorname{sim} \Rightarrow$ explique que é necessário o preenchimento do consentimento, e após anotar os dados do respondente inicie a entrevista. 
Anexo 8. Consentimento esclarecido

\section{CONSENTIMENTO}

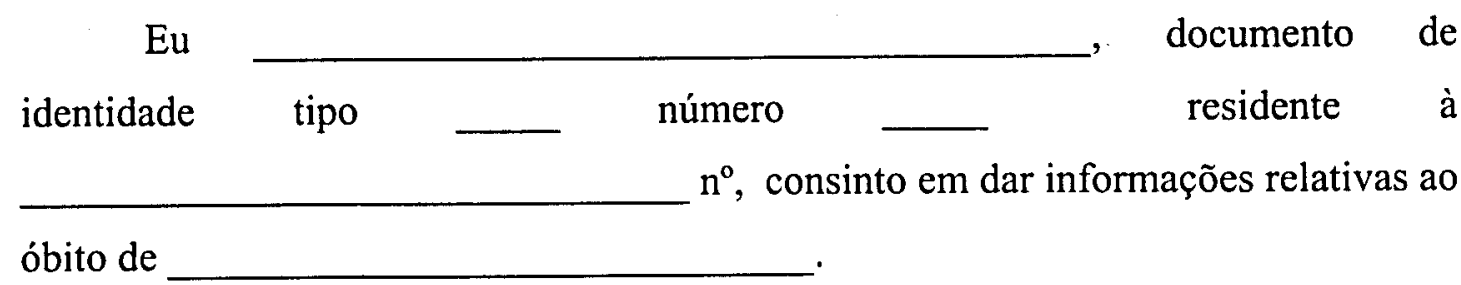

Fui comunicado que as informações fazem parte de uma pesquisa em saúde da mulher, e a entrevistadora comprometeu-se a guardar sigilo de todas as informações prestadas por mim.

Aracaju, de de 2002. 